NBER WORKING PAPER SERIES

\title{
THE IMPACT OF EDUCATION ON FAMILY FORMATION: QUASI-EXPERIMENTAL EVIDENCE FROM THE UK
}

\author{
Michael Geruso \\ Heather Royer \\ Working Paper 24332 \\ http://www.nber.org/papers/w24332 \\ NATIONAL BUREAU OF ECONOMIC RESEARCH \\ 1050 Massachusetts Avenue \\ Cambridge, MA 02138 \\ February 2018
}

We thank Julie Jefferies and Louise O'Leary for the considerable time and effort that they and their team have devoted to this project. It would not have been possible without the live births dataset that they supplied. We also thank Mary Grinsted for generously supplying the abortion data used in this paper and Kevin Lynch for his help with the Longitudinal Study. We are extremely grateful to Damon Clark for his invaluable input and help in securing the data. Thanks to various seminar participants, Sarah Bana, Jenna Stearns, Cathy Weinberger, and the UCSB Econometrics group for their comments and suggestions. We thank Alexandra Gecker, Chang Lee, and Corey White for excellent research assistance. The views expressed herein are those of the authors and do not necessarily reflect the views of the National Bureau of Economic Research.

NBER working papers are circulated for discussion and comment purposes. They have not been peer-reviewed or been subject to the review by the NBER Board of Directors that accompanies official NBER publications.

(C) 2018 by Michael Geruso and Heather Royer. All rights reserved. Short sections of text, not to exceed two paragraphs, may be quoted without explicit permission provided that full credit, including (C) notice, is given to the source. 
The Impact of Education on Family Formation: Quasi-Experimental Evidence from the UK Michael Geruso and Heather Royer

NBER Working Paper No. 24332

February 2018

JEL No. I26,J12,J13

\begin{abstract}
$\underline{\text { ABSTRACT }}$
We examine the impact of educational attainment on fertility and mating market outcomes. Using a regression discontinuity design, we exploit an extension of the compulsory schooling age from 15 to 16 in 1972 in the UK. The change was binding for a quarter of the population. Simple plots of the raw data show substantially lower teen fertility rates across the threshold of the reform, but no impacts on abortions and no impact on completed fertility by age 45 . In the mating market, the reform induced both men and women to marry more educated mates, consistent with positive assortative mating. We show that timing of the teen fertility reduction coincided with the timing of the extra induced schooling and that the probability of marrying a peer in the same academic cohort rose. These results suggest that school attendance may have important direct effects, in addition to and separate from the human capital effects of education.
\end{abstract}

\author{
Michael Geruso \\ University of Texas at Austin \\ Department of Economics \\ 1 University Station C3100 \\ Austin, TX 78712 \\ and NBER \\ mike.geruso@austin.utexas.edu \\ Heather Royer \\ Department of Economics \\ University of California, Santa Barbara \\ 2127 North Hall \\ Santa Barbara, CA 93106 \\ and NBER \\ royer@econ.ucsb.edu
}




\section{Introduction}

The inclusion of education in models of family formation (fertility and mate choice) has a long history. The early theoretical literature emphasized education's role in family formation via impacts on the opportunity cost of a woman's time (Becker, 1960, 1965; Mincer, 1963; Willis, 1973); on the quantity-quality margin of child investment (Becker and Lewis, 1974); on discount rates (Becker and Mulligan, 1997); and on knowledge of contraception (Rosenzweig and Schultz, 1989). More recent theoretical contributions on positive (Becker, 1981; Chiappori, Oreffice and Quintana-Domeque, 2012) and negative (Chiappori, Iyigun and Weiss, 2009) assortative mating in marriage markets have acknowledged educational attainment and marriage as part of a joint decision process, complicating the notion that correlation between educational attainment and family formation outcomes reflects a causal effect of education 1 The recognition that education, marriage, childbearing, and labor force participation are likely to be tied together in a forward-looking choice framework echoes the concern from the wage returns literature (e.g., Card, 2001) that OLS estimates of returns to education may be significantly biased due to sorting on preferences and ability.

Understanding the causal impact of education on family formation is important - not only because forming partnerships and bearing children are among the most important economic choices individuals make over their lifetimes, but also because the early theoretical literature on education and family formation continues to be widely invoked today, for example to explain patterns of female labor force participation and fertility delay. These models of family formation were mainly predicated on simple correlations, such as between completed education among women and the total fertility rate, with comparisons identified by comparing different cohorts of women or by looking cross-sectionally within cohorts (Willis, 1973). The relevant endogeneity concerns were noted at the time of these early studies, even if the data and econometric techniques were not yet advanced enough to confront them $2^{2}$

In this paper we examine how education (specifically the length of schooling) affects fertility and mating market outcomes. To do so, we exploit a powerful quasi-experiment that extended the

\footnotetext{
${ }^{1}$ Willis (1973) also explicitly recognized that educational investment, labor force participation, mating market outcomes, and childbearing may be jointly determined in a forward-looking decision process.

${ }^{2}$ As Willis (1973) wrote: "Although all of the effects of education except its effect on the market earnings capacity of the wife have been ruled out by assumption, it is recognized that education may well have a systematic effect on tastes, efficacy of fertility control, or efficiency in household production."
} 
compulsory schooling age in Britain by one year. Beginning with the September 1957 birth cohort, individuals had to stay in school through the term in which they turned 16 years old, whereas individuals born before September 1957 had to remain in school through the term in which they turned 15 years old. As these compulsory schooling laws were binding for many (roughly 35 percent of the population dropped out at the minimum schooling age), this reform had a profound effect on the school leaving decisions of many. The way this large quasi-experiment was implemented allows us to leverage regression discontinuity comparisons based on month $\times$ year of birth comparisons. Such comparisons overcome some of the identification concerns pointed out in the prior literature (Black, Devereux and Salvanes, 2008; Stephens and Yang, 2014) regarding the difficulty of isolating the effects of educational reforms from coinciding trends when using difference-in-differences designs. The institutional context here also allows us to sidestep critiques (e.g., Lang, 1993, Card, 2001) that in some settings, the local average treatment effect of compulsory schooling reforms are identified off of a small and potentially non-representative group of individuals. Given that the share of the affected population in our context was sizable, our estimated treatment effects are likely to come closer to estimating an average treatment effect (Oreopoulos, 2006).

We combine this research design with rich administrative and survey data on a range of family formation outcomes: conceptions, abortions, births across ages, and mating market outcomes that include effects on spouse characteristics. Simultaneously examining these various margins is important for understanding the underlying channels: For example, examining abortions gives insight into whether changes in observed births imply any changes in sexual behavior, and examining effects on the composition of women's spouses may be important for understanding fertility outcomes if the partner's preferences over children matter. We supplement the administrative data with in-depth contextual panel data from the National Child Development Study (NCDS). The NCDS followed a cohort of individuals born in March 1958 who were one of the first cohorts subjected to the new compulsory schooling age of 16 . The NCDS allows us to do something that is - to our knowledge - unique in the economics literature: directly identify the individuals for whom the compulsory schooling was binding (i.e., the compliers). The study asked respondents about when they would have left school if, counter to fact, the compulsory schooling age had remained set at age 15. We use these data to contrast stated and revealed preferences towards partnership and fertility between always-takers and compliers. We observe these respondents during the period of 
the extra schooling at age 16, which is useful in unpacking the mechanisms behind the effects we estimate.

Using administrative data on the universe of UK births, we find that the extra year of compulsory schooling led to a 30 percent decline in fertility at ages 16 and 17, with effects clearly visible in simple regression discontinuity plots. We provide the first evidence in the literature of education's impact on abortions, finding at most a negligible effect on abortions. This implies that the observed teen fertility reduction reflects primarily a decline in conceptions. This holds despite the fact that abortions were an important part of the fertility process in this context. Both in 1975 and in 2015, 15 to 20 percent of conceptions ended in abortion in England and Wales 3 Beyond the teenage years, we show that the fertility effects of the schooling reform are essentially zero. The 95 percent confidence interval for our IV estimate of a year of schooling's effect on completed family size excludes effects larger than one tenth the size of the OLS relationship. These precisely-estimated zeros stand in stark contrast to the robust cross-sectional associations between completed fertility and education that motivated the opportunity cost and quantity-quality tradeoff models and are still widely cited today.

At the same time, we show significant impacts on the mating market. Affected individuals (both men and women) have more educated spouses, consistent with theories of positive assortative mating. Our estimates imply that completing the basic high school credentialing in our setting leads to a 14 percentage point increase in the probability of a partnering with a male spouse with a credential (for women) and a 25 percentage point increase in the probability of partnering with a female spouse with a credential (for men). This change in educational sorting is not entirely explained by men and women marrying the same set of partners they would have in absence of the reform but who are now themselves more educated as a result of the reform. Simulations show that such a 'mechanical' effect would generate partner credential effects two orders of magnitude smaller than the effects we estimate. Additionally, as further evidence against a purely mechanical effect, we find that the compulsory schooling reform caused both men and women to have spouses closer to themselves in age - particularly someone in the same academic cohort. 4 Our data also allow us

\footnotetext{
${ }^{3}$ This statistic has remained relatively constant over time since abortion legalization. The calculation of the ratio of abortions to conceptions is based on the ratio of abortions to births plus abortions and thus ignores miscarriages which are heavily misreported. For teenagers, the ratio of abortions to conceptions is even higher.

${ }^{4}$ However, changes in the age gap are not completely accounted for by increases in marriage within the same academic cohort.
} 
to show that teen "shotgun" marriages, where a conception precedes the wedding, dramatically declined as a result of the schooling reform.

The family formation literature typically focuses on education affecting behaviors through changing economic opportunities or tastes, but our results point to an additional important factor in these decisions: the role of schooling itself. Examining the specific month-by-month timing of when the extra schooling occurred, we show that conceptions were reduced only during the time period when 15 and 16 year old females were newly constrained to remain in school. From the NCDS, there is suggestive evidence that compulsory schooling was likely a binding constraint on the peer group and tended to encourage teen females to delay cohabitation with older men. In this way, our paper expands a small body of work that has shown direct effects of being in school (Berthelon and Kruger, 2011), and connects to a broader literature considering "incapacitation" effects when juveniles are subject to increased supervision, or their time use is otherwise constrained (Lefgren and Jacob, 2003) $!^{5}$

Taken together, the evidence suggests that schooling has a direct effect on the probability of conceptions during school, in addition to and separate from the human capital effects of education, which we show play out in marriage markets over the longer term. In this way, we view our paper as contributing to an expanding the notion of what a "treatment" consists of when considering compulsory schooling; schooling has impacts beyond the standard productivity and signaling stories.

This paper also contributes by extending the recent literature on family formation in several important ways. First, much of the literature focuses on either fertility effects in isolation or assortative mating in isolation despite that these two processes are inherently intertwined. Papers in this literature include Currie and Moretti, 2003; Lefgren and McIntyre, 2006; Black, Devereux and Salvanes, 2008; Monstad, Propper and Salvanes, 2008; Lavy and Zablotsky, 2015; McCrary and Royer, 2011; Silles, 2011; Cygan-Rehm and Maeder, 2013; Grönqvist and Hall, 2013, Aaronson, Lange and Mazumder, 2014; Fort, Schneeweis and Winter-Ebmer, 2016, Güneş, 2016. Second, the regression discontinuity approach rests on a minimal set of assumptions. In particular, our methods allow us to overcome the challenges of addressing confounding time and cohort trends that can confound identification in other IV and difference-in-difference designs. Of the previously-

\footnotetext{
${ }_{5}^{5}$ Berthelon and Kruger (2011) exploit the lengthening of the time spent in school in Chile from 32 to 39 hours per week. They conclude from regional and time variation that increasing the time in school reduced teen fertility.
} 
mentioned studies, only McCrary and Royer (2011), which focuses on the infant health effects of extra schooling and exploits discontinuities in school starting ages, utilizes a regression discontinuity design $\sqrt[6]{6}$ Third, the combination of several administrative datasets along with detailed descriptive panel data allow us to document new facts and to flesh out the mechanisms behind the effects we find. For example, from the administrative data, we generate the first estimates in the literature of the impact of schooling on teen abortions, and from the NCDS panel, we provide a window into the reported preferences and revealed behaviors of compulsory schooling compliers during their teen years.

Besides contributing new empirical evidence to a long theoretical literature on education and family formation, our paper has several concrete policy implications: With the important caveat that we study only one margin of education, we note that schooling can be a powerful tool to reduce teenage fertility, which is widely considered bad for both teen mothers (Geronimus and Korenman, 1992; Goodman, Kaplan and Walker, 2004; Chevalier and Viitanen, 2003; Ashcraft, Fernández-Val and Lang, 2013) and their children (Royer, 2004; Painter and Levine, 2004). Importantly, we find that although schooling reduced teen births, it led to no reduction in completed fertility, implying that increasing educational attainment at the population level need not imply reductions in future levels of completed fertility ${ }^{7}$ This is a particularly relevant implication for Western Europe, where low fertility is a major concern in light of growing strains on pension systems and public health systems. Indeed, low fertility motivates significant policy intervention across Europe (see Kalwij, 2010 for an overview). Finally, we show that the compulsory schooling intervention had a multipliertype effect in that it increased in expectation the average education of affected individuals' spouses. Thus, further increases in the compulsory school age, including those that have taken place very recently in the UK, may have the distributional effect of raising the economic wellbeing of the individuals at the bottom of the educational attainment distribution (who are most likely to be impacted by such policies) beyond the direct effects on own education and earnings.

\footnotetext{
6 Fort, Schneeweis and Winter-Ebmer $(2016)$ use an empirical strategy focusing on comparisons across yearly birth cohorts, similar to a flexible difference-in-difference design. In the context of our data, which show strong trends even across different month of birth cohorts of the same cohort year, such a strategy would fail to adequately control for coinciding trends.

${ }^{7}$ Our results here are estimated in the context of a modern developed country, though we note that teen fertility reduction is often cited as an important motivation for increasing educational attainment among women in developing countries.
} 


\section{Compulsory Schooling Laws}

\section{A The Background of 1972 ROSLA}

Compulsory schooling laws in the UK are set at the national level $\left.\right|^{8}$ They include a maximum age by which children must start school and a minimum age at which children can leave school. Officially, children must be age 5 when they enter school; this has been the same since the late 1800's. September 1st is the standard school entry cutoff 9 In the UK, most students are kept on track (i.e., are in their predicted school grade given their date of birth) as students rarely skip grades and are rarely held back (Bono and Galindo-Rueda, 2007).

In 1947 and 1972, the UK increased the compulsory schooling age, in a policy action commonly referred to as ROSLA (Raising of the School Leaving Age). The first of these changes increased the minimum leaving age from 14 to 15 and the second extended it further to age 16 We focus exclusively on the 1972 ROSLA because fertility data are not available for the women affected by the 1947 ROSLA.

The 1972 ROSLA applied to students in England, Wales and Scotland. We focus on England and Wales because we do not have fertility data for Scotland. The exact timing of ROSLA was a surprise, although the discussion of increasing the school exit age spanned many years. During World War II, the government passed the 1947 ROSLA and further recommended a school-leaving age change to 16 when feasible 11 Later, the Crowther Report and the Newson Report (reports of the Central Advisory Council for Education in England) both recommended changing ROSLA to 16 in 1959 and 1963, respectively. Finally in 1964, action was taken to implement the change. The slated date was 1970-1971. But by 1968, the British government postponed ROSLA for two years. In March 1972, it was officially announced that the school-leaving age would increase by one year. The new school leaving age became effective on 1 September 1972. For identification purposes, it is beneficial that the compulsory change was implemented when the impacted cohorts

\footnotetext{
${ }^{8}$ Some of this discussion is adapted from Clark and Royer (2013).

${ }^{9}$ Local educational agencies (LEA) have the option of having multiple school entry cutoff dates (i.e., one for each of the three school terms) although at the time, LEAs were shifting towards having only one entry point (Woodhead, 1989).

${ }^{10}$ Several papers exploit the 1947 change to understand the effects of education on wages, happiness, crime, and health (e.g., Harmon and Walker, 1995, Oreopoulos, 2006, Devereux and Hart, 2010, Machin, Marie and Vujic, 2011, Clark and Royer, 2013).

${ }^{11}$ These details come from Woodin, McCulloch and Cowan (2013).
} 
were teenagers. There is no possibility that parents selectively timed the birth of their children (who are the mothers, wives and husbands in our study) to avoid the compulsory schooling change.

The effect of the policy change was that students who turned 15 before September 1972 (born August 1957 or earlier) were subject to a compulsory schooling age of 15, and students who turned 15 after this date (born September 1957 or later) were subject to a compulsory schooling age of 16. It is this comparison between the August 1957 birth cohort and the September 1957 birth cohort that our regression discontinuity exploits. The September/August contrast also coincides with the annual school entry cutoff and thus, any age-in-grade effects would confound our ROSLA effects, absent appropriate controls. As we discuss later, we address this via the inclusion of calendar month-of-birth dummies.

In the Appendix, we discuss in more detail some important aspects of the 1972 ROSLA. Appendix Figure 1 gives the maximum and minimum years of full-time education attained by those leaving school at the minimum school leaving age, which varies slightly depending on calendar month (season) of birth. As discussed further in Clark and Royer (2013) and described in more detail later, although the standard measure of educational attainment in British data is the age at which one leaves full-time education, we can interpret the differences in the age of terminating full-time education as differences in years of education.

A detail particularly relevant for our study is the treatment of pregnant females within the schooling system. Both before and after ROSLA, females who became pregnant during the period of compulsory schooling were required to continue with education through their pregnancy. They attended school until the later months of their pregnancy, after which they received an in-home, state-provided tutor. Thus a teen pregnancy did not result in a waiver from the compulsory schooling requirement.

Finally, unlike the 1947 reform, the 1972 ROSLA affected the acquisition of educational credentials. Much of this is due to the structure of the schooling system. At the completion of grade eleven, the last grade of enrollment for ROSLA compliers, students could sit for the O-level exams on various subjects 12

\footnotetext{
${ }^{12}$ The exam system has subsequently changed.
} 


\section{B The Impacts of the 1972 ROSLA}

How could the 1972 ROSLA impact family formation? The literature suggests several possibilities. First, an increase in a woman's education could impact tastes for childbearing directly. Second, education could alter labor market opportunities - through occupation choice or through wages - which could change the demand for children and the desired timing of childbearing. Third, education could influence the rate of time preference. Fourth, the extra schooling could impact health and thereby affect fertility at both the intensive and extensive margins. Fifth, it could influence the choice of mate, either through the mechanisms described above or directly through tastes.

Prior research, albeit limited, gives us some insights as to which of these channels may be operating as a consequence of the 1972 ROSLA 13 There were wage effects of the 1972 ROSLA for both men and women (Grenet, 2013). Thus, the long-noted mechanisms related to the opportunity cost of child bearing could be at play. The affected cohorts were also less likely to receive welfare and more likely to report being happy (Oreopoulos, 2007). Health impacts of the additional education were minimal (Clark and Royer, 2013) although more recent work (Barcellos, Carvalho and Turley 2017) suggests that there are effects in the tails of the health distribution with reductions in body size and increases in blood pressure 14 No prior study in this context examines underlying preferences over childbearing, marriage desiderata, or time preferences, though we provide some self-reported survey evidence related to each of these preference parameters below.

\section{Data}

Our study uses several datasets. We describe each of these in turn. The common variables linking our datasets are the month and year of birth of women whose education, fertility, and partnership outcomes we examine. Our analysis is at the level of month $\times$ year of birth cohorts, as we describe later ${ }^{15}$ A summary of the data sources and the relevant variables we extract from each is provided

\footnotetext{
${ }^{13}$ Most of the literature using the UK compulsory schooling laws focuses on the 1947 ROSLA, not the 1972 ROSLA.

${ }^{14}$ It should be noted that only Clark and Royer (2013) and Barcellos, Carvalho and Turley (2017) use month $\times$ year of birth regression discontinuity comparisons; the other studies either use year-of-birth regression discontinuity comparisons (Grenet, 2013) or difference-in-differences contrasts using Northern Ireland (Oreopoulos, 2007).

${ }^{15}$ Many of these measures come later in life (e.g., 2001 Census) after many years have lapsed since the required schooling. Clark and Royer (2013) find no impacts of ROSLA on survival to these later years, alleviating concerns about survival bias.
} 
in Appendix Table 1.

\section{A UK Labor Force Survey}

Information on educational attainment comes from the 1975-2002 UK Labor Force Survey (LFS). The LFS samples a large number of households to provide information on labor force participation, employment, and training. Around 60,000 households are interviewed in each wave. Between 1975 and 1983 the LFS was conducted biannually. Between 1983 and 1992 the LFS was an annual survey of a similar number of households. Since 1992, the survey has been a rotating quarterly panel, with the same households interviewed for five consecutive quarters. In the analysis, we include multiple observations per person when available, and cluster all results at the year of birth by month of birth level. Respondents' year and month of birth are available in public release LFS datasets up to 2002 .

Since its existence, LFS respondents have been asked about the age at which they first left fulltime continuous education. We use these data primarily to validate the first stage, the existence of which has been established elsewhere using different data sources (Clark and Royer, 2013). As argued in Clark and Royer (2013), we can interpret our first-stage estimates of effects on the age at which respondents left full-time schooling as effects on years of schooling. Our pooled sample of 1975-2002 LFS gives us a large sample of over 300,000 respondents born between 1954 and 1962 .

\section{B Live Birth Records}

Live birth data were supplied by the UK Office for National Statistics (ONS). The records cover every birth between 1970 and 2008 in England and Wales to mothers born in England, Wales, or Scotland-roughly 600,000 to 900,000 births per year 16 Since teen fertility is a relatively rare outcome, it is crucial to have a census of births. The births data are birth counts by mother's month and year of birth and child's month and year of birth but do not include parity information. Given that we rely mainly on across-cohort variation in education, it is not problematic that we do not observe individual-level birth data. Specifically, our regression framework, described later, does not require the inclusion of covariates aside from controls for cohort trends. Any pre-determined

\footnotetext{
${ }^{16}$ The birth records from England and Wales do not distinguish between mothers born in England and Wales and mothers born in Scotland. This poses minimal problems for our study, since only a small fraction of the women living in England and Wales during this time were emigrants from Scotland ( $<1$ percent).
} 
covariates, in principle, should be similar for individuals born immediately prior to September 1957 and individuals born immediately following September 1957 because sorting around this threshold would be impossible (as ROSLA was announced when the first affected cohorts were teenagers).

The structure of our data implies that we can recover cohort-specific fertility rates but not individual-level fertility rates. For instance, our data cannot distinguish between a scenario in which one woman bears her first child at age 20 and another woman from the same cohort bears her first child at age 24 and a scenario in which one woman bears her first child at age 20 and then her second at age 24 . In practice, since we find that the reform only impacts fertility among females aged 16 and 17, who are very likely to have been first-time mothers, the missing parity information is of little consequence. Moreover, under the assumption that education affects fertility behavior mainly in one direction (i.e., either increasing it or decreasing it), the inability to distinguish parity will not cause us to mischaracterize the results 17

For each cohort of women, we construct age-specific and total fertility rates according to standard practice (Preston, Heuveline and Guillot, 2001). The numerator in the age-specific rate for birth cohort $c$ is the number of births to women of cohort $c$ covering a particular age range (e.g., $[16,17))$. The denominator is the number of women alive in that age range. It is not possible to know exactly how many women are alive at each point in time. Thus, we generate the denominator by multiplying the size of the female cohort at birth (obtained from the Registrar's Annual Reports) with a succession of age- and calendar year-specific survival rates for the UK (obtained from the Human Mortality Database). We validate these denominator estimates by comparing our predictions for each cohort size in 1991 and 2001 with cohort size as measured by the 1991 and 2001 Censuses. Our estimates and these numbers line up very closely. This correlation ranges between 0.93 and 0.95 .

The total fertility rate (TFR) aggregates the age specific rates. Cohort TFR reflects the average number of children that women in the cohort bear over their lifetime, conditional on surviving

\footnotetext{
${ }^{17}$ For example, counter to this assumption, suppose that the reform influences one woman to increase her fertility from 2 to 3 children and influences another to reduce her fertility from 1 child to being childless. In this case, the total number of children born is unchanged but this overall effect masks important heterogeneity. In studying the effects of education quality on fertility among blacks, Aaronson, Lange and Mazumder (2014) argue that there could be positive effects along the extensive margin increasing the probability of having at least one child and at the same time negative effects along the intensive margin due to the quality and quantity tradeoff. However, in the British Household Panel Survey, the correlation of age left full-time schooling with the probability of having any children and the correlation of age left full-time schooling with the probability of having more than 1 child conditional on having at least 1 child are both negative.
} 
through their fecund years.

\section{Abortion Records}

Detailed abortion records come from the UK Office of National Statistics. Like the live birth records, these data are counts by women's month and year of birth. Unlike the live birth records, these are limited to a narrower range of cohorts born around the reform threshold. They also cover only abortions performed in the teen years (the only years for which we find any fertility effect). These data allow us to construct teen (15-19) abortion rates for cohorts of women born within a 36-month window of the ROSLA threshold.

The context of the 1972 ROSLA is uniquely suited to examining the role of abortions; the quasiexperiment we exploit occurred in the era of modern fertility when abortion and contraceptives (e.g., the birth control pill and intrauterine devices) were available. The 1967 Abortion Act legalized abortion in the UK. This Act covered abortions for teenagers, did not require parental consent or notification, and incurred no out-of-pocket costs. Oral contraceptives became available in 1961 through the National Health Service ${ }^{18}$ Moreover, abortions were and are an important part of the fertility picture; the ratio of abortions to births in our sample varies from 1.7 abortions per birth for 15 year olds to 0.3 for 19 year olds. The teenage abortion rates experienced by the near-ROSLA cohorts were even higher than those experienced by cohorts in the US and UK today 19

\section{UK Census Extracts}

We commissioned several extracts of the 2001 Census that are useful for understanding the mating market effects of the extra education. These extracts allow us to track the age difference between partners as a function of each partner's month $\times$ year of birth and the educational credentials of each spouse in relation to their own month $\times$ year of birth. In addition, we can quantify how ROSLA affected own educational credentials.

\footnotetext{
${ }^{18}$ http://news.bbc.co.uk/onthisday/hi/dates/stories/december/4/newsid_3228000/3228207.stm).

${ }^{19}$ US statistics are from https://www .guttmacher.org/report/us-adolescent-pregnancy-trends-2013
} 


\section{E National Child Development Study}

Finally, we use data from the National Child Development Study (NCDS). This is a panel dataset for which survey administrators attempted to track 100 percent of babies born in Great Britain in one week of March 1958 into adulthood. This cohort was one of the first to be subject to the 1972 ROSLA. Information collected at ages 7, 11, 16, 23, 33, and 41 offer insight into cohort members' school activities and stated and revealed preferences over fertility and partnerships during the extra year of compulsory schooling and beyond. Because the NCDS covers just a single post-ROSLA cohort, we cannot use our main regression discontinuity strategy.

However, these data contain a unique feature that allows us to directly identify compliers and always takers. When participants were 16, the study asked the cohort members when they would have dropped out of school had the 1972 ROSLA not been in place. Responses to this question, which we validate as informative, allow us to examine whether compliers are different from alwaystakers in their stated preferences at 16, conditional on being exposed to exactly the same years of schooling at the time of stating those preferences. This analysis, which reveals significant sorting on tastes for early family formation, provides context for our precisely estimated null effect of education on completed family size, despite a large cross-sectional correlation. We also use these data to provide deep context regarding relationships in the teen years, shedding light on the mechanisms behind our teen fertility and mating market findings.

\section{Empirical Strategy: Regression Discontinuity Framework}

Our empirical strategy leverages the difference in the minimum school exit age resulting from the 1972 ROSLA. Specifically, we use a regression discontinuity framework to compare individuals born immediately on either side of the September 1st 1957 cutoff, who we argue are similar except for their relevant compulsory schooling exposure. Our analysis proceeds in two steps: first, documenting that the 1972 ROSLA did indeed change educational attainment as intended, and second, examining the subsequent effects of ROSLA on fertility and family formation. 


\section{A Educational Impacts of the 1972 ROSLA}

To estimate the first-stage educational impacts of the 1972 ROSLA, we follow the fuzzy regression discontinuity setup (Imbens and Lemieux, 2008, Lee and Lemieux, 2010). That is, we estimate local linear regression equations of the following form using data near the September 1957 cohort threshold:

$$
E_{c}=\gamma_{0}+\gamma_{1} D_{c}+\gamma_{2} R_{c}+\gamma_{3} D_{c} R_{c}+u_{c},
$$

where $E_{c}$ is an average educational attainment measurement for month $\times$ year of birth cohort $c$ (e.g., the fraction leaving school at age 15 or the average age at school exit), $D_{c}$ is an indicator for whether the cohort is affected by the 1972 ROSLA (equal to 1 for cohorts born September 1957 and later and 0 otherwise), $R_{c}$ is the running or forcing variable (the month $\times$ year of birth relative to September 1957) centered such that $R=0$ is the September 1957 cohort, and $u_{c}$ is the error term 20

While the Labor Force Survey data on education would allow us to estimate this regression using the individual-level micro-data, all of our outcomes (births, abortions, education and age of mate) are measured as averages at the month $\times$ year-of-birth level, so we aggregate the LFS data to the month $\times$ year-of-birth level. We weight these regressions by cohort size calculated as described in the data section. The inclusion of $R_{c}$ captures cohort trends, and the inclusion of $D_{c} R_{c}$ allows the cohort trends to differ on either side of the September 1957 cutoff. We know no a priori reason why they should differ, other than that these cohorts experienced their later teen years during a time of rapidly-changing fertility trends throughout the OECD.

Our regression discontinuity estimator effectively contrasts outcomes for September and August cohorts born in the same year. The parameter of interest $\left(\gamma_{1}\right)$ can be thought of as the "jump" in the dependent variable at the program threshold. This is the sense in which our research design exploits the comparison of cohorts "just unaffected" and "just affected" by the reform. However, to the extent that relative age or age at school entry affects the outcomes of interest, our estimates of $\gamma_{1}$ will be confounded. We can net out this potentially confounding variation via the inclusion of month-of-birth fixed effects, which can be separately identified from cohort trends because the

\footnotetext{
${ }^{20}$ In this context, for most individuals educational attainment can be derived from age at school exit with little error because retention rates are low ( $<5$ percent). See http://eacea.ec.europa.eu/education/eurydice/documents/ thematic_reports/126EN_HI.pdf
} 
regression samples include cohorts born in the same calendar months across several birth years. We report all results with and without these month of birth controls. In practice, for most outcomes, the addition of these fixed effects has little impact on our estimates of $\gamma_{1}$.

\section{B Fertility and Mating Market Impacts of the 1972 ROSLA}

To evaluate the effects of ROSLA on our main outcomes of interest - fertility and assortative mating outcomes - we estimate regressions of a form very similar to that of equation (1) except that our dependent variable is different. That is,

$$
Y_{c}=\beta_{0}+\beta_{1} D_{c}+\beta_{2} R_{c}+\beta_{3} D_{c} R_{c}+v_{c}
$$

where $Y_{c}$ is an outcome of interest (e.g., fertility rate at age 17), and $\beta_{1}$ is the estimate of the ROSLA impact on that outcome. Note that our information on educational attainment and on fertility and mating market outcomes come from different datasets. Thus, to derive the return to an extra year of schooling on any of our outcomes $Y_{c}$, we can estimate $\beta_{1} / \gamma_{1}$, the standard Wald IV estimate using a two-sample instrumental variables strategy (Angrist and Krueger, 1992).

\section{Choice of a Bandwidth}

Estimating these equations requires deciding on how close to the September 1957 threshold to restrict attention. We follow the cross-validation procedure of Ludwig and Miller (2007) to determine the appropriate bandwidth. The method minimizes the square of the prediction errors from the local linear model. Because we estimate a variety of effects (births at 16, 17, 18, 19, etc.), we choose one bandwidth for each similar set of outcomes (e.g., education or marriages or births). For example, when looking at teenage fertility, we find the strongest visual evidence of effects at age 17. We then choose the bandwidth that performs best in the cross-validation statistic for the age 17 outcome and use it for all of the other teenage fertility outcomes.

In principle, the bandwidth should not matter too much with a convincing design. To demonstrate robustness, we estimate models with both narrower and wider bandwidths than what the Ludwig and Miller (2007) cross-validation suggests. There are other several bandwidth selector algorithms (Imbens and Kalyanaraman, 2012, Calonico, Cattaneo and Titiunik, 2014). Calonico, 
Cattaneo and Titiunik (2014) argue that traditional bandwidth estimators choose bandwidths that are too large for the distributional assumptions invoked and as a result introduce a non-negligible source of bias. Calonico, Cattaneo and Titiunik (2014) consider the case with a continuous running variable whereas we have a discrete running variable (i.e., month $\times$ year of birth). For this reason, we do not use their selection algorithm for our main set of estimates. Nonetheless, we present estimates following the procedure of Calonico, Cattaneo and Titiunik (2014), which are similar to our main results.

\section{Identifying Assumptions}

A key advantage of the regression discontinuity approach is the minimal set of assumptions needed for identification. We must assume that individuals born immediately prior to and immediately following September 1957 are otherwise identical except for their educational attainment. Ex ante, this assumption seems plausible as the policy change was not pre-announced. Moreover, it is testable, at least in terms of observables. For each observable characteristic that should be predetermined, one can test whether the characteristic has a discontinuity at the September 1957 threshold. Clark and Royer (2013) perform this analysis, for example examining the number of births and stillbirths among the birth cohorts that grow up to be the students, wives, husbands, and parents in our data, and find no evidence of discontinuities in these outcomes.

In order for our IV estimates to measure the causal effect of a year of additional schooling at age 15, we must assume that the 1972 ROSLA does not affect fertility through channels other than its effect on the probability of experiencing a year of full-time education at age 15 . This exclusion restriction would be violated, for instance, if the law was accompanied with a change in the accommodations for pregnant students. As we discuss above, the policy environment did not change along this dimension.

\section{First Stage Effect on Education}

\section{A Age Left Schooling}

We begin by reporting estimates of the impact of ROSLA on educational attainment. Figure 1 shows the impact of the 1972 ROSLA on age at school exit for women and men. Specifically, each 
point in this figure represents the average outcome for a cohort defined by month and year of birth. The three sets of points trace the fraction who left school by age 15 , by age 16 , and by age 17 . The lines are local linear regression fits to those underlying points using the chosen bandwidth.

ROSLA affected schooling decisions exactly as the policy was designed. The reform had an immediate impact on age at school exit as there is a clear drop in the fraction leaving by 15 , starting with the September 1957 cohort. This drop is on the order of 25 percentage points. Estimates are similar for men and women. The extra year of required schooling at age 15 did not induce students to stay much beyond what was mandated by ROSLA as there were minimal impacts on the probability of leaving school by age 16 or 17 .

While Figure 1 suggests that most students complied with the new law, there is a non-negligible share of individuals who report not complying ( $<8$ percent for most cohorts). The apparent lack of compliance is particularly high among cohorts born in June, July, and especially August. This is because school was not in session when these individuals turned 16. School ends in late May for 15/16 year-olds, and according to the 1972 ROSLA rule, summer-borns are considered to have met the schooling requirement if they leave at the end of the grade. For non-summer borns, it appears that some of the reported non-compliance is measurement error. The LFS is a panel, so we can look at the various responses given by the same respondent about the age at which he or she left school. Over 10 percent of respondents who report leaving school at age 15 also report leaving school at 16 in a different survey wave. (All waves were reported as adults and close in time to each other.) Further, the NCDS, which interviewed the March 1958 cohort when the respondents were 16 years old and recall error would be lower, shows that less than 1 percent of respondents reported leaving school before age 16 .

In Table 1, we quantify the patterns observed in Figure 1. In Panel A, we report discontinuity estimates of $\gamma_{1}$ (see equation 1) for different educational outcomes. The estimation sample includes 48 months of birth cohort data on either side of the ROSLA threshold (i.e., 96 months in total). The reported mean of the dependent variable is for the August 1957 birth cohort. ROSLA led to a 27 and a 25 percentage point reduction in the fraction of individuals leaving schooling by age 15 for women and men, respectively.

As evident in Figure 1, ROSLA did not induce large fractions of cohorts to stay in school beyond the extra year. Specifically, the effects on leaving at age 16 and 17 are -2 and -1 percentage points. 
The overall effect on age at which respondents left full-time education is 0.31 years for women and 0.38 years for men, which are highly statistically significant with t-statistics exceeding 5 . Figure 2 displays the corresponding regression discontinuity plots for age leaving full-time education.

These results are extremely robust to the inclusion of different seasonal controls. In Panel B of Table 1, we control for any cohort seasonality and age-in-grade effects by re-estimating regression equation (1) with a full set of month-of-birth dummies excluding the September month-of-birth dummy ${ }^{21}$ Given the consistency of the month-of-birth pattern across cohorts, calendar month-ofbirth dummies are likely to adequately control for these patterns. Nonetheless, to further demonstrate robustness, in Panel $\mathrm{C}$ we exclude the summer borns (i.e., those born in June, July, and August) from the sample, instead of adding calendar month-of-birth dummies. The results in all cases are similar to those from Panel A, demonstrating the strength of this research design and first stage. These first-stage estimates are also essentially identical to those of Clark and Royer (2013) who utilize different data 22

In Appendix Tables $2 \& 3$, we show that the results are not very sensitive to the selected bandwidth. In Appendix Table 2, for each outcome, we provide the estimates using the Calonico, Cattaneo and Titiunik (2014) bandwidth selector and estimation procedure. In Appendix Table 3, we show how our estimates vary under other bandwidths. For both of these tables, we include month-of-birth fixed effects in addition to the standard regression discontinuity design variables. However, in a few cases, the Calonico, Cattaneo and Titiunik (2014) chosen bandwidth is smaller than 12 months. In these cases, we drop the month-of-birth fixed effects from the Calonico, Cattaneo and Titiunik (2014) estimation procedure. The outcomes for which we consider this alternative specification are denoted with an asterisk in these appendices.

\section{B LATE, Credentialing, and Human Capital}

While these regressions verify the existence of a clear first-stage relationship, several other points from Panel A are worthy of discussion. First, the size of the impacted population is considerable.

\footnotetext{
${ }^{21}$ We have also estimated models where we allow the effects of month of birth to differ on either side of the September 1957 threshold. The results are similar.

${ }^{22}$ For a point of reference, Clark and Royer (2013) use the General Household Survey and the Health Survey of England. For women, their first-stage estimate on age at which respondents left full-time schooling is 0.31 and on leaving by age 15 is -0.27 when calendar month-of-birth fixed effects are included. For men, the analogous statistics are 0.36 and -0.25 .
} 
Over a quarter of the post-reform population had its school leaving age impacted by the 1972 ROSLA. As such, the estimated local average treatment effects (LATE) may be closer to the average treatment effect (ATE) in this context (Oreopoulos, 2006). In comparison, difference-in-differences designs exploiting compulsory schooling changes in other contexts have been identified off of only about 5 percent of population in the US (Lleras-Muney, 2005) and only about 12 percent in Norway (Black, Devereux and Salvanes, 2008). Second, the set of compliers for whom we identify the effect of a year of education is a policy-relevant subpopulation. Because we exploit a policy change, rather than some other type of natural experiment, the compliers in our context are the marginal types whose behaviors can be altered by policy. Third, we do not have to worry about weak instruments given the strength of the first stage; the F-statistic on the first-stage estimates for exiting school by age 15 exceeds 150 . Such worries have hindered analysis of compulsory schooling in other countries (see Black, Devereux and Salvanes, 2008 for a discussion of this) ${ }^{23}$ Finally, and somewhat unique to this institutional context, the strength and robustness of the first stage combined with the manner in which the reform was implemented allows us to use regression discontinuity methods rather than difference-in-differences methods; the regression discontinuity design may be preferable given the relatively weak assumptions needed for identification.

As in any identification scheme based on schooling reforms, compliers take on the extra schooling only when required to, and there may be a concern that compliers acquire little human capital in that extra year. There are several reasons to believe this is not the case in our context. First, there was significant investment in teachers and physical infrastructure leading up to the reform, which was necessary to accommodate the larger student body. The student-teacher ratios, a crude measure of education quality, were essentially unchanged across the reform, as we show in Appendix Figure 2. As long as the trend in educational investment does not change discretely, starting with the September 1957 cohort, our identification strategy is still valid. Second, Grenet (2013) estimates a 6-7 percent hourly wage return to a year of schooling from the 1972 ROSLA. Finally, using our own data we can provide some additional insight on what the ROSLA treatment entailed by examining an alternative measure of education: performance on high stakes exit exams. For this, we use information from the 2001 Census, which included retrospective responses about the highest

\footnotetext{
${ }^{23}$ Black, Devereux and Salvanes $\sqrt{2008)}$ show in the context of US data that difference-in-differences estimates of compulsory schooling's effects on education lead to weak first-stage estimates with the inclusion of state-specific trends along with the appropriate calculation of standard errors.
} 
credentials attained during secondary schooling.

During our study period, students took O-level and A-level subject-specific exams. Passing O-level exams at the end of grade 11 (age 16) conferred a "qualification" credential, and these O-level qualifications served as the standard credential awarded at secondary school-leaving. Alevel exams were used for university admissions. ${ }^{24}$ Table 2 displays the regression discontinuity estimates for women (left side) and men (right side) where the dependent variables across columns are these qualification outcomes. For both genders, there is a substantial drop in the fraction with no qualifications: -25 percent for females and -16 percent for men. There is a coinciding shift to having 1 or more O-level exam credential or $1 \mathrm{~A}$-level. ${ }^{25}$ There is also a drop in the fraction having other qualifications (which include other more vocational degrees), so part of the shift to O-level exams appears to be a movement from vocational credentials to academic credentials ${ }^{26}$ However, there is no effect of having a higher level of credential beyond 1 A-level exam. This is consistent with the visual evidence in Figure 1, since more than 1 A-level exam would indicate intentions to attend college, and Figure 1 shows no large spillover effects to educational attainment beyond age 16.

Before moving on to our main findings, we note that it is plausible that ROSLA had general equilibrium effects in the sense of changing the environment to which "control" (pre-ROSLA) cohorts were exposed. This is because treatment and control cohorts were living in the same communities and competing with each other in the same labor markets and mating markets. If so, then our research design identifies the differential impact of ROSLA on post-ROSLA cohorts (who experienced the new equilibrium and the education treatment) and pre-ROSLA cohorts (who experienced only the new equilibrium). It is important to understand that identification here does not require assuming there are no general equilibrium effects on mating markets - much the same as estimating the wage returns to education using schooling reforms does not require assuming that there are no general equilibrium effects of such reforms on labor markets. In short, the comparison of outcomes between pre- and post-ROSLA cohorts is valid in the presence of general equilibrium

\footnotetext{
${ }^{24} \mathrm{~A}$ levels continue to exist in the UK. O levels were eventually replaced with the General Certificate of Secondary Education. O-level exams are the lower level exams taken at the end of grade 11. A-level exams are used in university admissions.

${ }^{25}$ The 2001 Census we received are aggregated such that $1+$ O-levels and 1 A-level groups are combined together.

${ }^{26}$ The other qualification category includes City and Guilds which awards vocational qualifications, Royal Society of Acts or Oxford, Cambridge and RSA which is a professional typing credential, and BTEC or Edexcel which are privately-administered academic, vocational, or work-based credentials.
} 
effects, though one might expect effects to differ from what would be estimated in the partial equilibrium setting of changing educational attainment for just a small group of individuals.

\section{Fertility Results}

Having established the strength of the first stage, we now shift to the main focus of the paper family formation. We start here by examining the effects of the ROSLA reform on fertility before turning to the mating market in Section VII ${ }^{27}$

\section{A Teenage Fertility}

ROSLA extended compulsory schooling during the teen years. Figure 3 presents plots of age-specific fertility rates across cohorts over the teen years in a format analogous to that in Figure 2. These fertility rates are calculated according to age-last-birthday. Thus, the age 16 rate captures births in the exact age range $[16,17)$, and the age 17 rate captures births in the exact age range $[17,18)$. The figure shows declines across the policy threshold for fertility at 16 and 17, but no visually obvious effects at later ages. The magnitude and significance of these ROSLA effects are explored in Table 3 , which presents reduced-form estimates (unscaled by the first stage) $2^{28}{ }^{29}$

Table 3 shows that ROSLA led to significant declines in fertility at age 17 . The age 17 effects range from -0.0031 to -0.0034 , depending on the inclusion of month of birth fixed effects. These magnitudes are economically meaningful. A reduction of 3.1 births per thousand 17-year-old women corresponds to an 8 percent decline. Scaling by the first stage effect on years of education (0.31) generates a Wald IV estimate equal to a 26 percent decline.

The age 16 estimates are similarly large, though somewhat sensitive to specification. This is likely because a birth at age 16 is a rare event. The Panel A estimate on age 16 fertility is -0.0018 ,

\footnotetext{
${ }^{27}$ General fertility patterns in the UK and Europe during our sample period are discussed in the Appendix and help to give some context to the underlying cohort trends we observe here.

${ }^{28}$ Our data do not allow us to examine fertility at ages below 15 . The administrative birth records begin in 1970 , which means that the first cohort for whom we could calculate an age 14 birth rate is January 1956. This leaves us with too small a pre-reform sample to do meaningful estimation. However, little is lost by this limitation. Fertility at age 14 is a rare event, even in our dataset of the universe of births. Thus any age 14 estimates would have been associated with large standard errors and driven by just a handful of births nationally.

${ }^{29}$ The Table 3 teen fertility estimates are based on a narrower data window than the Table 1 education estimates. These different windows are those suggested by a cross-validation procedure. Intuitively, the fertility window is narrower because, around the ROSLA threshold, fertility trends are more rapidly changing than education trends. In suggesting a narrower window, the cross-validation procedure implicitly takes account of this feature of the data.
} 
which is statistically significant at $p<0.05$. The Panel B and $\mathrm{C}$ specifications yield estimates that are indistinguishable from zero. Since the age 16 effects are sensitive to specification, it helps to view these estimates in the context of Figure 3. Declines in both age 16 and 17 fertility are visually apparent in the figure. In terms of size, the middle-range estimate for the age 16 fertility effects of -0.0018 (Table 3, Panel A) corresponds to a 10 percent decline. After scaling by the first stage effect, this represents a 32 percent decline.

Beyond age 17, we observe no ROSLA impacts on teenage fertility. Consistent with the visual impression of Figure 3, the estimates for age 18 and age 19 fertility are small (2.6 percent and 0.3 percent of their means, respectively) and statistically insignificant 30 To explore channels behind these teen effects, we examine below how the timing of reductions in teen conceptions aligns with the timing of the new schooling. We defer this discussion until Section E because it requires reorganizing the data to define implied conception dates as relative to the dates of new schooling.

Finally, we note that there appears to be a significant change in the slope of the age 19 fertility trend near the policy threshold. Upon closer inspection the timing for this change would have been 1976-1977. This 1976 effect, which occurs in the age 19 plot among cohorts born in late 1957, is also apparent in the age 18 plot among cohorts born in late 1958, in the age 17 plot among cohorts born in late 1959, and in the age 16 plot among cohorts born in late 1960. In Appendix Figure 3, we draw on fertility data from France and Germany and show that these countries similarly experienced this trend break in 1976. Because these other European countries shared the same trend break, and because the trend break was year-specific rather than cohort-specific, it seems safe to conclude that this has nothing to do with ROSLA and instead reflects general trends in fertility in Europe at that time.

\section{B Births by Marriage Status}

We can separate in-marriage and out-of-marriage births in the administrative birth records. Appendix Figure 4 shows the regression discontinuity plots for in-marriage and out-of-marriage birth rates, and Appendix Table 4 presents the analogous regression discontinuity estimates with standard errors. Appendix Tables 2 and 3 examine the robustness of these estimates to varying bandwidths

\footnotetext{
${ }^{30}$ The finding of no ROSLA effects on fertility at ages 18 and 19 extends to ROSLA effects on fertility rates in one-year age intervals up to 45 .
} 
and estimation procedures.

Appendix Figure 4 clearly shows that the overall fertility impacts we see for ages 16 and 17 come from a decline in in-marriage fertility. The magnitudes of the regression discontinuity estimates for in-marriage births are similar to those in Table 3 for fertility overall. Because marriage itself may be affected by ROSLA, it is not immediately apparent whether the drop is due to a change in marriage or a change in fertility conditional on marriage. However, aggregate national statistics describing births within 8 months of marriage can shed some light on this: In this population and time period, essentially all marriages among 16-17 year-old females were preceded by a conception B1 Because essentially all births in-marriage were indicative of a "shotgun" marriage (i.e., conception, then marriage, then birth), the observed drop in in-marriage births has a near one-to-one correspondence with a drop in "shotgun" marriages. In contrast, there is no fall in birth rates for out-of-marriage fertility. Our identification strategy cannot be used to determine whether the overall decline in births reflects substitution only from in-marriage births to no births, or if there was substitution from in-marriage towards out-of-marriage status that exactly cancelled a substitution from out-ofmarriage births to no births. What is clear, however, is that ROSLA caused a decline in "shotgun" weddings.

\section{Abortions and Conceptions}

A crucial element missing from past economic studies is how abortion may mediate the impact of education on fertility. Usually abortion data are difficult to obtain. In the United States, abortions are not universally reported across states. In the UK, due to the existence of the National Health Service, which provides universal healthcare including abortions, the corresponding administrative abortion micro-data are more reliable and comprehensive.

Information on terminations allows us to better understand how education affects conception and sexual behavior, rather than inferring these behaviors by observing births alone. For example,

\footnotetext{
${ }^{31}$ The UK's Office of National Statistics (ONS) reports summary statistics on births taking place within 8 months following a marriage, implying that the conception preceded the wedding. In 1972 there were 2,767 such births to 16-year-old married women. Our main births dataset show that in 1972 the total number of births to 16-year-old married women was approximately 2,887 . (The number depends slightly on what one assumes about the mother's and baby's exact date of birth within their birth months.) Therefore, essentially all in-marriage births among 16-year-olds followed the pattern of: conception, then marriage, then birth. In the same time period, 87 percent of in-marriage births to 17-year-olds followed this same "shotgun" pattern. Appendix Table 5 shows a complete listing of these statistics by age and year.
} 
the education-related reductions in fertility among 16 and 17 year olds would be consistent with a reduction in conceptions and no effect on abortions or consistent with no effect on conceptions and an increase in abortions.

In Table 4, we present the reduced-form regression discontinuity estimates for abortions at ages 15 through 19. Figure 4 shows the analogous figures. Across all of the ages, all of the specifications, and alternative bandwidths (see Appendix Tables 2 and 3), there is no strong evidence of an impact of ROSLA on abortion rates. Most of the reduced form point estimates range from 1 to 3 percent of the mean abortion rates. The exception is the age 15 effect, which implies a 6 to 9 percent reduction in abortion rates relative to the mean, but because the mean incidence is so low, the estimates are imprecise.

Rather than examining abortions and births separately, we can combine these data together to estimate effects on conceptions. To do this, we adjust the timing of abortions to be consistent with that of births. For example, an abortion in September 1974 would have likely resulted in a birth in the first half of 1975 if the abortion had not occurred. To align the timing, we age abortions forward by 7 months (most abortions occur before 12 weeks of gestation) and add abortions and births together to form our "conception" rate. Of course, this measure misses miscarriages.

Appendix Table 6 presents the ROSLA effects on this measure of conceptions. The increase in school exit age reduces the conception rate at ages 16 and 17 by 12 percent $\left(=\frac{-0.33}{2.75}\right)$ and 9 percent $\left(=\frac{-0.50}{5.48}\right)$ in the reduced-form estimates in Panel A. These effects are statistically significant at the 1 percent level, though again the significance of the age 16 result is sensitive to specification. These magnitudes align with those for birth rates. And like the age 18 and 19 effects on birth rates, conception effects for ages 18 and 19 are much smaller and statistically insignificant.

In summary, the abortion and conception results indicate that 15- through 17-year-old teens changed behavior primarily by reducing the probability of a conception rather than by increasing abortions, despite the high baseline abortion rates in this context. Further, the negligible effects of education on fertility for the older teenagers were not due to changes in conceptions that were merely counteracted by matching changes to abortion decisions. 


\section{Cumulative Fertility}

Since the earliest of the ROSLA-impacted cohorts have completed their fertility by the early 2000's, we can also examine the impacts on completed family size. Figure 5 plots the regression discontinuity figure for cumulative fertility from ages 16 to 45 (inclusive) ${ }^{32}$ This cumulative fertility rate is constructed as the sum of each cohort's age-specific rates up to age 45. Because of the nature of our births data, we do not observe completed fertility at age 45 at the individual level. However, the cumulative rate we calculate would exactly equal the average completed family size found in individual data provided that all women in the cohort survived through their childbearing years. Since the probability of survival from 16 to 45 among these cohorts was above 98 percent, we view our cumulative fertility measure as a good measure of average completed family size 33

Figure 5 suggests that there was no effect of increased schooling on completed fertility. The scale of the vertical axis is measured in average births per cohort woman, and the apparent null effect of the reform is contained within a very narrow band of births per woman. Table 5 presents regression discontinuity estimates corresponding to Figure 5, as well as an expanded set of cumulative fertility outcomes. Cumulative births between 16 and 25, 16 and 30, 16 and 35, 16 and 40, and 16 and 45 are considered as outcomes. The reduced form effects implied by Figure 5 and the last column of Table 5 range from -0.0055 to 0.0073 children. Even after this reduced form effect is scaled by the ROSLA effect on years of schooling, this range is only -0.018 to 0.023 children.

To put this effect size in context, note that for cohorts of women born near the reform threshold, an additional year of education at age 16 is associated with a decline in total fertility of 0.248 children in the cross section (see Geruso, 2010). Our IV estimates are an order of magnitude smaller. The finding of no completed fertility effect is robust to alternative regression specifications and bandwidths (see Appendix Tables 2 and 3).

\footnotetext{
${ }^{32}$ Cohort-specific cumulative fertility is often referred to as the cohort total fertility rate (TFR). Cohort TFR, which is derived from age-specific rates for a fixed cohort, differs from period TFR, which is derived from age-specific rates for a fixed point in time.

${ }^{33}$ It should be noted that measurement error in the denominator of fertility rates (i.e., the number of women alive) cannot explain our results. In particular, our regression discontinuity estimate in the presence of this measurement error is equal to $\frac{D^{*}}{D} \times$ (true regression discontinuity effect) where $D^{*}$ is the true denominator and $\mathrm{D}$ is the denominator with measurement error. To derive this, we assume that the regression discontinuity estimator is the difference in fertility rates for nearby cohorts and further assume that the number of women in the nearby cohorts is the same. Using Census data, we can approximate $\frac{D^{*}}{D}$ well since these Censuses are intended to be 100 percent samples. For the 1991 and 2001 Censuses for the cohorts we study, this ratio ranges from 1.044 to 1.069. This means that the true regression discontinuities are slightly smaller than what we estimate but not appreciably so.
} 
We can also compare our estimates to the most relevant studies within the existing literature. Black, Devereux and Salvanes (2008) and Monstad, Propper and Salvanes (2008) utilize educational reforms in Norway that extended the length of compulsory schooling by 2 years, standardized curriculum, and increased access to schools. Fort, Schneeweis and Winter-Ebmer (2016) exploit several different compulsory schooling reforms across Europe. Our estimated effect on total fertility is not far from the estimate of Monstad, Propper and Salvanes (2008) of -0.009 but is much smaller than that of Fort, Schneeweis and Winter-Ebmer (2016), who find that an additional year of schooling changes fertility by -0.28 in the UK using the 1947 reform and a positive estimate for continental Europe of 0.21 children using the 1947 compulsory schooling reform ${ }^{34}$ Besides addressing different time periods and educational margins, a plausible explanation for the differences in estimates is methodology. These prior studies exploit difference-in-differences or yearly birth cohort comparison designs. As fertility trends are uncommonly strong during this period (see Appendix Figure 3), our regression discontinuity approach may be particularly well-suited to controlling for time and cohort trends.

Finally, we note that although at first glance it may seem that our findings of large negative teen fertility effects and small or zero completed fertility effects imply positive "catch up" effects beyond the teenage years, this is not necessarily true. Instead, because teen fertility is such a small component of average completed family size, the confidence intervals on our fertility effects include both this catch-up story and the polar opposite story under which the teen fertility effects lead to a permanent (albeit tiny) reduction in completed fertility.

These possibilities can be seen in Figure 6, which aggregates information from 30 separate regression discontinuity estimates ${ }_{35}^{35}$ Each point in the plots represents an estimate of the cumulative fertility effect between age 16 and the indicated age. The first point in the left panel, for example, represents the cumulative effect from 16 to 16, and corresponds to the ROSLA effect on the age 16 fertility rate from Table 3, Panel B, column (2). The last point in this plot represents the cumulative effect from 16 to 45, corresponding to the Table 5, Panel B, column (5) estimate. The left panel in the figure displays estimates for which cumulative fertility is measured in levels, while

\footnotetext{
${ }^{34} \mathrm{As}$ for teenage fertility, our estimate on teenage fertility is one-third the size of the Black, Devereux and Salvanes, 2008 study.

${ }^{35}$ These follow the Panel B specifications from Tables 1 through 5, and are based on local linear regressions that include month of birth dummies.
} 
the right panel presents estimates for which cumulative fertility measured in natural logs. Fertility rates vary considerably with age, and the right panel estimates can be interpreted as percentage changes. Examining percentage changes this way makes the increasing cumulative fertility denominators more apparent. Panel B of Figure 6 shows that the cumulative effects begin at age 16 and then fade away, as the averted teen births become swamped by the larger number of births at older ages.

\section{E "Direct Effects" on Fertility versus Human Capital Channels}

The difference between the teenage fertility effects and the cumulative fertility effects seems to contrast with the predictions from the classic theoretical literature on fertility decisions (Becker, 1960; Willis, 1973; Becker, 1965, Becker and Lewis, 1974). This literature emphasizes human capital effects operating on fertility decisions in many ways, including altering time preferences, altering the opportunity cost of non-labor market activities such as child rearing, and altering the equilibrium mating outcomes such as spouse's income and education. These types of human capital effects are expected to impact the timing of childbearing and number of children 36 Note that under any such theories, one would expect the influence of education to be permanent, with potential fertility impacts throughout the life cycle. In contrast, we document fertility effects that are short-lived and only appear in the teen years.

On the other hand, some recent empirical work has suggested a more direct role of spending time in school, possibly due to more intense monitoring of activities or exposure to different peers (i.e., classmates in school versus coworkers out of school). For example, in Chile the lengthening of the school day was associated with fertility reductions (Berthelon and Kruger, 2011). It is also plausible that spending time in school could directly impact mating outcomes by changing peers, and that these mate effects could play a role in the observed fertility outcomes (a theme we return to in Section VII).

To begin to untangle the various possibilities, we classify the many potential channels from

\footnotetext{
${ }^{36}$ Classical theories linking fertility and education emphasize the role of opportunity costs and the tradeoff between quantity and quality of children (Becker, 1960, Willis, 1973, Becker, 1965, Becker and Lewis, 1974). Increases to a woman's education raise the opportunity cost of her time and lead to the combination of income and substitution effects influencing fertility in opposite directions. To explain the strong cross-sectional correlation between education and fertility, Willis (1973) argues that the substitution effect trumps the income effect. Becker (1965) and Becker and Lewis (1974) discuss a substitution from quantity towards quality with ambiguous effects on family size.
} 
education to fertility into two broad categories: the human capital effects and the "direct effects" of schooling. We begin in Figure 7 by reorganizing the data to examine in finer detail the timing of fertility effects relative to the timing of the new compulsory schooling period. Doing so allows us to test the conjecture that the reduction in pregnancies carried to term is coincident in time with current school attendance.

Students in the UK could only leave school at a small set of allowed leaving dates, corresponding to the end of school terms. Thus the exact ages over which the new schooling takes place varied depending on the month of birth of the woman. For example, for the September cohort, this extra schooling would have happened between the ages of 15 years and 7 months and 16 years and 7 months. For January-borns the new schooling occurs between 15 years and 3 months and 16 years and 3 months.

For each calendar month, we calculate the woman's age range (at the the resolution of months) for the period over which the extra schooling would have occurred. This equals the actual period of new required schooling for post-ROSLA cohorts and the counterfactual period of new schooling that pre-ROSLA cohorts were not actually exposed to. We subtract 9 months from the birth dates to calculate a conception date. Using this re-organization of the data, we construct the implied conception rates for the 12 month period before the extra schooling (labeled "before new schooling"), for the 12 months during the extra schooling period ("new schooling period"), and for the 12 months after the extra schooling period ("post new schooling period"). Returning to our example of the September-born women, the conceptions during new schooling for the Septemberborns would correspond to fertility rates for ages in the range of 16 years and 4 months to 17 years and 4 months.

Figure 7 shows our regression discontinuity estimates, along with 95 percent confidence intervals, of the effect of the 1972 ROSLA on $\ln$ (fertility rate) for each of these three relative-to-schoolattendance time periods 37 With the caveats that we cannot account for preterm births or the exact day of birth of the mother - both of which add noise to our estimates - the fertility effects line up remarkably closely with the new period of compulsory schooling. The only statistically significant effect on fertility is the one corresponding to the new period in school. Effects for the

\footnotetext{
${ }^{37}$ Because each of these estimates combines fertility at different exact ages, we use $\ln$ (fertility rate) as the dependent variable. This facilitates comparing fertility rates at different ages, because fertility rate levels rise rapidly with age during the teenage years.
} 
other periods are smaller and statistically insignificant.

To explain these effects that occur only during the period of new schooling, we must explain why females were less likely to become pregnant during the new compulsory schooling period, but not before or after 38 An obvious explanation is that they had fewer opportunities to become pregnant: less contact and less time with older men that they might have met in other contexts, such as the workplace. Aggregate national statistics from the UK from this period reveal that the vast majority of teen marriages and among 16- and 17-year-old females and a large share of their pregnancies were associated with matches to older men 39 This suggests that exposure to older men may be an important factor for teen pregnancy. This leads us in the next section to examining the mating market to provide a more complete picture of the ROSLA effects. Although mating and fertility are likely to be linked, most prior empirical work on the effects of education has examined one or the other outcome in isolation.

\section{Mating Market Outcomes}

In this section, we examine how the schooling reform impacted the mating market outcomes for affected cohorts ${ }^{40}$ We analyze effects on two dimensions of mate characteristics: spousal education and age gaps between spouses. The aggregate patterns of assortative mating along educational attainment and age have long attracted the interest of economists and other social scientists (e.g., Qian and Preston, 1993; Qian, 1998, Lewis and Oppenheimer, 2000, Greenwood et al., 2014), and there is some prior econometric evidence of how one's own education impacts the educational attain-

\footnotetext{
${ }^{38}$ One counterpoint to our argument that schooling has an incapacitation effect is that for teenagers, conceptions are fewer during the summer. Under incapacitation, we would expect that summer conceptions would be higher when women had more free time. Incapacitation may work differently in these two settings - given that leaving school for the summer is different from leaving school permanently.

${ }^{39}$ Although there are no available micro data that indicate date of marriage, aggregate national statistics reveal that female teenagers who were marrying must have been marrying older men. In 1972 there were 8,295 married 16-year-old females compared to just 629 married 16-year-old males. In the same year, there were 17,967 married 17-year-old females and 3,044 married 17-year-old males. These facts, combined with the observation from our main dataset that more than half of births to 16- and 17-year-old women were in-marriage, suggest that partnering with older men was an important component of the teen fertility picture.

${ }^{40}$ Schooling could impact the characteristics of one's mate in several ways. A theoretical literature (e.g., Becker, 1973 Konrad and Lommerud, 2000, Iyigun and Walsh, 2007, Chiappori, Iyigun and Weiss, 2009) emphasizes the return of education in the marriage market in addition to the labor market. These returns may operate through several mechanisms; increases in education may change preferences over spouses directly; the acquisition of additional education may alter one's share of the marital surplus by strengthening one's bargaining power in the marriage; or, through changes in occupation or employment status, extra schooling may affect opportunities to meet more-educated potential mates.
} 
ment of one's partner - using within-twin pair variation in schooling levels (Behrman, Rosenzweig and Taubman, 1994) and using discontinuities in university admissions criteria (Kaufmann, Messner and Solis, 2015). There is no prior empirical work of which we are aware estimating impact of education on the age difference between spouses, despite that this age gap is often noted as an object of interest in studies of marriage (e.g., Stevenson and Wolfers, 2007), is used as a measure of marital bargaining power (e.g., Casterline, Williams and McDonald, 1986), and is interpreted in mating models as being informative of the gender-specific division of marital surplus between spouses (Bhaskar, 2015, Brandt, Slow and Vogel, 2016).

\section{A Assortative Mating by Education}

We find that the educational reform significantly affected spousal educational attainment. In Figures $8 \& 9$ and in the corresponding Table 6 , we report ROSLA's impacts on the partner's educational outcomes. Figure 8 shows, as a function of the wife's date of birth, the probability of the male spouse having: no qualifications, 1 or more O-level exam or 1 A-level exam, and 2 or more A-level exams or higher 41 O- and A-level exams are sets of high-stakes national exams covering different subjects. O-level exams happen after grade 11 (the grade in which most will turn 16). A-level exams are administered two years later and are used for university admission. Figure 9 presents the analogous results for men. It is important to keep in mind that we observe these individuals in the 2001 Census, many years after the 1972 ROSLA. As such, we interpret these effects as the long-run impacts on mate choice. Conditioning the analysis on marriage is valid in this case because we find there is no effect of ROSLA on the probability of marriage 42

Both women and men affected by ROSLA were less likely to marry partners with no qualifications. The regression discontinuity estimates are similar for men and women - a statisticallysignificant reduction of 1.0 to 1.4 percentage points across specifications in Table 6 . Figures 8 \& 9 visually confirm these estimates, which are remarkably stable across specifications and bandwidths (see Appendix Tables 2 and 3). When scaled by the first stage effect on own years of schooling,

\footnotetext{
${ }^{41}$ These categories are mutually exclusive, and the category divisions were chosen by the UK Census.

${ }^{42}$ For men, the regression discontinuity point estimates on an indicator for married are a statistically insignificant -0.0004 and -0.0006 for the 1991 and 2001 Censuses (off of bases of 0.69 and 0.66 for those years, respectively). For women, the effects are -0.0086 and 0.0001 for the same years off of bases of 0.66 and 0.74 -also statistically insignificant despite large samples. Using educational variation resulting from quarter of birth, Lefgren and McIntyre (2006) also find no impact of a woman's education on the probability of marriage.
} 
these effects amount to a $22\left(=\frac{-0.0123}{0.237 \times 0.24}\right)$ and $28\left(=\frac{-0.0143}{0.187 \times 0.30}\right)$ percent reduction for women and men, respectively, in the probability of marrying an individual with no educational qualifications 43 Alternatively viewed, these results imply that a 10 percentage point drop in one's own probability of having no credentials leads to a $1.8\left(=\frac{0.10 \times-0.0123}{-0.07}\right)$ percentage point decline in the male spouse having no credentials and a $3.6\left(=\frac{0.10 \times-0.0143}{-0.04}\right)$ percentage point decline in the female spouse having no credentials 44 These effects are comparable in magnitude to estimates derived from within-twin pair variation in educational attainment. Behrman, Rosenzweig and Taubman (1994) estimate that a year of additional schooling for a male translates into marrying a wife with 0.3 to 0.4 more years of schooling 45

Our results on spousal educational attainment, considered alongside the 6-7 percent own wage returns to the 1972 ROSLA documented by Grenet (2013) for both men and women, suggest the potential for important impacts of ROSLA on the household's overall economic wellbeing. In particular, our results illustrate how educational attainment can have multiplicative effects on household wellbeing by changing mate quality and mate earnings. This accords with work by Lefgren and McIntyre (2006), who document in the US that an important part of the return to schooling for women operates through the husband's earning capacity.

Despite these effects on own and partner's earning potentials, the large assortative mating results we find stand in clear contrast to our null findings with respect to completed fertility, creating somewhat of a puzzle ${ }^{46}$ In principle, the income and substitution (opportunity cost of time) effects associated with additional schooling could exactly cancel, but perhaps a more plausible explanation behind the null fertility findings is that - unlike the assortative mating patterns - the cross-sectional association between childbearing and female education is driven largely by underlying heterogeneity in preferences over family size. Below we shed some light on this issue by turning to self-reported survey data collected at age 16, with which we show that in the absence of ROSLA, women from the affected cohorts would have sorted themselves into educational paths in a way that was correlated with their stated fertility preferences.

\footnotetext{
${ }^{43}$ See the Panel B specifications of Tables 1 and 6.

${ }^{44}$ See columns 1 and 5 of Table 2 .

${ }^{45}$ They do not estimate the effect of a wife's schooling on her husband's schooling.

${ }^{46}$ It would perhaps be unsurprising to find no fertility effects if there were no substitution effects - due to higher wages - or income changes - such as those generated by matching to a more educated, higher-earning partner (Goldin, 1997). But here we observe the scope for direct income effects through one's higher wages and indirect income effects through assortative mating.
} 
Because ROSLA affected both men and women, it is natural to ask how much of the observed positive assortative mating results are a consequence of a mechanical effect-i.e., post-reform cohorts marrying the same individuals as they would have in absence of this policy, but with these mates gaining additional education because of ROSLA. We address this question in two ways. First, we simulate the expected magnitude of such a mechanical effect, given the pre-ROSLA spousal age gap distribution (i.e., assuming no ROSLA-generated effect on the spousal age gap). If the particular spouses chosen were unaffected by the reform, then the pattern of age gaps would be unchanged. By multiplying the pre-ROSLA probability of marrying someone of the same age by the effects on academic credentials from Table 2, we simulate the declines in the probability of one's spouse having no credentials to be -0.00077 and -0.0004 for males and females, respectively. These simulated effects are almost two orders of magnitude smaller than the estimates presented in Table 6, so Table 6 is not simply reflecting a mechanical effect in which individuals marry the same-aged partners as before who now have more education due to ROSLA ${ }^{47}$ Intuitively, this finding makes sense given that the probability of marrying someone in a particular month $\times$ year birth cohort is small. Under the counterfactual assumption of no shifting of the mate age distribution, a person in the first post-ROSLA cohort is only slightly more likely to marry a post-ROSLA individual than a person in the last pre-ROSLA cohort 48

Second, we can also assess whether the observed assortative mating by educational attainment is mechanical by testing whether the reform affected the age gaps between spouses. We do so in the next two subsections. If the effect of ROSLA on marital sorting was entirely a mechanical effect in which the same partners (each now more educated) paired up, we would expect to see no impact of ROSLA on the spousal age gap or on the probability of marrying a classmate.

\section{B Partner's Age}

In Appendix Figure 5, we display the regression discontinuity graphs for the age gap between spouses. In the left panel we show the husband's age minus wife's age as a function of the woman's

\footnotetext{
${ }^{47}$ Note also that this calculation assumes that the trends in educational attainment are zero, though allowing for such trends in education has little impact on the estimates.

${ }^{48}$ For example, suppose for simplification that the age gap distribution was such that women had an equal probability of marrying men 0 to 24 months older than them (i.e., the age gap distribution has 25 points of support). Thus, the probability of marrying any one month $\times$ year birth cohort is 4 percent. Then, pre-ROSLA women who were born in August 1957 will not be marrying anyone affected by ROSLA whereas only one of the 25 potential mate cohorts for September 1957 ROSLA women (i.e., September 1957 men) will be affected by ROSLA.
} 
month $\times$ year of birth. In the right panel we show the wife's age minus husband's age as a function of the man's month $\times$ year of birth. These plots are seasonally-adjusted by removing month-of-birth effects 49 The level of the pre-ROSLA means in the plots show that on average, men married women who were 2 years younger. Appendix Table 7 presents the corresponding regression discontinuity estimates in columns 1 and 3. Unlike for the previous outcomes, the inclusion of month-of-birth fixed effects do matter. As seen in raw plots, there is a systematic difference in partner's age between August-borns and September-borns related to the school entry date of September 1st. For this reason, our preferred specification is the set of estimates in Panel B, which include month-of-birth fixed effects.

Although estimates are less precise than the effects on academic credentials, for women there is a decrease in the average age gap at the threshold. That is, women who had to stay in school until 16 marry men closer in age to them. The corresponding regression discontinuity estimate is -0.87 months (a 3 percent reduced-form effect and a 12 percent IV effect), which is statistically significant at the 1 percent level ${ }_{50}^{0}$ On the other hand, there is not a similar effect for men on the average age gap, though the results are somewhat noisy. We also examine effects at different points of the age gap distribution in Appendix Figure 6. A clear pattern from that set of results is that for both men and women there is an increased probability in marrying someone who is within one year of age 51

\section{Partnering with Classmates}

We can also examine in finer detail whether the additional year in high school affected the probability of marrying someone in the same academic cohort, using marriage outcomes from the 2001 Census. Because we observe only dates of births and not classroom or school assignments, these mating market results come with the important caveat that we cannot distinguish between teen partnerships begun in school with actual classmates and mating decisions made later in life with partners whose exact age implies they could have been a classmate.

\footnotetext{
${ }^{49}$ We regress the age gap on a set of month-of-birth dummies, take the residuals, and add back the mean age gap to obtain these seasonally-adjusted numbers.

${ }^{50}$ This estimate comes from a local linear regression with month-of-birth dummies.

${ }^{51}$ In that figure for men (for women), the 0.002 (0.004) estimate at age gap of 0 years implies that men (women) born in September 1957 have a 0.002 (0.004) increase in probability of marrying someone of the same age compared to comparable individuals born just before that date.
} 
In Figure 10, we compute the fraction of individuals within each month-of-birth cohort who marry someone in their same academic cohort (a potential classmate), and plot our standard regression discontinuity figure for that outcome. An academic cohort starts with September births and ends with August births of the following year. Due to clear seasonality in the data by month of birth, Figure 10 plots the de-seasonalized patterns 52 Both for men and women, the probability of marrying a classmate increases following ROSLA. The reduced-form regression discontinuity point estimates for marrying a classmate from the preferred specification which controls for seasonality are 0.0043 and 0.0032 for women and men respectively (see columns 2 and 4 of Appendix Table 7). These point estimates correspond to just under a 5 percent increase and are statistically-significant at the 5 percent level.

The magnitudes of these effects are slightly larger than the impacts of teen births, though not directly comparable, since these partnership outcomes likely reflect the decisions of many women who were never at risk for a teen pregnancy. Another way to put these estimates in context is to ask what fraction of the changes in the spousal age gap due to ROSLA could be explained by effects on the probability of marrying a classmate. ${ }^{53}$ If we start with the age gap distribution for pre-ROSLA individuals and then alter that distribution by increasing the probability of marrying someone of the same academic cohort by the estimated effect size while simultaneously decreasing the probability of marrying someone 2 years older (the mean spousal age gap), the implied effect on overall age gap would be -0.006 for men and -0.008 for women. These effects are significantly smaller than the regression discontinuity effects on the age gap of -0.076 and -0.868 for men and women, respectively.

In summary, ROSLA's impacts on the probability that one matched to a peer in the same academic cohort can at most explain only a small part of the age and education assortative mating results. The remainder could be attributable to the additional schooling changing preferences over spouses and to the additional schooling changing the post-school peer group in the workplace, along with other assortative mating channels (though the precise mechanisms behind assortative mating are not yet well documented in the literature). With our design, it is not possible to distinguish the

\footnotetext{
${ }^{52}$ For women, the oldest in class are less likely to marry a classmate than the youngest in the class (a 0.11 probability versus a 0.13 probability). For men, the pattern is the reverse with a slightly larger difference between the oldest and the youngest (a 0.15 probability versus a 0.11 probability). This seasonality is unaffected by ROSLA.

${ }^{53}$ Here, we can only calculate an upper bound because the age criterion we use does not guarantee that a couple shared a classroom or a school.
} 
importance of each of these channels. This stands in contrast to the teen fertility effects, the timing of which is completely consistent with ROSLA affecting conceptions only when teens were newly enrolled in school. For this outcome in particular, one possible explanation is that the increase in required schooling affected teen fertility by influencing which men women partnered with at age 16. We further explore this possibility next.

\section{Further Insights from the National Child Development Study}

The administrative data we have exploited thus far, while extensive and comprehensive, offers little context about the lives of the men and women we study. The NCDS is much better suited for this purpose. It follows a cohort of individuals born in March 1958 - one of the first post-ROSLA cohorts. The panel includes survey waves at several ages, including at age 16. This allows us to observe stated and revealed preferences over fertility and partnerships (including non-marital sexual partnerships) while these individuals were still in school. A unique benefit of the NCDS is that we can use it to identify the complier population, as the study asked respondents about their desired school-leaving age.

\section{i Direct Identification of Compliers}

Because the NCDS covers just a single post-ROSLA cohort, we cannot use our main regression discontinuity strategy. However, at the time they were 16, respondents were asked: "Do you wish that you could have left [school] when you were 15?" Adopting the classic instrumental variables language, we call respondents who wished to leave school at 15 but stayed on until at least 16 the compliers, and call the respondents who didn't wish to leave at 15 and who stayed on until at least 16 the always-takers ${ }^{54} 55$

These hypothetical responses are remarkably informative. The fraction of self-identified compliers in the NCDS (0.31) is very close to the fraction of LFS respondents among the pre-reform cohorts born between 1954 and 1957 who report actually leaving school at 15 (0.33). We can further

\footnotetext{
${ }^{54}$ Below we display statistics separately for the always-takers who left at 16 and for the always-takers who left at 17 or later.

${ }^{55}$ We primarily rely on respondent self-identification as a complier. In the case of missing or "uncertain" responses to this question, we use the interviewed parent's answer to a question regarding the parent's preferences over their child leaving at age 15. Parents were asked whether they, "wish that [the child] had been able to leave school at fifteen?" These parent replies account for 23 percent of our observations, though the pattern of results reported below is not sensitive to how these cases are handled.
} 
assess the validity of these responses by exploiting regional variation within England and Wales in these statistics. The scatterplot in Appendix Figure 7 shows that the fraction of NCDS respondents stating a wish to leave school at age 15 in each region strongly correlates with the fraction of LFS respondents actually leaving school at age 15 in that region just prior to the reform. The correlation between these region-specific actual dropout means and our constructed complier measure is 0.83 , supporting the idea that the self-reports about the counterfactual are informative 56

\section{ii Preferences and Partnerships at 16 and 17}

We use the age-16 and age-23 waves of the NCDS to observe cohort members at the points in time closest to the new schooling period. We focus on differences in stated and revealed preferences between the compliers and always-takers. From these comparisons, we obtain two new insights. First, we find that compliers are different from always-takers in their preferences, even conditional on being exposed to the same years of schooling. They are more short-sighted and prefer earlier family formation. Second, even amongst teenagers, there is a substantial age gap between women and their sexual partners. This consistent with our age gap results above, and suggests that one of the mechanisms by which ROSLA could have affected teen fertility is by reducing the exposure of teenage females to older men.

In Panel A of Table 7, we begin by reporting stated preferences over childbearing and partners. The table is limited to female respondents in the NCDS. Column (1) lists responses for compliers (left at 16 but wished to leave at 15). Columns (2) and (3) list responses for always takers (wished to leave at 16 or later), split according to whether they actually left at 16 or at $17+$. In all cases, responses to preference questions were collected in the spring of the final year of compulsory schooling, when the entire cohort would have just turned (or would have been about to turn) 16 . The birth outcomes data were collected in a later wave.

First, it is interesting - but perhaps not surprising given results above - to note that at age 16, which is during the additional year of schooling, the compliers and always takers differed in their stated preferences over mates and childbearing. For example, 32 percent of compliers preferred to have a first child by age 21, while only 17 percent of the always takers in column (2) expressed

\footnotetext{
${ }^{56}$ Some error would be present even if all respondents predicted their counterfactual accurately because the LFS measures region of current (later-life) residence and the NCDS measures region of birth.
} 
that same preference. By significant margins, compliers were also more likely report that marriage at younger ages is best. Thirty percent of compliers reported that marriage by age 19 is best, compared to fifteen percent of the always takers who would ultimately exit school at exactly the same time, and compared to just five percent of the always takers who would ultimately exit school at 17 or later. These stated preference differences are correlated with actual birth outcomes: The bottom rows of Panel A show dramatic variation in teen births that is correlated with these stated preferences and with complier status, taking place in the months and years following these responses.

The results here give important context to our finding above of no impact on long-run fertility outcomes: Preference heterogeneity appears to be a key part of the observed correlation between educational investment decisions and fertility demand. As another indication of significant educational sorting on preferences, Panel A also reports student responses to a general question about forward-lookingness: Students were asked to indicate agreement or disagreement with the statement "I think there is no point planning for the future." 35 percent of compliers agreed, compared to 17 percent of always takers in the second column. Differences in the preferences reported in Panel A cannot be driven by schooling differences, because respondents would have been exposed to the same length of schooling at the time of the survey. We do not know whether the additional year of schooling had no effect on the childbearing preferences of the compliers, but we do know from these statistics that experiencing the additional year of schooling did not cause complier preferences to converge to those of the always-takers who would also go on to complete their schooling at age 16.

We can look more closely at certain kinds of partnerships in the NCDS to gain insight into mate characteristics. Panel B shows that while essentially all women lived with their guardians on their 16th birthday, a substantial minority left home at 16 or 17, many to begin cohabitating with a mate. Among both compliers and always-takers, the men with whom these women began cohabitation were substantially older. Among 16 year-old women, the 25th percentile of the partnering man's age was 18 and the median was 20. The same data also reveal that a full third of the women cohabitating at 16 had a birth by 16 , and over one half had a birth by 17 . Similar patterns are found for women who began cohabitating at 17 . These descriptive statistics show that women who were in serious relationships at 16 and 17 were uniformly partnering with much older men.

The fact that both compliers and always-takers lived at home until the end of schooling, after 
which a substantial minority began cohabitating with older men, suggests that the reform may have delayed the initiation of cohabitating partnerships for complier women. Thus one potential reason that fertility declined at ages 16 and 17 is that the additional year of schooling limited women's exposure to older men at age 16 . This is consistent with our regression discontinuity results in the Census data that show a positive effect of the reform on the probability of marrying a similarly-aged classmate, which could serve as a substitute for an older man.

\section{E Interpreting the Mating Market Results}

We conclude with a discussion of how to interpret marriage results, given that these markets are two-sided and that the nature of the variation means that "treated" and "control" cohorts were mixing together in the same pools of potential mates. An important strength of our research design is that ROSLA impacted a large fraction of the relevant cohorts. As such, our results reflect the general equilibrium effects of extending schooling to a whole national cohort of individuals. But this also implies that the mating markets for "control" cohorts could be affected by the reform, as the flows of potential mates for these control cohorts into and out of the marriage markets change following ROSLA.

Even under the assumption that the all UK marriage markets are in this sense treated, our strategy of contrasting pre and post-ROSLA individuals competing in those markets remains valid. This is because our identification strategy does not assume anything about the nature of preROSLA marriage markets relative to post-ROSLA marriage markets. Our regression discontinuity estimates isolate the differential effect of ROSLA on those born just following September 1957 and on those born just prior to September 1957, regardless of the structure of marriage markets in which they jointly participate. Thus, while it is unknowable how a ROSLA-affected woman born in September 1957 would fare in the pre-ROSLA mating market, what we identify clearly is how she fares relative to an interchangeable woman seeking a mate among the same pool, but who was born a month earlier and so not subject to the new compulsory schooling.

Finally, it is worth noting that the phenomenon of treated and not-treated cohorts competing against each other in the same markets is not special to the marriage context; the same mixing of treatment and control individuals in the same market applies to studies of labor market outcomes that exploit compulsory schooling reforms. What is different here is that the affected and non- 
affected cohort members may match with each other, rather than with an outside third party such as an employer. While there is no policy variation we could imagine that would affect many individuals but did not have this feature, it means there are limits to what we can infer from this research design. For example, we cannot know how pre- and post-ROSLA cohorts would differentially fare in the pre-ROSLA marriage markets.

\section{Discussion}

The long literature modeling a link between education and fertility emphasizes the impact of education on preferences, income, and the opportunity costs of raising children. In our context, the role of time spent in school itself appears to play a larger role in fertility outcomes. Extending the length of schooling leads to a decline in teenage births and "shotgun" marriages without a corresponding rise in abortions - plausibly because it kept teen women from socializing with older men. The extended schooling also made it more likely for affected men and women to marry someone from their same academic cohort. Fertility effects beyond the teen years are at most small, a sharp contrast with the cross-sectional associations between education and family size that motivated an economic theory of the family that continues to be widely invoked today.

In contrast, long-run impacts on mating market outcomes are large and aligned with the aggregate, cross-sectional relationships. Just as a wide literature in economics, demography, and other social sciences has documented assortative mating on education, income, and age in the cross section and over time, we show that there is a clear causal impact of increasing one's own educational attainment on the characteristics of one's mate. In particular, we find another year of schooling at age 16 leads to a large decline in the probability of marrying a spouse without a high school credential.

Overall, our results reinforce the idea that the value of schooling extends beyond just the wage returns 57 For countries in which declining fertility rates and the consequent aging populations are straining budgets for social programs, our findings suggest that reductions in teenage fertility, which are a widely adopted policy goal, can occur without reductions in overall fertility. In terms of distributive implications, we show that compulsory schooling has the potential to improve the

\footnotetext{
${ }^{57}$ See Oreopoulos and Salvanes 2011) for further discussion of this.
} 
wellbeing of the poor, who are the individuals most likely to drop out of school, through the multiplicative effects of assortative mating. Such non-wage effects should be considered when evaluating ongoing reforms of the compulsory schooling laws. Very recent changes to UK compulsory schooling laws may provide new research opportunities to examine these phenomena as the affected cohorts now age, enter labor markets, and form partnerships and families 58

\footnotetext{
${ }^{58}$ UK Coalition Government increased the compulsory schooling age to 17 in September 2013 and further augmented it to 18 in 2015.
} 


\section{References}

Aaronson, Daniel, Fabian Lange, and Bhashkar Mazumder. 2014. "Fertility transitions along the extensive and intensive margins." The American Economic Review, 104(11): 37013724 .

Angrist, Joshua D, and Alan B Krueger. 1992. "The effect of age at school entry on educational attainment: an application of instrumental variables with moments from two samples." Journal of the American Statistical Association, 87(418): 328-336.

Ashcraft, Adam, Iván Fernández-Val, and Kevin Lang. 2013. "The Consequences of Teenage Childbearing: Consistent Estimates When Abortion Makes Miscarriage Non-random." The Economic Journal, 123(571): 875-905.

Barcellos, Silvia, Leandro Carvalho, and Patrick Turley. 2017. "Distributional Effects of Education on Health." University of Southern California Working Paper.

Becker, Gary. 1960. "An Economic Analysis of Fertility." In Demographic and Economic Change in Developed Countries, Conference of the Universities-National Bureau Committee for Economic Research, a Report of the National Bureau of Economic Research. Princeton, NJ:Princeton University Press.

Becker, Gary. 1965. "A Theory of the Allocation of Time." The Economic Journal, 75(299): 493517.

Becker, Gary, and H. Gregg Lewis. 1974. "Interaction between Quantity and Quality of Children." In Economics of the Family: Marriage, Children, and Human Capital. , ed. Theodore W. Schultz, 81-90. University of Chicago Press.

Becker, Gary S. 1973. "A Theory of Marriage: Part I." Journal of Political Economy, 81(4): 813846.

Becker, Gary S. 1981. A Treatise on the Family. Harvard University Press.

Becker, Gary S, and Casey B Mulligan. 1997. "The endogenous determination of time preference." The Quarterly Journal of Economics, 729-758.

Behrman, Jere R., Mark R. Rosenzweig, and Paul Taubman. 1994. "Endowments and the Allocation of Schooling in the Family and in the Marriage Market." Journal of Political Economy, $1131-1174$.

Berthelon, Matias E., and Diana I. Kruger. 2011. "Risky Behavior among Youth: Incapitation Effects of School on Adolescent Motherhood and Crime in Chile." Journal of Public Economics, 95(1-2): 41-53.

Bhaskar, Venkataraman. 2015. "The demographic transition and the position of women: A marriage market perspective."

Black, Sandra E., Paul J. Devereux, and Kjell G. Salvanes. 2008. "Staying In the Classroom and Out of the Maternity Ward? The Effect of Compulsory Schooling Laws on Teenage Births." The Economic Journal, 118(530): 1025-1054. 
Bono, Emilia Del, and Fernando Galindo-Rueda. 2007. "The Long-Term Impacts of Compulsory Schooling: Evidence from a Natural Experiment in School Leaving Dates." Centre for the Economics of Education, London School of Economics and Political Science Working Paper.

Brandt, Loren, Aloysius Slow, and Carl Vogel. 2016. "Large demographic shocks and small changes in the marriage market." Journal of the European Economic Association, 14: 1437-1468.

Calonico, Sebastian, Matias D. Cattaneo, and Rocio Titiunik. 2014. "Robust Nonparametric Confidence Intervals for Regression-Discontinuity Designs." Econometrica, 82(6): 2295-2326.

Card, David. 2001. "Estimating the Return to Schooling: Progress on Some Persistent Econometric Problems." Econometrica, 69(5): 1127-1160.

Casterline, John B, Lindy Williams, and Peter McDonald. 1986. "The age difference between spouses: variations among developing countries." Population Studies, 40(3): 353-374.

Chevalier, Arnaud, and Tarja K. Viitanen. 2003. "The Long-Run Labour Market Consequences of Teenage Motherhood in Britain." Journal of Population Economics, 16(2): 323-343.

Chiappori, Pierre-Andre, Murat Iyigun, and Yoram Weiss. 2009. "Investment in Schooling and the Marriage Market." American Economic Review, 99(5): 1689-1713.

Chiappori, Pierre-Andre, Sonia Oreffice, and Climent Quintana-Domeque. 2012. "Fatter Attraction: Anthropometric and Socioeconomic Matching on the Marriage Market." Journal of Political Economy, 120(4): 659-695.

Clark, Damon, and Heather Royer. 2013. "The Effect of Education on Adult Mortality and Health: Evidence from Britain." American Economic Review, 103(6): 2087-2120.

Currie, Janet, and Enrico Moretti. 2003. "Mother's Education and the Intergenerational Transmission of Human Capital: Evidence From College Openings." Quarterly Journal of Economics, 118(4): 1495-1532.

Cygan-Rehm, Kamila, and Miriam Maeder. 2013. "The Effect of Education on Fertility: Evidence from a Compulsory Schooling Reform." Labour Economics, 25: 35-48.

Devereux, Paul J., and Robert A. Hart. 2010. "Forced to be Rich? Returns to Compulsory Schooling in Britain." Economic Journal, 120(549): 1345-1364.

Fort, Margherita, Nicole Schneeweis, and Rudolf Winter-Ebmer. 2016. "Is Education Always Reducing Fertility? Evidence from Compulsory Schooling Reforms." The Economic Journal, 126(595): 1823-1855.

Geronimus, Arline T., and Sanders Korenman. 1992. "The Socioeconomic Consequences of Teen Childbearing Reconsidered." Quarterly Journal of Economics, 107(4): 1187-1214.

Geruso, Michael. 2010. "Education and Childbearing: What are the Links?" Research in Public Policy - CMPO Bulletin, Univestiy of Bristol.

Goldin, Claudia. 1997. "Career and Family: College Women Look to the Past." In Gender and Family Issues in the Workplace. , ed. Francince Blau and Ronald Ehrenberg, 20-58. Russell Sage Press. 
Goodman, Alissa, Greg Kaplan, and Ian Walker. 2004. "Understanding the Effects of Early Motherhood in Britain: The Effects on Mothers." Institute for the Study of Labor (IZA) Research Paper Series, Discussion Paper No. 1131.

Greenwood, Jeremy, Nezih Guner, Georgi Kocharkov, and Cezar Santos. 2014. "Marry Your Like: Assortative Mating and Income Inequality." The American Economic Review, 104(5): 348 .

Grenet, Julien. 2013. "Is Extending Compulsory Schooling Alone Enough to Raise Earnings? Evidence from French and British Compulsory Schooling Laws." The Scandinavian Journal of Economics, 115: 176-210.

Grönqvist, Hans, and Caroline Hall. 2013. "Education policy and early fertility: Lessons from an expansion of upper secondary schooling." Economics of Education Review, 37: 13-33.

Güneş, Pınar Mine. 2016. "The Impact of Female Education on Teenage Fertility: Evidence from Turkey." The BE Journal of Economic Analysis \& Policy, 16(1): 259-288.

Harmon, Colm, and Ian Walker. 1995. "Estimates of the Economic Return to Schooling for the United Kingdom." American Economic Review, 85(5): 1278-1286.

Imbens, Guido W., and Karthik Kalyanaraman. 2012. "Optimal Bandwidth Choice for the Regression Discontinuity Estimator." Review of Economic Studies, 79(3): 933-959.

Imbens, Guido W., and Thomas Lemieux. 2008. "Regression Discontinuity Designs: A Guide to Practice." Journal of Econometrics, 142(2): 615-635.

Iyigun, Murat, and Randall P. Walsh. 2007. "Building the Family Nest: Premarital Investments, Marriage Markets, and Spousal Allocations." The Review of Economic Studies, $74(2): 507-535$.

Kalwij, Adriaan. 2010. "The Impact of Family Policy Expenditure on Fertility in Western Europe." Demography, 47(2): 503-519.

Kaufmann, Katja M, Matthias Messner, and Alex Solis. 2015. "Elite Higher Education, the Marriage Market and the Intergenerational Transmission of Human Capital."

Konrad, Kai A, and Kjell Erik Lommerud. 2000. "The bargaining family revisited." Canadian Journal of Economics/Revue canadienne d'économique, 33(2): 471-487.

Lang, Kevin. 1993. "Ability bias, discount rate bias and the return to education."

Lavy, Victor, and Alexander Zablotsky. 2015. "Women's schooling and fertility under low female labor force participation: Evidence from mobility restrictions in Israel." Journal of Public Economics, 124: 105-121.

Lee, David S., and Thomas Lemieux. 2010. "Regression Discontinuity Designs in Economics." Journal of Economic Literature, 48(2): 281-355.

Lefgren, Lars, and Brian A Jacob. 2003. "Are Idle Hands the Devil's Workshop? Incapacitation, Concentration, and Juvenile Crime." American Economic Review, 93(5): 1560-1577.

Lefgren, Lars, and Frank L. McIntyre. 2006. "The Relationship between Women's Education and Marriage Outcomes." Journal of Labor Economics, 24(4): 787-830. 
Lewis, Susan K, and Valerie K Oppenheimer. 2000. "Educational assortative mating across marriage markets: Nonhispanic whites in the United States." Demography, 37(1): 29-40.

Lleras-Muney, Adriana. 2005. "The Relationship between Education and Adult Mortality in the United States." Review of Economic Studies, 72(1): 189-221.

Ludwig, Jens, and Douglas L. Miller. 2007. "Does Head Start Improve Children's Life Chances? Evidence from a Regression Discontinuity Design." The Quarterly Journal of Economics, 122(1): 159-208.

Machin, Stephen, Olivier Marie, and Suncica Vujic. 2011. "The Crime Reducing Effect of Education." The Economic Journal, 121(552): 463-484.

McCrary, Justin, and Heather Royer. 2011. "The Effect of Female Education on Fertility and Infant Health: Evidence from School Entry Policies Using Exact Date of Birth." American Economic Review, 101(1): 158-195.

Mincer, Jacob. 1963. "Market Prices, Opportunity Costs, and Income Effects." In Measurement in Economics: Studies in Mathematical Economics and Econometrics in Memory of Yehuda Grunfeld. , ed. Carl F. Christ. Stanford:Stanford University Press.

Monstad, Karin, Carol Propper, and Kjell G. Salvanes. 2008. "Education and Fertility: Evidence from a Natural Experiment." The Scandinavian Journal of Economics, 110(4): 827-852.

Oreopoulos, Philip. 2006. "Estimating Average and Local Average Treatment Effects of Education When Compulsory Schooling Laws Really Matter." The American Economic Review, 96(1): 152-175.

Oreopoulos, Philip. 2007. "Do Dropouts Drop Out Too Soon? Wealth, Health and Happiness from Compulsory Schooling." Journal of Public Economics, 91(11): 2213-2229.

Oreopoulos, Philip, and Kjell G Salvanes. 2011. "Priceless: The Nonpecuniary Benefits of Schooling." The Journal of Economic Perspectives, 159-184.

Painter, Gary, and David I. Levine. 2004. "Daddies, Devotion, and Dollars: How Do They Matter for Youth?" American Journal of Economics and Sociology, 63(4): 813-850.

Preston, Samuel H., Patrick Heuveline, and Michel Guillot. 2001. Demography: Measuring and Modeling Population Processes. New York, NY:Palgrave MacMillan.

Qian, Zhenchao. 1998. "Changes in assortative mating: The impact of age and education, 19701890." Demography, 35(3): 279-292.

Qian, Zhenchao, and Samuel H Preston. 1993. "Changes in American marriage, 1972 to 1987: Availability and forces of attraction by age and education." American Sociological Review, 482-495.

Rosenzweig, Mark R, and T Paul Schultz. 1989. "Schooling, information and nonmarket productivity: contraceptive use and its effectiveness." International Economic Review, 457-477.

Royer, Heather. 2004. "What All Women (and Some Men) Want to Know: Does Maternal Age Affect Infant Health?" Center for Labor Economics and the University of California, Berkeley, Working Paper No. 68. 
Silles, Mary A. 2011. "The Effect of Schooling on Teenage Childbearing: Evidence using Changes in Compulsory Education Laws." Journal of Population Economics, 24(2): 761-777.

Stephens, Melvin, and Dou-Yan Yang. 2014. "Compulsory Education and the Benefits of Schooling." The American Economic Review, 104(6): 1777-1792.

Stevenson, Betsey, and Justin Wolfers. 2007. "Marriage and divorce: Changes and their driving forces." The Journal of Economic Perspectives, 21(2): 27-52.

Willis, Robert J. 1973. "A New Approach to the Economic Theory of Fertility Behavior." Journal of Political Economy, 81(2): S14-S64.

Woodhead, Martin. 1989. "School starts at five... or four years old? The rationale for changing admission policies in England and Wales." Journal of Education Policy, 4(1): 1-21.

Woodin, Tom, Gary McCulloch, and Steven Cowan. 2013. Secondary Education and the Raising of the School-Leaving Age: Coming of Age? New York, NY:Palgrave MacMillan. 


\section{Appendix A: 1972 ROSLA}

We define the treatment of interest as experiencing an extra year of full-time education at age 15. We have characterized the 1972 ROSLA as increasing the minimum leaving age from 15 to 16. It seems natural to suppose that ROSLA did, therefore, push significant fractions of students into this treatment.

While this intuition is approximately correct, it is worth noting that the school leaving rules were slightly more complicated. In particular, there were two possible points at which students could leave school at the minimum leaving age: Easter (i.e., the end of the spring term) and June/July (i.e., the end of the summer term). Students born between 1 September and 31 January were eligible to leave at Easter; students born 1 Febuary to 31 August were required to remain in school until the summer. For a student born in September 1957, the 1972 ROSLA meant that the earliest leaving point was Easter 1974 rather than Easter 1973. For a student born in February 1958, the 1972 ROSLA meant that the earliest leaving point was summer 1974 rather than summer 1973.

Because students born between February and August could leave in June/July, some would actually leave before the minimum school leaving age (both before and after the 1972 ROSLA). This can account for some of the apparent non-compliance seen in Figure 1. Because the 1972 ROSLA required students to remain until age 16, this meant the earliest academic year they could leave was the academic year in which students took O-level and CSE exams. Since these exams are taken in May/June, this meant that some students, such as those born in early July, would technically have left at the minimum age under the old system (i.e., age 15) but below the minimum age under the new system (i.e., also at age 15, albeit almost one year later). This can account for some of the increased non-compliance that appears to follow the 1972 ROSLA. 


\section{Appendix B: Fertility Trends in Europe}

It is important to understand the environment in which the compulsory schooling change occurred. Fertility declined dramatically between the mid-1960s and the mid-1970s in the UK. Appendix Figure 3 displays the trend, along with trends in the US, France and Germany for comparison. In the UK, by 1975, total fertility had fallen to modern, below-replacement levels.

The post-1972 ROSLA period in the UK, marked by the vertical line, is a period of low and stable fertility (1972-2002). Modern fertility rates in the UK are quite comparable to those of the US and France. Given the similarity of fertility today and at the time of the enactment of the 1972 ROSLA, the 1972 ROSLA is almost ideal for studying the education-fertility relationship: early enough for the affected women to have now completed their fertility, but late enough for them to be informative about childbearing in a modern setting. Moreover, the cohorts just affected by the reform have shared the same access to abortion services throughout their fecund lives as women today. Additionally, at the time, birth control pills were available to all women through the National Health Services 59

Aside from total fertility, we examine teenage births, often an explicit target of fertility policies. As seen in Appendix Figure 3, teen fertility also declined through the 1960s and 1970s, although in the UK it fell slightly slower and slightly later than total fertility. The timing of the fertility decline is consistent with a possible effect of the 1972 ROSLA, but all countries depicted in the graph exhibit a similarly-timed decline, raising the possibility of confounding trends. This highlights the importance of using a research design that can credibly control for these cohort and time trends. Teen fertility in the UK stabilized at a level higher than those seen elsewhere in Western Europe but below that seen in the US. As of 2009, about one in eight females in the UK bore a child before age 20 .

\footnotetext{
${ }^{59}$ Intrauterine devices (IUDs) were also obtainable at the time but were not widely used and were quite different than today's IUDs.
} 


\section{Figure 1. Identifying Variation: Ages Left Full Time Schooling By Cohort}

\section{Panel A: Women}

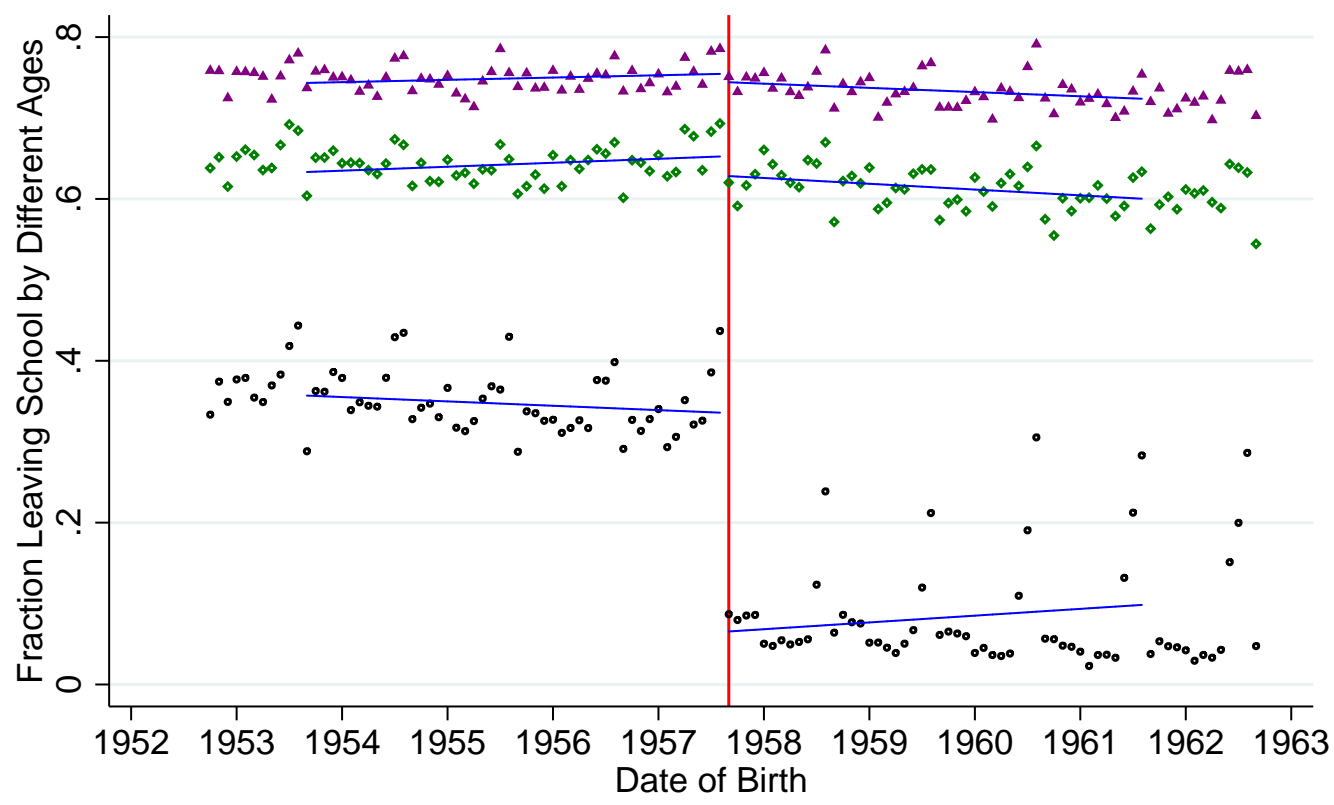

- left school by age 15 - left school by age 16

- left school by age 17

Panel B: Men

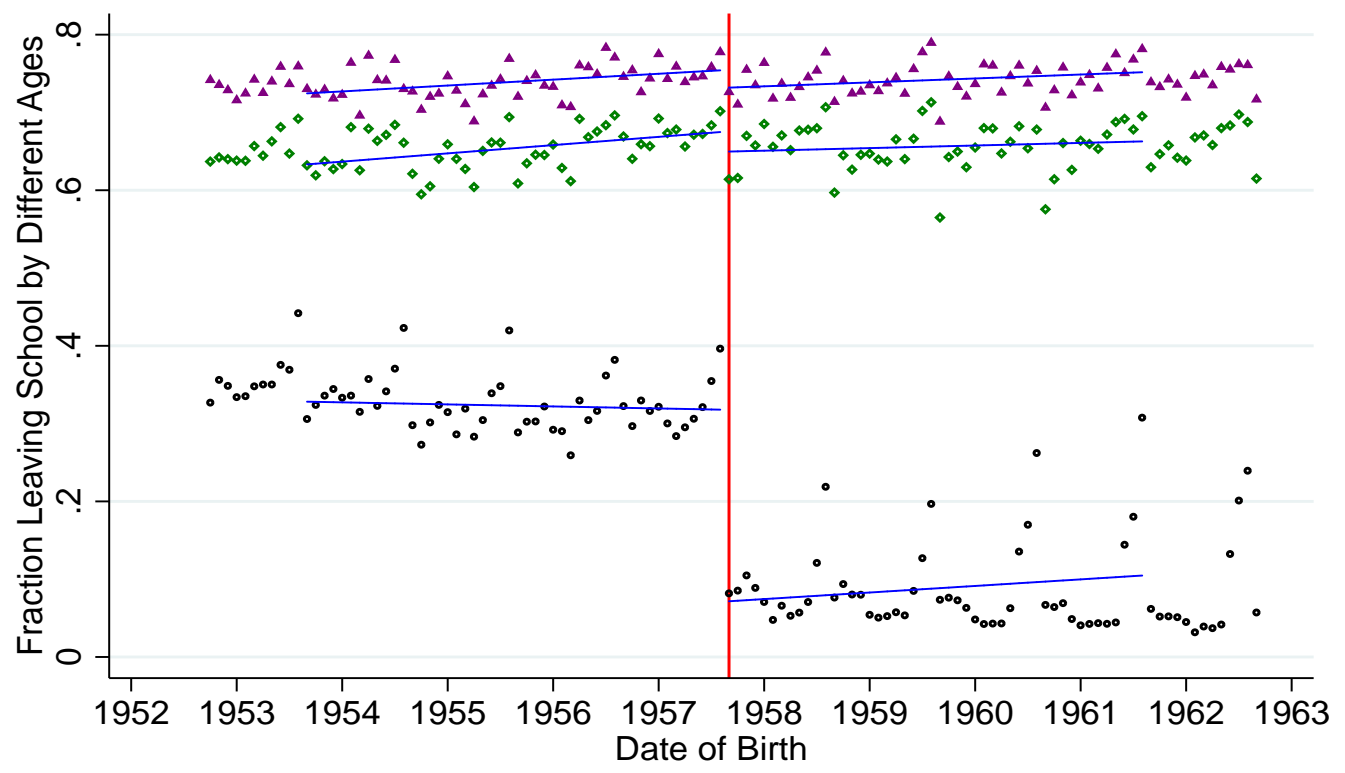

- left school by age 15 left school by age 16

$\triangle$ left school by age 17

Notes: Each point on these figures represents a mean for a cohort sharing the same month and year of birth. The plotted lines are local linear regression fits to those points over the chosen bandwidth. The vertical line indicates the ROSLA threshold with the first post-reform cohort born September 1957. Data come from the UK Labor Force Survey, pooled 1975-2002 and restricted to those born in the UK and resident in England or Wales at the time of the interview. Respondents were asked the age at which they first left continuous, full-time education. 
Figure 2. First Stage Effect of ROSLA on Mean Age of School Exit Panel A: Women

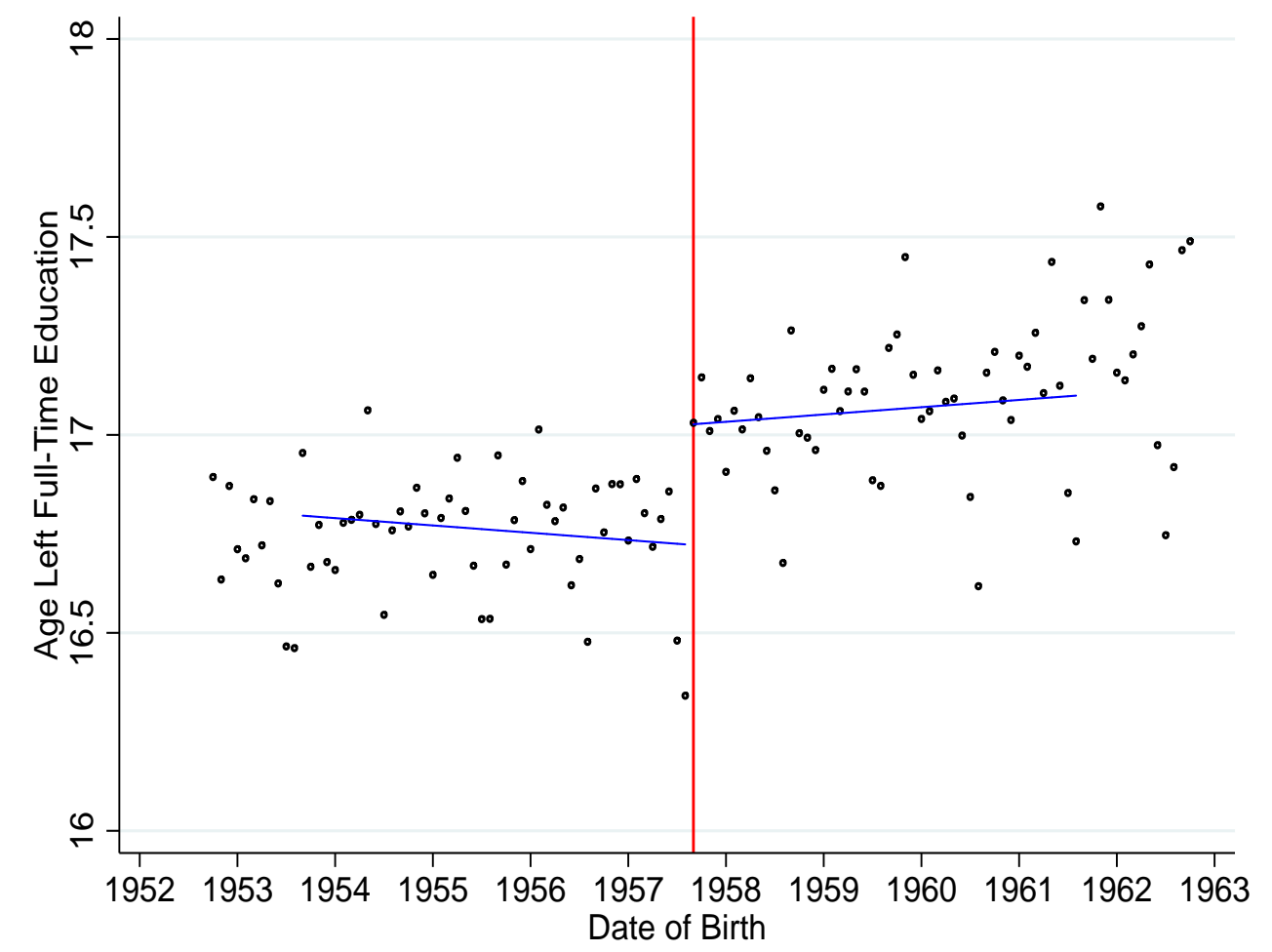

Panel B: Men

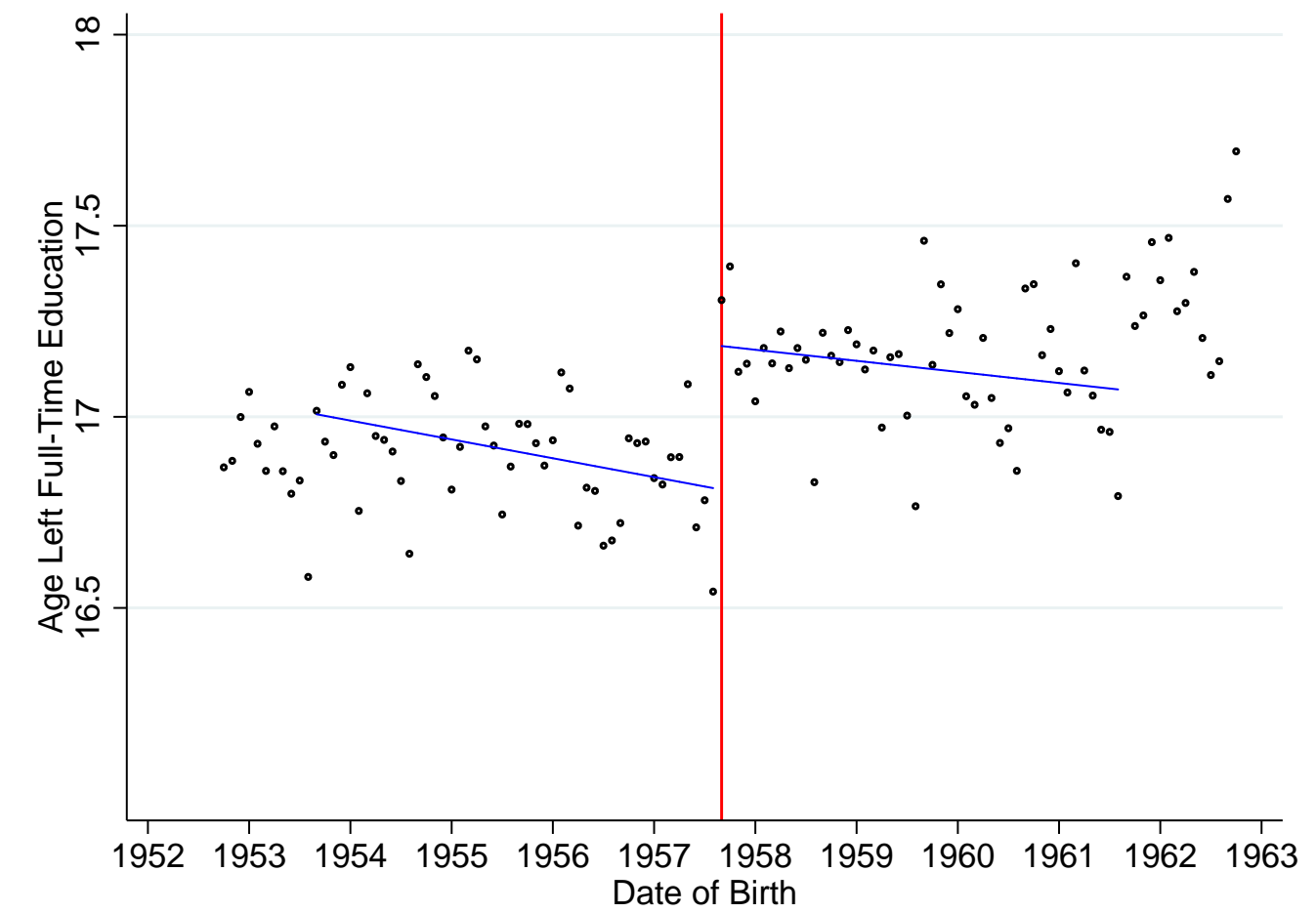

Notes: The impact of the 1972 ROSLA on educational attainment. Each point represents the mean average age at school exit for a cohort sharing the same month and year of birth. The plotted lines are local linear regression fits to those points over the chosen bandwidth. The vertical line indicates the ROSLA threshold with the first post-reform cohort born September 1957. Data come from the UK Labor Force Survey, pooled 1975-2002 and restricted to those born in the UK and resident in England or Wales at the time of the interview. Respondents were asked the age at which they first left continuous, full-time education. 


\section{Figure 3. Births to 16 and 17 Year Olds Decline with New Schooling}
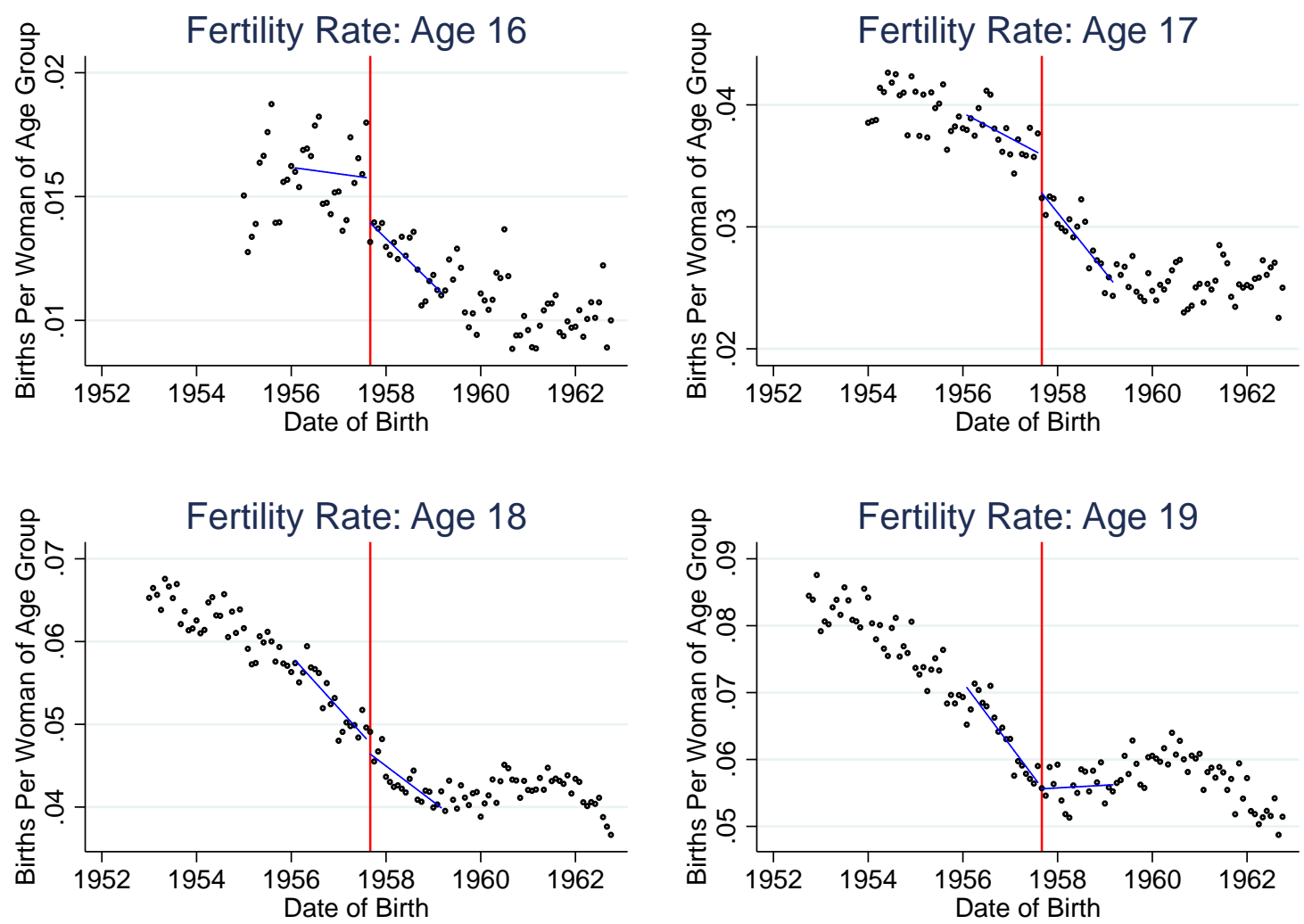

Notes: The impact of the 1972 ROSLA on fertility. Each point represents the fertility rate (number of births/size of population) for a cohort of women sharing the same month and year of birth. The plotted lines are local linear regression fits to those points over the chosen bandwidth. The vertical line indicates the ROSLA threshold with the first post-reform cohort born September 1957. 


\section{Figure 4. No Corresponding Increase in Teen Abortions}
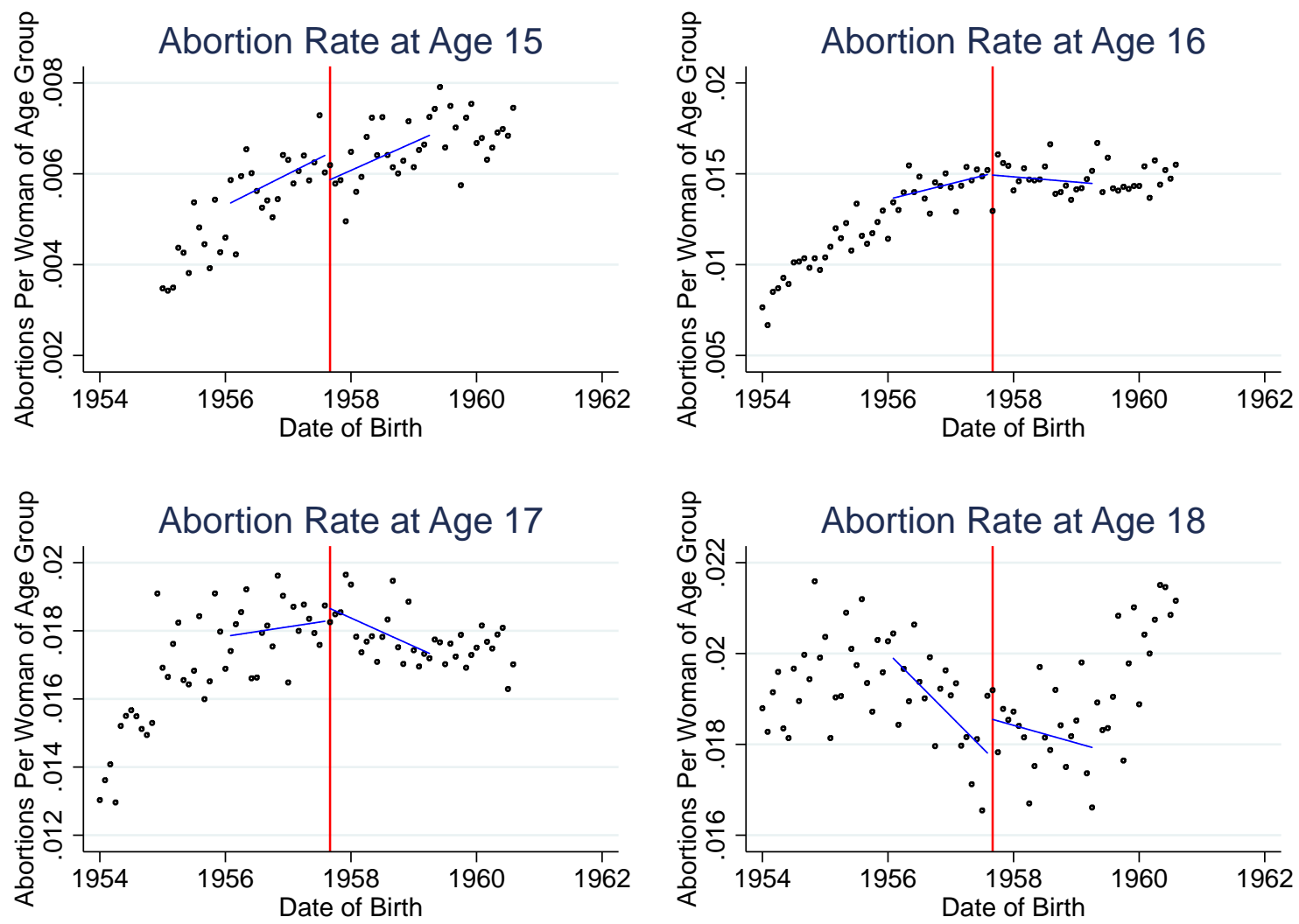

Notes: The impact of the 1972 ROSLA on abortion rates. Each point represents the abortion rate (number of abortions/size of population) for a cohort of women sharing the same month and year of birth. The plotted lines are local linear regression fits to those points over the chosen bandwidth. The vertical line indicates the ROSLA threshold with the first post-reform cohort born September 1957. 


\section{Figure 5. No Effect on Completed Fertility}

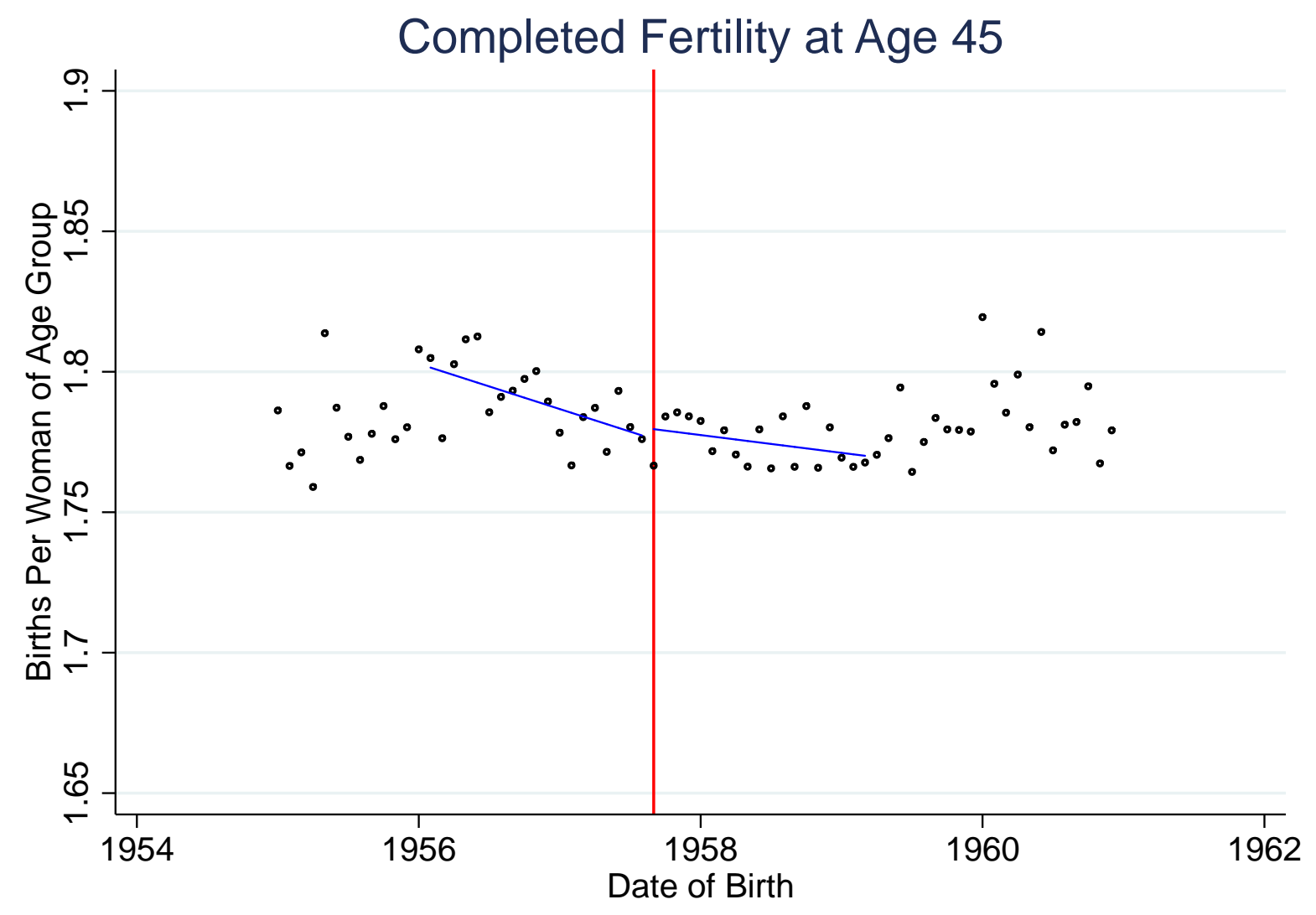

Notes: The impact of the 1972 ROSLA on completed fertility (i.e, the sum of age specific fertility rates from 16 to 45). Each point represents the average number of children born to a cohort of women sharing the same month and year of birth. The plotted lines are local linear regression fits to those points over the chosen bandwidth. The vertical line indicates the ROSLA threshold, with the first post-reform cohort born September 1957. 


\section{Figure 6. Unfolding of Cumulative Fertility Effects with Age}
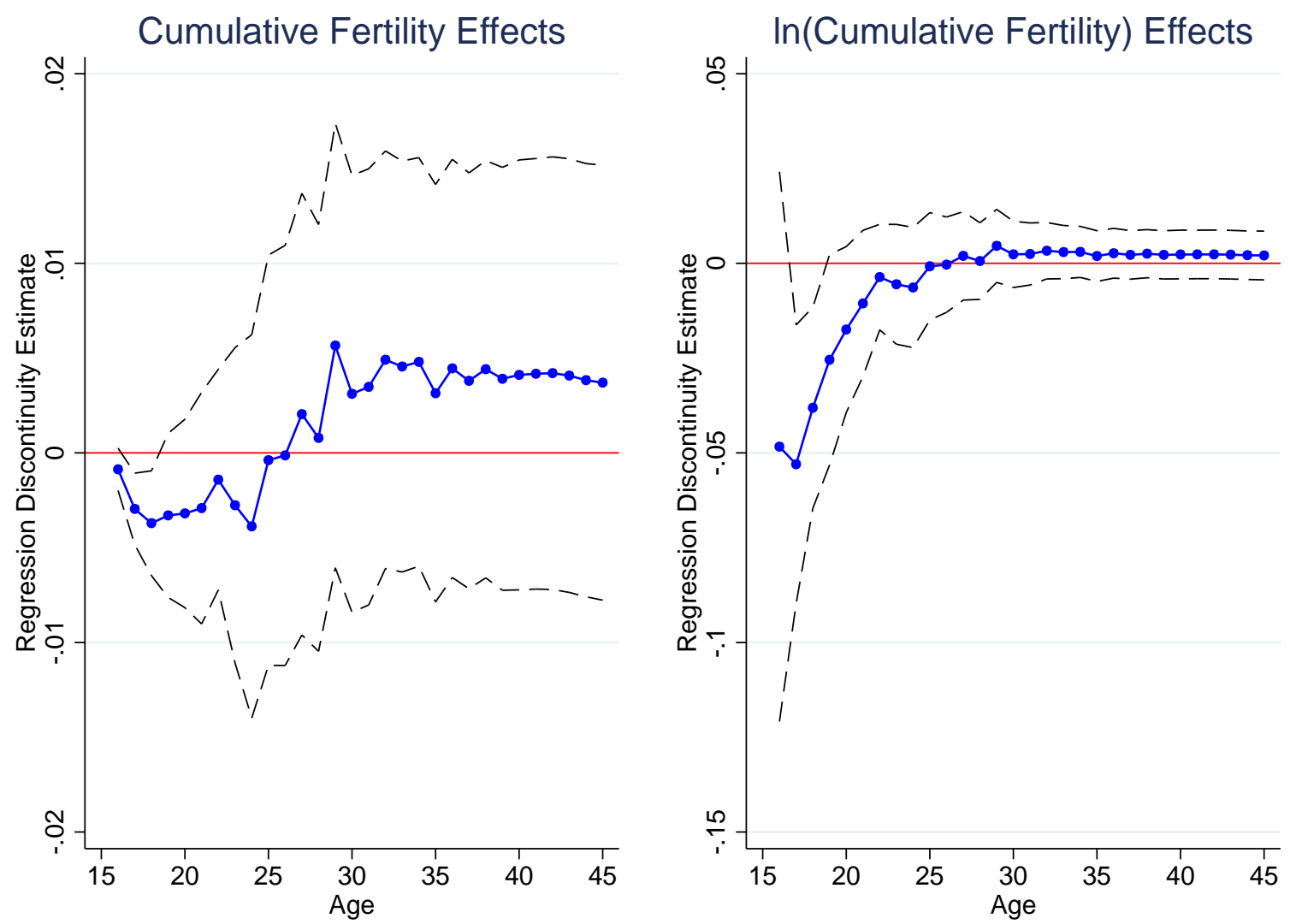

Notes: The impact of the 1972 ROSLA on cumulative fertility. Each point in the plots represents a regression discontinuity estimate of the reduced form effect of ROSLA on cumulative fertility from 16 up to and including the indicated age. The regression discontinuity regressions include the year $\mathrm{x}$ month of birth running variable, a dummy for the post-ROSLA cohorts, and their interaction along with month of birth dummies. Pointwise $95 \%$ confidence intervals are plotted as dotted lines. The left panel plots level effects, which are measured in counts of children per woman. The right panel plots effects on natural log of cumulative fertility. Cumulative fertility at each age $\mathrm{x}$ is the sum of age-specific fertility rates from 16 to $\mathrm{x}$, inclusive. Since the first point in each panel represents the cumulative effect from 16 to 16, it corresponds exactly with the regression discontinuity estimate of the reform on the age 16 fertility rate. Robust pointwise standard errors are estimated. 
Figure 7. Detailed Timing of Fertility Effects over Schooling Years

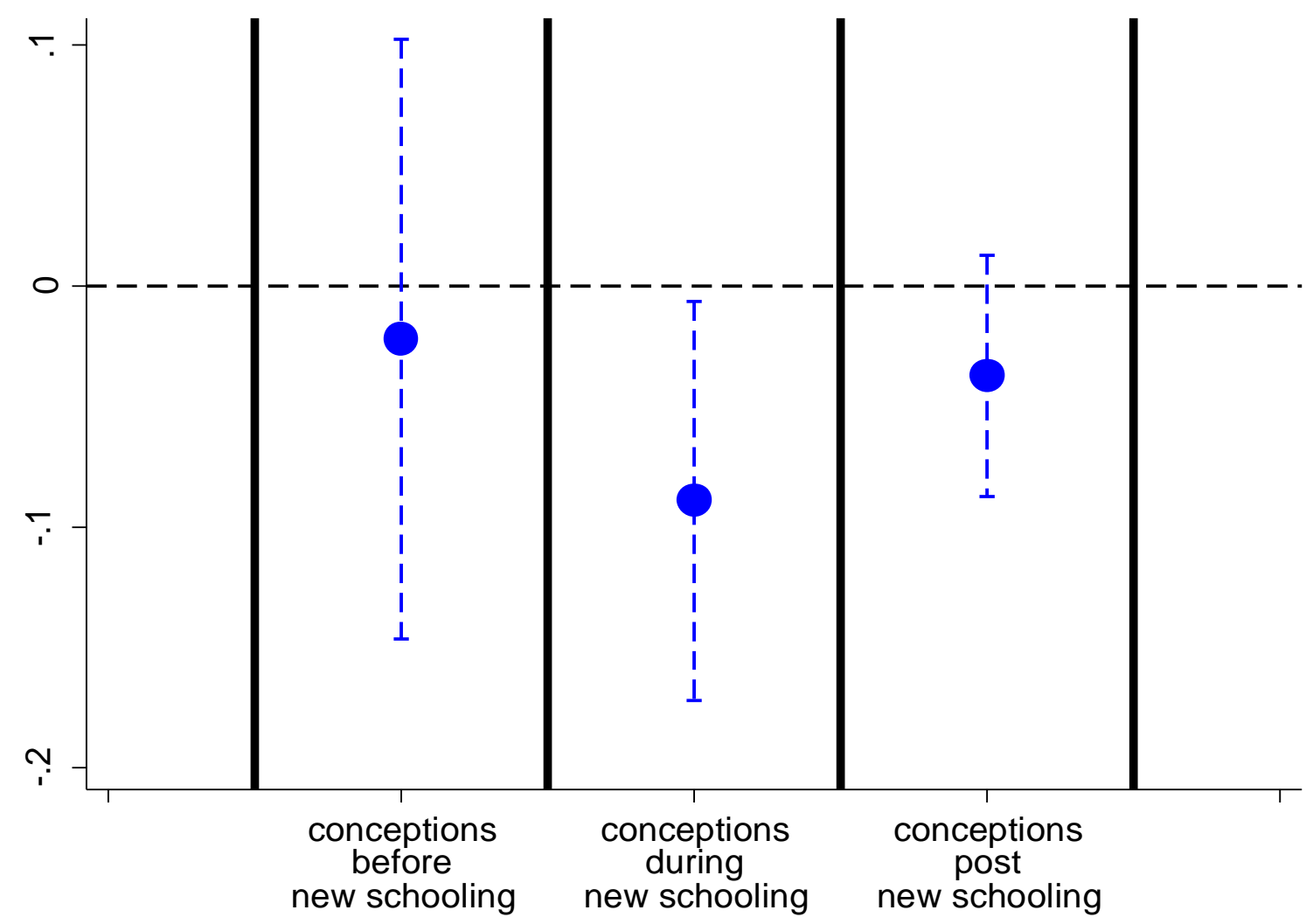

Notes: The impact of the 1972 ROSLA on fertility over certain schooling periods. Each blue dot represents the regression discontinuity estimate of the effect of the ROSLA on $\ln$ (fertility rate) during that time period. The dashed lines represent the $95 \%$ confidence intervals. Robust standard errors are estimated. See text for more details. 


\section{Figure 8. ROSLA Increased Educational Attainment of Woman's Mate}
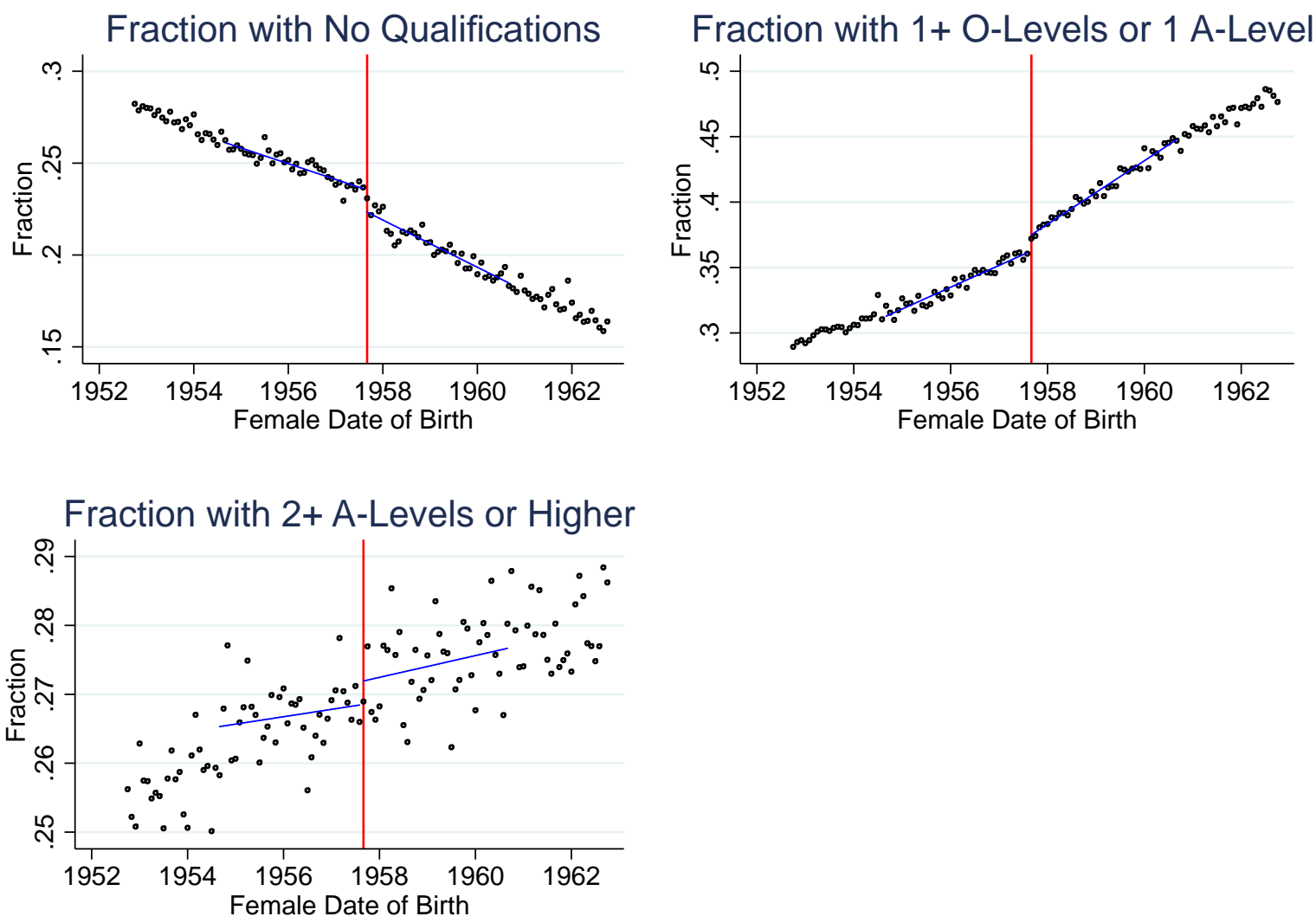

Notes: The impact of the 1972 ROSLA on the educational attainment of a woman's mate. Each point represents the fraction of women of the same month and year of birth cohort who have a mate of a certain education level. The plotted lines are local linear regression fits to those points over the chosen bandwidth. The vertical line indicates the ROSLA threshold with the first post-reform cohort born September 1957. 


\section{Figure 9. ROSLA Increased Educational Attainment of Man's Mate}
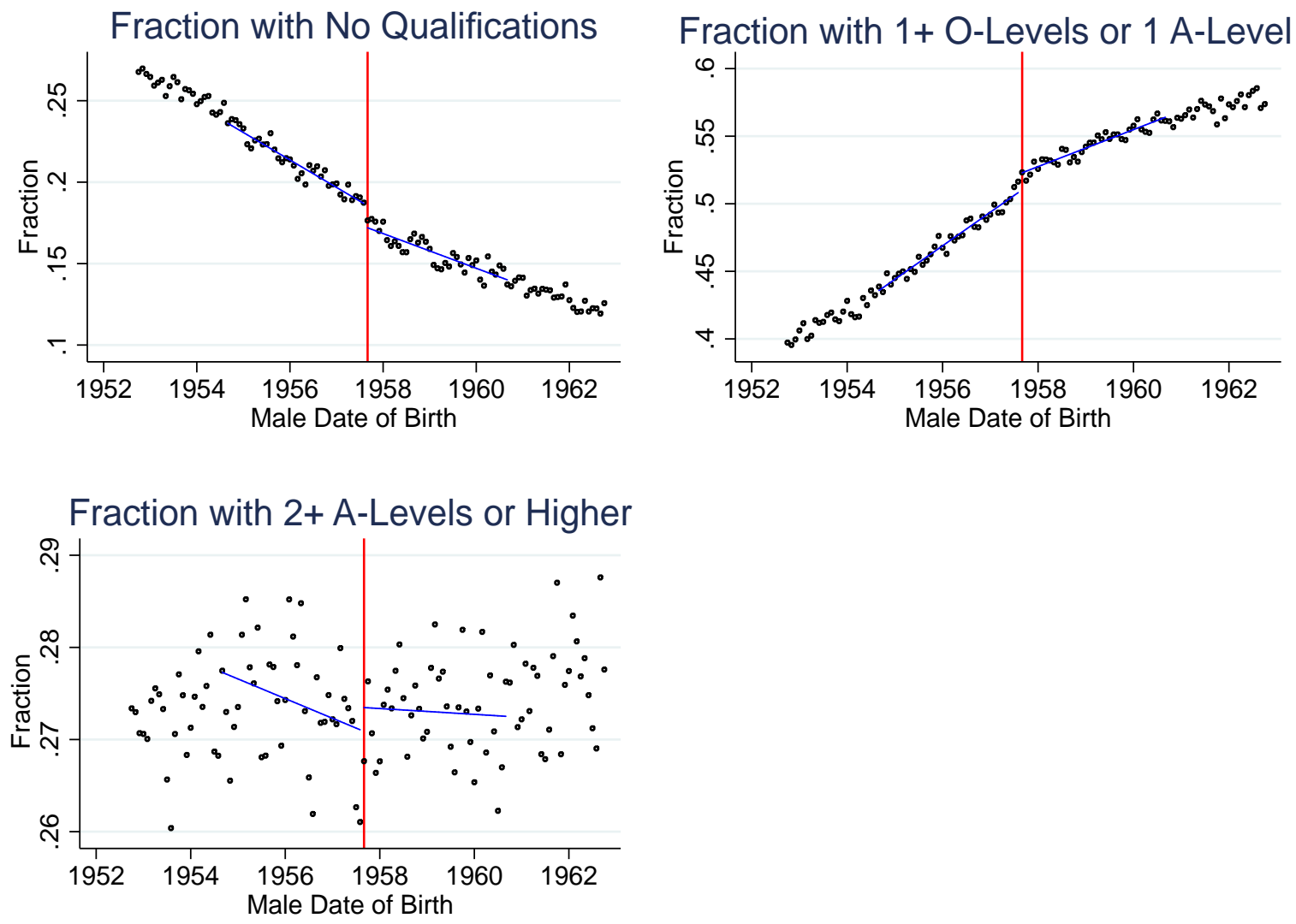

Notes: The impact of the 1972 ROSLA on the educational attainment of a man's mate. Each point represents the fraction of men of the same month and year of birth cohort who have a mate of a certain education level. The plotted lines are local linear regression fits to those points over the chosen bandwidth. The vertical line indicates the ROSLA threshold with the first post-reform cohort born September 1957. 


\section{Figure 10. ROSLA Increased Probability of Marrying Someone in the Same Academic Cohort}
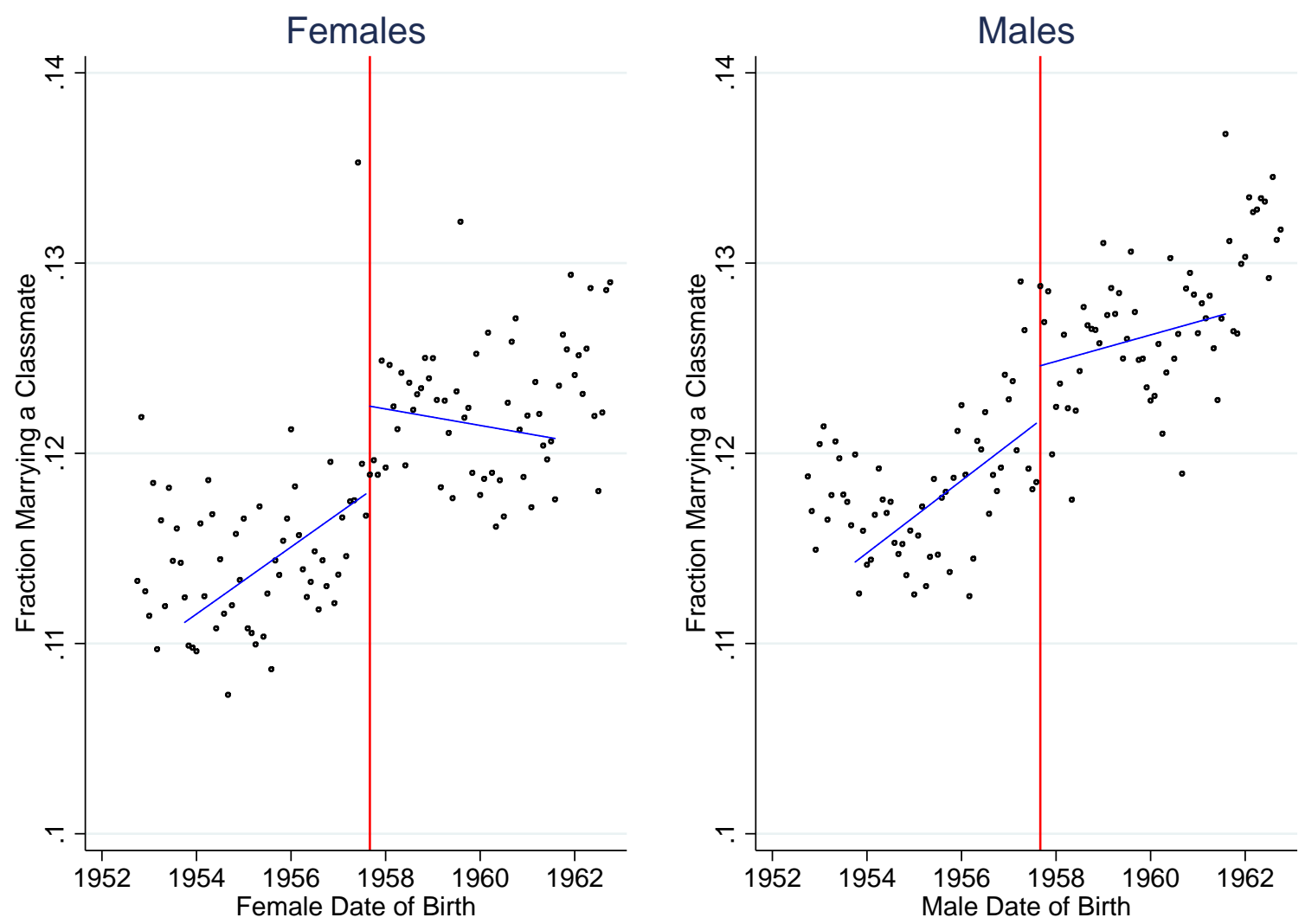

Notes: The impact of the 1972 ROSLA on probability of marrying someone in the same academic cohort; women's mates are represented by the left panel and men's mates are represented by the right panel. Each point represents the fraction marrying a classmate for women of the same month and year of birth (left panel) or men of the same month and year of birth (right panel). Seasonality adjustments are performed by regressing the cohort fraction on a set of month-of-birth dummies, taking the residuals, and then adding the mean fraction marrying a classmate. The plotted lines are local linear regression fits to those points over the chosen bandwidth. The vertical line indicates the ROSLA threshold, with the first post-reform cohort born September 1957. 
Table 1. Effect of ROSLA on Age of School Exit - Labor Force Surveys

\begin{tabular}{|c|c|c|c|c|c|c|c|c|}
\hline & \multicolumn{4}{|c|}{ "Women } & \multicolumn{4}{|c|}{$\overline{\overline{M e n}}$} \\
\hline & \multicolumn{8}{|c|}{ Dependent Variable: } \\
\hline & $\begin{array}{l}\text { left school } \\
\text { by age } 15\end{array}$ & $\begin{array}{c}\text { left school } \\
\text { by age } 16\end{array}$ & $\begin{array}{l}\text { left school } \\
\text { by age } 17\end{array}$ & $\begin{array}{l}\text { age left full- } \\
\text { time ed }\end{array}$ & $\begin{array}{c}\text { left school } \\
\text { by age } 15\end{array}$ & $\begin{array}{c}\text { left school } \\
\text { by age } 16\end{array}$ & $\begin{array}{c}\text { left school } \\
\text { by age } 17\end{array}$ & $\begin{array}{l}\text { age left full- } \\
\text { time ed }\end{array}$ \\
\hline \multicolumn{9}{|c|}{ Panel A: Linear cohort trend interacted with threshold } \\
\hline Discontinuity & $\begin{array}{c}-0.27 * * \\
(0.02)\end{array}$ & $\begin{array}{l}-0.02 * \\
(0.01)\end{array}$ & $\begin{array}{l}-0.01 \\
(0.01)\end{array}$ & $\begin{array}{l}0.31 * * \\
(0.06)\end{array}$ & $\begin{array}{c}-0.25^{* *} \\
(0.02)\end{array}$ & $\begin{array}{c}-0.03^{* *} \\
(0.01)\end{array}$ & $\begin{array}{c}-0.02^{* *} \\
(0.01)\end{array}$ & $\begin{array}{l}0.38 * * \\
(0.06)\end{array}$ \\
\hline Observations & 96 & 96 & 96 & 96 & 96 & 96 & 96 & 96 \\
\hline Bandwidth & 48 & 48 & 48 & 48 & 48 & 48 & 48 & 48 \\
\hline Mean Dependent Variable & 0.437 & 0.693 & 0.785 & 16.34 & 0.396 & 0.702 & 0.777 & 16.54 \\
\hline \multicolumn{9}{|c|}{ Panel B: Linear cohort trend interacted with threshold + month-of-birth dummies } \\
\hline Discontinuity & $\begin{array}{c}-0.24 * * \\
(0.01)\end{array}$ & $\begin{array}{l}-0.01 \\
(0.01)\end{array}$ & $\begin{array}{l}-0.00 \\
(0.00)\end{array}$ & $\begin{array}{l}0.24 * * \\
(0.04)\end{array}$ & $\begin{array}{c}-0.22^{* *} \\
(0.01)\end{array}$ & $\begin{array}{l}-0.01 \\
(0.01)\end{array}$ & $\begin{array}{c}-0.01 * \\
(0.01)\end{array}$ & $\begin{array}{l}0.30 * * \\
(0.04)\end{array}$ \\
\hline Observations & 96 & 96 & 96 & 96 & 96 & 96 & 96 & 96 \\
\hline Bandwidth & 48 & 48 & 48 & 48 & 48 & 48 & 48 & 48 \\
\hline Mean Dependent Variable & 0.437 & 0.693 & 0.785 & 16.34 & 0.396 & 0.702 & 0.777 & 16.54 \\
\hline \multicolumn{9}{|c|}{ Panel C: Linear cohort trend interacted with threshold with summer borns dropped } \\
\hline Discontinuity & $\begin{array}{c}-0.24^{* *} \\
(0.01)\end{array}$ & $\begin{array}{l}-0.02 \\
(0.01)\end{array}$ & $\begin{array}{l}-0.01 \\
(0.01)\end{array}$ & $\begin{array}{c}0.21 * * \\
(0.04)\end{array}$ & $\begin{array}{c}-0.22 * * \\
(0.01)\end{array}$ & $\begin{array}{c}-0.02^{*} \\
(0.01)\end{array}$ & $\begin{array}{c}-0.02^{*} \\
(0.01)\end{array}$ & $\begin{array}{c}0.29 * * \\
(0.05)\end{array}$ \\
\hline Observations & 72 & 72 & 72 & 72 & 72 & 72 & 72 & 72 \\
\hline Bandwidth & 48 & 48 & 48 & 48 & 48 & 48 & 48 & 48 \\
\hline Mean Dependent Variable & 0.437 & 0.693 & 0.785 & 16.34 & 0.396 & 0.702 & 0.777 & 16.54 \\
\hline
\end{tabular}


Table 2. Effect of ROSLA on Qualifications - 2001 Census

\begin{tabular}{|c|c|c|c|c|c|c|c|c|}
\hline & \multicolumn{4}{|c|}{ Women } & \multicolumn{4}{|c|}{ Men } \\
\hline & \multicolumn{8}{|c|}{ Dependent Variable: } \\
\hline & $\begin{array}{c}\text { No } \\
\text { Qualifications }\end{array}$ & $\begin{array}{c}1+\text { O-levels or } \\
1 \text { A-level }\end{array}$ & $\begin{array}{c}2+\text { A-Levels } \\
\text { or Higher }\end{array}$ & $\begin{array}{c}\text { Other } \\
\text { Qualifications }\end{array}$ & $\begin{array}{c}\text { No } \\
\text { Qualifications }\end{array}$ & $\begin{array}{c}1+\text { O-levels or } \\
1 \text { A-level }\end{array}$ & $\begin{array}{c}2+\text { A-Levels } \\
\text { or Higher }\end{array}$ & $\begin{array}{c}\text { Other } \\
\text { Qualifications }\end{array}$ \\
\hline \multicolumn{9}{|c|}{ Panel A: Linear cohort trend interacted with threshold } \\
\hline Discontinuity & $\begin{array}{c}-0.07 * * \\
(0.01)\end{array}$ & $\begin{array}{c}0.09 * * \\
(0.01)\end{array}$ & $\begin{array}{c}0.00 \\
(0.00)\end{array}$ & $\begin{array}{c}-0.02^{* *} \\
(0.00)\end{array}$ & $\begin{array}{c}-0.04^{* *} \\
(0.00)\end{array}$ & $\begin{array}{l}0.08 * * \\
(0.01)\end{array}$ & $\begin{array}{c}0.00 \\
(0.00)\end{array}$ & $\begin{array}{c}-0.04^{* *} \\
(0.00)\end{array}$ \\
\hline Observations & 100 & 100 & 100 & 100 & 100 & 100 & 100 & 100 \\
\hline Bandwidth & 50 & 50 & 50 & 50 & 50 & 50 & 50 & 50 \\
\hline Mean Dep Var & 0.284 & 0.373 & 0.285 & 0.0583 & 0.250 & 0.347 & 0.277 & 0.126 \\
\hline \multicolumn{9}{|c|}{ Panel B: Linear cohort trend interacted with threshold + month-of-birth dummies } \\
\hline Discontinuity & $\begin{array}{c}-0.07 * * \\
(0.00)\end{array}$ & $\begin{array}{l}0.09 * * \\
(0.00)\end{array}$ & $\begin{array}{c}0.00 \\
(0.00)\end{array}$ & $\begin{array}{c}-0.02 * * \\
(0.00)\end{array}$ & $\begin{array}{c}-0.04^{* *} \\
(0.00)\end{array}$ & $\begin{array}{l}0.08 * * \\
(0.00)\end{array}$ & $\begin{array}{c}0.00 \\
(0.00)\end{array}$ & $\begin{array}{c}-0.04^{* *} \\
(0.00)\end{array}$ \\
\hline Observations & 100 & 100 & 100 & 100 & 100 & 100 & 100 & 100 \\
\hline Bandwidth & 50 & 50 & 50 & 50 & 50 & 50 & 50 & 50 \\
\hline Mean Dep Var & 0.284 & 0.373 & 0.285 & 0.0583 & 0.250 & 0.347 & 0.277 & 0.126 \\
\hline \multicolumn{9}{|c|}{ Panel C: Linear cohort trend interacted with threshold with summer borns dropped } \\
\hline Discontinuity & $\begin{array}{c}-0.06 * * \\
(0.01)\end{array}$ & $\begin{array}{c}0.08^{* *} \\
(0.01)\end{array}$ & $\begin{array}{c}0.00 \\
(0.00)\end{array}$ & $\begin{array}{c}-0.02^{* *} \\
(0.00)\end{array}$ & $\begin{array}{c}-0.04^{* *} \\
(0.01)\end{array}$ & $\begin{array}{l}0.07 * * \\
(0.01)\end{array}$ & $\begin{array}{c}0.00 \\
(0.00)\end{array}$ & $\begin{array}{c}-0.04^{* *} \\
(0.00)\end{array}$ \\
\hline Observations & 74 & 74 & 74 & 74 & 74 & 74 & 74 & 74 \\
\hline Bandwidth & 50 & 50 & 50 & 50 & 50 & 50 & 50 & 50 \\
\hline Mean Dep Var & 0.284 & 0.373 & 0.285 & 0.0583 & 0.250 & 0.347 & 0.277 & 0.126 \\
\hline \multicolumn{9}{|c|}{$\begin{array}{l}\text { Notes: Each column and row is the regression discontinuity estimate from a separate regression. Column headers list the dependent variable. Panel A includes linear } \\
\text { controls for cohort trends, interacted with the threshold to allow different pre- and post-reform trends. Panel B adds dummies for month of birth. Panel C drops } \\
\text { summer borns to deal with the fact that they could drop out of school at the end of May of the year they reached the compulsory schooling age. The other } \\
\text { qualification category includes City and Guilds which awards vocational qualifications, Royal Society of Acts or Oxford, Cambridge and RSA which is a professional } \\
\text { typing credential, and BTEC or Edexcel which are privately-administered academic, vocational, or work-based credentials. The mean of the dependent variable is } \\
\text { measured for the cohort born in August } 1957 \text {, the last pre-reform cohort. Data come from UK } 2001 \text { Census. The samples are restricted to those born in the UK and } \\
\text { resident in England or Wales at the time of the interview. Each observation is a cohort-cell mean. Regressions are weighted by cohort sizes. Robust standard errors are } \\
\text { in parentheses. Bandwidth is measured in months. } * \text { : p-value }<0.05, * *: \text { p-value }<0.01\end{array}$} \\
\hline
\end{tabular}


Table 3. Effect of ROSLA on Teenage Fertility

\begin{tabular}{|c|c|c|c|c|c|}
\hline & \multicolumn{5}{|c|}{ Dependent Variable: Fertility Rate at Age } \\
\hline & 15 & 16 & 17 & 18 & 19 \\
\hline \multicolumn{6}{|c|}{ Panel A: Linear cohort trend interacted with threshold } \\
\hline Discontinuity & $\begin{array}{l}-0.0002 \\
(0.0002)\end{array}$ & $\begin{array}{c}-0.0018^{*} \\
(0.0007)\end{array}$ & $\begin{array}{c}-0.0031 * * \\
(0.0008)\end{array}$ & $\begin{array}{l}-0.0013 \\
(0.0012)\end{array}$ & $\begin{array}{l}-0.0002 \\
(0.0014)\end{array}$ \\
\hline Observations & 38 & 38 & 38 & 38 & 38 \\
\hline Bandwidth & 19 & 19 & 19 & 19 & 19 \\
\hline Mean Dependent Variable & 0.0036 & 0.0180 & 0.0377 & 0.0496 & 0.0590 \\
\hline \multicolumn{6}{|c|}{ Panel B: Linear cohort trend interacted with threshold + month-of-birth dummies } \\
\hline Discontinuity & $\begin{array}{l}-0.0005 \\
(0.0005)\end{array}$ & $\begin{array}{l}-0.0001 \\
(0.0008)\end{array}$ & $\begin{array}{c}-0.0034 * * \\
(0.0010)\end{array}$ & $\begin{array}{c}0.0022 \\
(0.0026)\end{array}$ & $\begin{array}{l}-0.0004 \\
(0.0014)\end{array}$ \\
\hline Observations & 38 & 38 & 38 & 38 & 38 \\
\hline Bandwidth & 19 & 19 & 19 & 19 & 19 \\
\hline Mean Dependent Variable & 0.0036 & 0.0180 & 0.0377 & 0.0496 & 0.0590 \\
\hline \multicolumn{6}{|c|}{ Panel C: Linear cohort trend interacted with threshold with summer borns dropped } \\
\hline Discontinuity & $\begin{array}{l}-0.0002 \\
(0.0003)\end{array}$ & $\begin{array}{l}-0.0008 \\
(0.0009)\end{array}$ & $\begin{array}{c}-0.0024^{* *} \\
(0.0007)\end{array}$ & $\begin{array}{l}-0.0001 \\
(0.0013)\end{array}$ & $\begin{array}{l}-0.0001 \\
(0.0018)\end{array}$ \\
\hline Observations & 29 & 29 & 29 & 29 & 29 \\
\hline Bandwidth & 19 & 19 & 19 & 19 & 19 \\
\hline Mean Dependent Variable & 0.0036 & 0.0180 & 0.0377 & 0.0496 & 0.0590 \\
\hline
\end{tabular}

Notes: Each column and row is the regression discontinuity estimate from a separate regression. Column headers list the dependent variable. Panel A includes linear controls for cohort trends, interacted with the threshold to allow different preand post-reform trends. Panel B adds dummies for month of birth. Panel C drops summer borns to deal with the fact that they could drop out of school at the end of May of the year they reached the compulsory schooling age. The mean of the dependent variable is measured for the cohort born in August 1957, the last pre-reform cohort. Data come from live birth records supplied by the UK Office of National Statistics, containing all births in England and Wales to mothers born in England, Wales, and Scotland, 1970-2008. These are supplemented with data on cohort sizes generated by registrar reports of cohort sizes at birth and mortality rates from the Human Mortality Database. Each observation is a cohort-cell mean. Regressions are weighted by cohort sizes. Robust standard errors are in parentheses. Bandwidth is measured in months. * :pvalue $<0.05,{ }^{* *}$ :p-value $<0.01$ 
Table 4. Effect of ROSLA on Abortion Rates

\begin{tabular}{|c|c|c|c|c|c|}
\hline & \multicolumn{5}{|c|}{ Dependent Variable: Abortion Rate at Age } \\
\hline & 15 & 16 & 17 & 18 & 19 \\
\hline \multicolumn{6}{|c|}{ Panel A: Linear cohort trend interacted with threshold } \\
\hline Discontinuity & $\begin{array}{l}-0.00055 \\
(0.00036)\end{array}$ & $\begin{array}{l}-0.00002 \\
(0.00057)\end{array}$ & $\begin{array}{c}0.00033 \\
(0.00042)\end{array}$ & $\begin{array}{c}0.00071 \\
(0.00058)\end{array}$ & $\begin{array}{l}-0.00055 \\
(0.00058)\end{array}$ \\
\hline Observations & 38 & 38 & 38 & 38 & 38 \\
\hline Bandwidth & 19 & 19 & 19 & 19 & 19 \\
\hline Mean Dependent Variable & 0.00603 & 0.0152 & 0.0187 & 0.0191 & 0.0178 \\
\hline \multicolumn{6}{|c|}{ Panel B: Linear cohort trend interacted with threshold + month-of-birth dummies } \\
\hline Discontinuity & $\begin{array}{l}-0.00036 \\
(0.00038)\end{array}$ & $\begin{array}{c}0.00045 \\
(0.00046)\end{array}$ & $\begin{array}{c}0.00008 \\
(0.00049)\end{array}$ & $\begin{array}{c}0.00057 \\
(0.00047)\end{array}$ & $\begin{array}{l}-0.00063 \\
(0.00060)\end{array}$ \\
\hline Observations & 38 & 38 & 38 & 38 & 38 \\
\hline Bandwidth & 19 & 19 & 19 & 19 & 19 \\
\hline Mean Dependent Variable & 0.00603 & 0.0152 & 0.0187 & 0.0191 & 0.0178 \\
\hline \multicolumn{6}{|c|}{ Panel C: Linear cohort trend interacted with threshold with summer borns dropped } \\
\hline Discontinuity & $\begin{array}{l}-0.00043 \\
(0.00041)\end{array}$ & $\begin{array}{c}0.00010 \\
(0.00072)\end{array}$ & $\begin{array}{c}0.00033 \\
(0.00056)\end{array}$ & $\begin{array}{c}0.00058 \\
(0.00064)\end{array}$ & $\begin{array}{l}-0.00045 \\
(0.00078)\end{array}$ \\
\hline Observations & 29 & 29 & 29 & 29 & 29 \\
\hline Bandwidth & 19 & 19 & 19 & 19 & 19 \\
\hline Mean Dependent Variable & 0.00603 & 0.0152 & 0.0187 & 0.0191 & 0.0178 \\
\hline
\end{tabular}

Notes: Each column and row is the regression discontinuity estimate from a separate regression. Column headers list the dependent variable. Panel A includes linear controls for cohort trends, interacted with the threshold to allow different preand post-reform trends. Panel B adds dummies for month of birth. Panel C drops summer borns to deal with the fact that they could drop out of school at the end of May of the year they reached the compulsory schooling age. The mean of the dependent variable is measured for the cohort born in August 1957, the last pre-reform cohort. Data come from abortion records supplied by the UK Office of National Statistics, containing all terminations in England and Wales to 15-19 year old mothers born in England, Wales, and Scotland, 1970-1980. These are supplemented with data on cohort sizes generated by registrar reports of cohort sizes at birth and mortality rates from the Human Mortality Database. Each observation is a cohort-cell mean. Regressions are weighted by cohort sizes. Robust standard errors are in parentheses. Bandwidth is measured in months. ${ }^{*}$ :p-value $<0.05, * *$ :p-value $<0.01$ 
Table 5. Effect of ROSLA on Cumulative Fertility

\begin{tabular}{|c|c|c|c|c|c|}
\hline & \multicolumn{5}{|c|}{ Dependent Variable: Cumulative Fertility Rate for Ages } \\
\hline & $16-25$ & $16-30$ & $16-35$ & $16-40$ & $16-45$ \\
\hline \multicolumn{6}{|c|}{ Panel A: Linear cohort trend interacted with threshold } \\
\hline Discontinuity & $\begin{array}{l}-0.0063 \\
(0.0073)\end{array}$ & $\begin{array}{l}-0.0005 \\
(0.0073)\end{array}$ & $\begin{array}{c}0.0022 \\
(0.0059)\end{array}$ & $\begin{array}{c}0.0037 \\
(0.0058)\end{array}$ & $\begin{array}{c}0.0036 \\
(0.0058)\end{array}$ \\
\hline Observations & 38 & 38 & 38 & 38 & 38 \\
\hline Bandwidth & 19 & 19 & 19 & 19 & 19 \\
\hline Mean Dependent Variable & 0.777 & 1.327 & 1.639 & 1.756 & 1.776 \\
\hline \multicolumn{6}{|c|}{ Panel B: Linear cohort trend interacted with threshold + month-of-birth dummies } \\
\hline Discontinuity & $\begin{array}{c}0.0009 \\
(0.0049)\end{array}$ & $\begin{array}{l}-0.0011 \\
(0.0062)\end{array}$ & $\begin{array}{l}-0.0075 \\
(0.0070)\end{array}$ & $\begin{array}{l}-0.0050 \\
(0.0084)\end{array}$ & $\begin{array}{l}-0.0055 \\
(0.0089)\end{array}$ \\
\hline Observations & 38 & 38 & 38 & 38 & 38 \\
\hline Bandwidth & 19 & 19 & 19 & 19 & 19 \\
\hline Mean Dependent Variable & 0.777 & 1.327 & 1.639 & 1.756 & 1.776 \\
\hline \multicolumn{6}{|c|}{ Panel C: Linear cohort trend interacted with threshold with summer borns dropped } \\
\hline Discontinuity & $\begin{array}{l}-0.0004 \\
(0.0093)\end{array}$ & $\begin{array}{c}0.0058 \\
(0.0092)\end{array}$ & $\begin{array}{c}0.0075 \\
(0.0080)\end{array}$ & $\begin{array}{c}0.0074 \\
(0.0080)\end{array}$ & $\begin{array}{c}0.0073 \\
(0.0080)\end{array}$ \\
\hline Observations & 29 & 29 & 29 & 29 & 29 \\
\hline Bandwidth & 19 & 19 & 19 & 19 & 19 \\
\hline Mean Dependent Variable & 0.777 & 1.327 & 1.639 & 1.756 & 1.776 \\
\hline
\end{tabular}

Notes: Each column and row is the regression discontinuity estimate from a separate regression. Cumulative fertility at each age $\mathrm{x}$ is the sum of age-specific fertility rates 16 to $\mathrm{x}$, inclusive. Column headers list the dependent variable. Panel A includes linear controls for cohort trends, interacted with the threshold to allow different pre- and post-reform trends. Panel B adds dummies for month of birth. Panel C drops summer borns to deal with the fact that they could drop out of school at the end of May of the year they reached the compulsory schooling age. The mean of the dependent variable is measured for the cohort born in August 1957, the last pre-reform cohort. Data come from live birth records supplied by the UK Office of National Statistics, containing all births in England and Wales to mothers born in England, Wales, and Scotland, 1970-2008. These are supplemented with data on cohort sizes generated by registrar reports of cohort sizes at birth and mortality rates from the Human Mortality Database. Each observation is a cohort-cell mean. Regressions are weighted by cohort sizes. Robust standard errors are in parentheses. Bandwidth is measured in months. ${ }^{*}$ : p-value $<0.05, \quad * *$ : p-value $<0.01$ 
Table 6. Effect of ROSLA on Partner's Educational Credentials

\begin{tabular}{|c|c|c|c|c|c|c|c|c|}
\hline & & 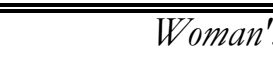 & $\overline{\text { s Mate }}$ & & & Man's & Mate & \\
\hline & $\begin{array}{c}\text { No } \\
\text { Qualifications }\end{array}$ & $\begin{array}{c}1+\text { O-levels or } \\
1 \text { A-level }\end{array}$ & $\begin{array}{c}2+\text { A-Levels } \\
\text { or Higher }\end{array}$ & $\begin{array}{c}\text { Other } \\
\text { Qualifications }\end{array}$ & $\begin{array}{c}\text { No } \\
\text { Qualifications }\end{array}$ & $\begin{array}{c}1+\text { O-levels or } \\
1 \text { A-level }\end{array}$ & $\begin{array}{c}2+\text { A-Levels } \\
\text { or Higher }\end{array}$ & $\begin{array}{c}\text { Other } \\
\text { Qualifications }\end{array}$ \\
\hline Panel A: Linear & cohort trend intera & acted with threshold & & & & & & \\
\hline Discontinuity & $\begin{array}{c}-0.0122^{* *} \\
(0.0022)\end{array}$ & $\begin{array}{c}0.0123^{* *} \\
(0.0016)\end{array}$ & $\begin{array}{c}0.0036 \\
(0.0025)\end{array}$ & $\begin{array}{c}-0.0037^{*} \\
(0.0015)\end{array}$ & $\begin{array}{c}-0.0137 * * \\
(0.0022)\end{array}$ & $\begin{array}{c}0.0125^{* *} \\
(0.0021)\end{array}$ & $\begin{array}{c}0.0028 \\
(0.0026)\end{array}$ & $\begin{array}{l}-0.0016^{*} \\
(0.0007)\end{array}$ \\
\hline Observations & 72 & 72 & 72 & 72 & 72 & 72 & 72 & 72 \\
\hline Bandwidth & 36 & 36 & 36 & 36 & 36 & 36 & 36 & 36 \\
\hline Mean Dep Var & 0.237 & 0.361 & 0.266 & 0.137 & 0.187 & 0.516 & 0.261 & 0.0352 \\
\hline Panel B: Linear & cobort trend interac & acted with threshold & + month-of-birt & b dummies & & & & \\
\hline Discontinuity & $\begin{array}{c}-0.0123^{* *} \\
(0.0019)\end{array}$ & $\begin{array}{c}0.0124 * * \\
(0.0018)\end{array}$ & $\begin{array}{c}0.0028 \\
(0.0021)\end{array}$ & $\begin{array}{l}-0.0029 \\
(0.0017)\end{array}$ & $\begin{array}{c}-0.0143^{* *} \\
(0.0019)\end{array}$ & $\begin{array}{c}0.0140 * * \\
(0.0017)\end{array}$ & $\begin{array}{c}0.0017 \\
(0.0019)\end{array}$ & $\begin{array}{l}-0.0014 \\
(0.0009)\end{array}$ \\
\hline Observations & 72 & 72 & 72 & 72 & 72 & 72 & 72 & 72 \\
\hline Bandwidth & 36 & 36 & 36 & 36 & 36 & 36 & 36 & 36 \\
\hline Mean Dep Var & 0.237 & 0.361 & 0.266 & 0.137 & 0.187 & 0.516 & 0.261 & 0.0352 \\
\hline Panel C: Linear & cohort trend interac & icted with threshold & with summer bor & ns dropped & & & & \\
\hline Discontinuity & $\begin{array}{c}-0.0101^{* *} \\
(0.0026)\end{array}$ & $\begin{array}{c}0.0131^{* *} \\
(0.0020)\end{array}$ & $\begin{array}{c}0.0016 \\
(0.0027)\end{array}$ & $\begin{array}{c}-0.0047 * \\
(0.0020)\end{array}$ & $\begin{array}{c}-0.0104^{* *} \\
(0.0026)\end{array}$ & $\begin{array}{c}0.0155^{* *} \\
(0.0020)\end{array}$ & $\begin{array}{l}-0.0034 \\
(0.0023)\end{array}$ & $\begin{array}{l}-0.0017 \\
(0.0009)\end{array}$ \\
\hline Observations & 54 & 54 & 54 & 54 & 54 & 54 & 54 & 54 \\
\hline Bandwidth & 36 & 36 & 36 & 36 & 36 & 36 & 36 & 36 \\
\hline Mean Dep Var & 0.237 & 0.361 & 0.266 & 0.137 & 0.187 & 0.516 & 0.261 & 0.0583 \\
\hline $\begin{array}{l}\text { Notes: Each colum } \\
\text { controls for cohor } \\
\text { summer borns to } ~ \\
\text { qualification categ } \\
\text { typing credential, a } \\
\text { measured for the c }\end{array}$ & $\begin{array}{l}\mathrm{nn} \text { and row is the } \mathrm{r} \\
\text { t trends, interacted } \\
\text { deal with the fact } t \\
\text { ory includes City a } \\
\text { and BTEC or Edex } \\
\text { cohort born in Aug }\end{array}$ & $\begin{array}{l}\text { regression discontin } \\
\text { d with the threshold } \\
\text { that they could drop } \\
\text { and Guilds which aw } \\
\text { xcel which are priva } \\
\text { gust } 1957 \text {, the last }\end{array}$ & $\begin{array}{l}\text { huity estimate frot } \\
\text { to allow differen } \\
\text { out of school at } \\
\text { wards vocational } \\
\text { tely-administered }\end{array}$ & $\begin{array}{l}\text { m a separate regr } \\
\text { at pre- and post- } \\
\text { the end of May } \\
\text { qualifications, Ro } \\
\text { academic, vocat }\end{array}$ & $\begin{array}{l}\text { Column he } \\
\text { trends. Pane } \\
\text { e year they re: } \\
\text { ciety of Acts } \\
\text { or work-base } \\
2001 \text { Census. }\end{array}$ & $\begin{array}{l}\text { list the depe } \\
\text { dds dummies } \\
\text { the compuls } \\
\text { xford, Camb } \\
\text { dentials. The } \\
\text { observation } \\
<005 \text { **. }\end{array}$ & $\begin{array}{l}\text { ariable. Pat } \\
\text { nth of birt } \\
\text { ooling age. } \\
\text { hd RSA wh } \\
\text { f the depe } \\
\text { hort-cell } m\end{array}$ & $\begin{array}{l}\text { includes linear } \\
\text { nel C drops } \\
\text { other } \\
\text { a professional } \\
\text { t variable is } \\
\text { Regressions are }\end{array}$ \\
\hline
\end{tabular}




\begin{tabular}{|c|c|c|c|}
\hline & $\begin{array}{c}(1) \\
\text { Left at } 16 \\
\text { Preferred leaving } \\
\text { at } 15 \\
\text { (Compliers) }\end{array}$ & $\begin{array}{r}(2) \\
\text { Left at } 16 \\
\text { Preferrec } \\
(\text { Alw }\end{array}$ & $\begin{array}{l}\text { (3) } \\
\text { Left at } 17+ \\
\text { g past } 15 \\
\text { kers) }\end{array}$ \\
\hline \multicolumn{4}{|l|}{ Panel A: Birth Prefernces and Outcomes } \\
\hline Plan to leave school at 16 (after current year) & 0.99 & 0.79 & 0.23 \\
\hline Agree: no point in planning for future & 0.35 & 0.17 & 0.08 \\
\hline $\begin{array}{l}\text { Best to start childbearing: (stated preference) } \\
\text { by age } 19 \\
\text { by age } 21\end{array}$ & $\begin{array}{l}0.08 \\
0.32\end{array}$ & $\begin{array}{l}0.02 \\
0.17\end{array}$ & $\begin{array}{l}0.01 \\
0.08\end{array}$ \\
\hline $\begin{array}{l}\text { Best to be married: (stated preference) } \\
\text { by age } 17 \\
\text { by age } 19\end{array}$ & $\begin{array}{l}0.04 \\
0.30\end{array}$ & $\begin{array}{l}0.01 \\
0.15\end{array}$ & $\begin{array}{l}0.00 \\
0.05\end{array}$ \\
\hline $\begin{array}{l}\text { Birth Outcomes } \\
\text { Child by age } 16 \\
\text { Child by age } 17 \\
\text { Child by age } 18\end{array}$ & $\begin{array}{l}0.03 \\
0.09 \\
0.16\end{array}$ & $\begin{array}{l}0.01 \\
0.05 \\
0.09\end{array}$ & $\begin{array}{c}0 \\
0.01 \\
0.02\end{array}$ \\
\hline Obs & 1,134 & 1,602 & 1,501 \\
\hline \multicolumn{4}{|l|}{ Panel B :Cohabitating Partnerships } \\
\hline Lived with guardians on 16th birthday & 0.99 & 0.99 & 1.00 \\
\hline \multicolumn{4}{|l|}{ Among respondents who cohabitated at 16} \\
\hline $\begin{array}{l}\text { Partner age: } 25 \text { th percentile } \\
\text { Partner age: Median }\end{array}$ & $\begin{array}{l}18 \\
20\end{array}$ & $\begin{array}{c}18 \\
19.5\end{array}$ & \\
\hline First cohabitating partnership at 17 & 0.11 & 0.06 & 0.02 \\
\hline \multicolumn{4}{|l|}{ Among respondents who cohabitated at 17} \\
\hline $\begin{array}{l}\text { Partner age: } 25 \text { th percentile } \\
\text { Partner age: Median }\end{array}$ & $\begin{array}{l}19 \\
20\end{array}$ & $\begin{array}{l}19 \\
21\end{array}$ & $\begin{array}{l}18 \\
20\end{array}$ \\
\hline Obs & 908 & 1,256 & 1,488 \\
\hline
\end{tabular}

Notes: Sample includes NCDS female respondents. Columns sub-divide sample by preferred school-leaving age, as reported by the NCDS cohort member at the time they were 16. Respondents were asked: "... do you wish that you could have left when you were 15?" Missing and "uncertain" cohort member responses are filled in with their parents' responses to the question: "In the study child's case do they wish that he/she had been able to leave school at fifteen?" 


\section{Appendix Figure 1. Maximum/Minimum Years and Terms of Full-Time Education For Those Leaving at Minimum Leaving Age by Birthdate}

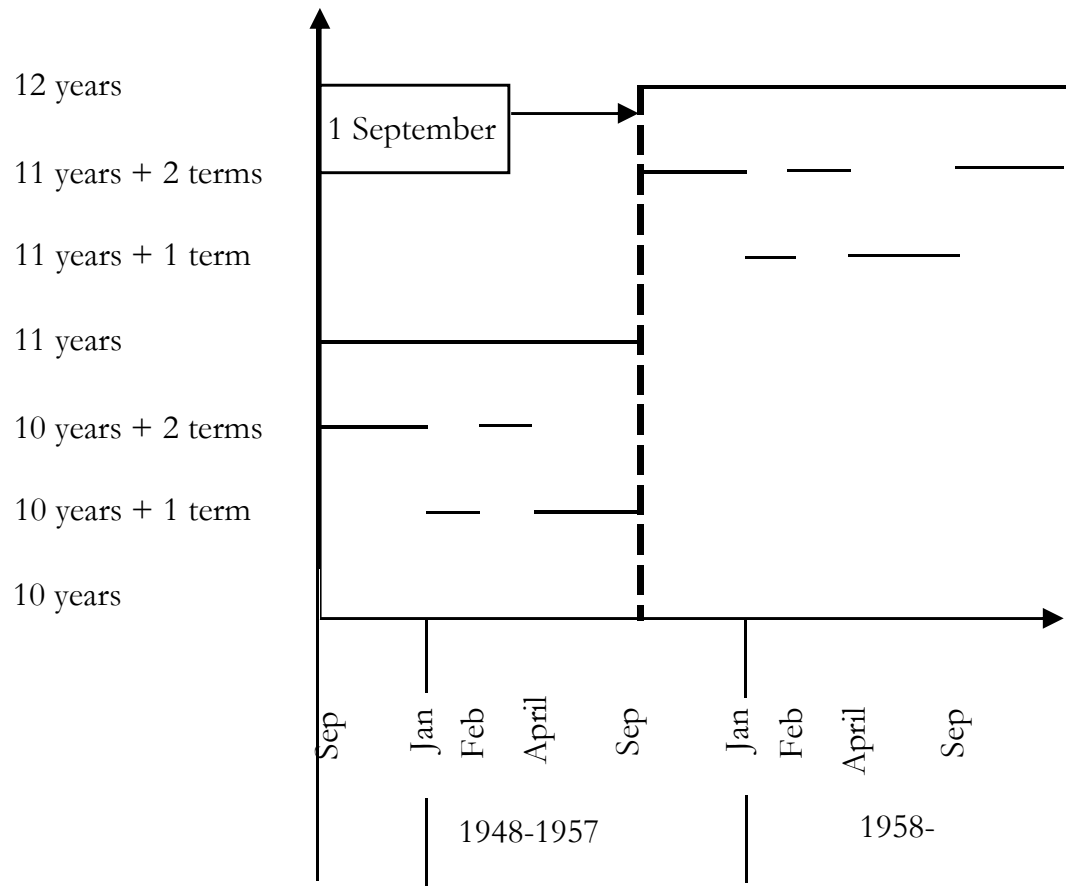

Notes: Source is Clark and Royer (2013). The x-axis denotes different birth cohorts. For example, the first part of the $x$-axis refers to those between January and August over the years 1948-1956. The y-axis displays the minimum and maximum years and terms of fulltime education for those who report leaving at the minimum school leaving age. There exists a minimum and a maximum because students that report leaving at the minimum school leaving age (e.g., 15) could have left at the first available opportunity or could have continued for one or two more terms before leaving. For example, people born in January in the years 1948-1956 who report leaving at the compulsory school leaving age (15) would have spent 10 years and one term in full-time education had they left at the first opportunity. 


\section{Appendix Figure 2. Trends in Student/Teacher Ratio Over Time}

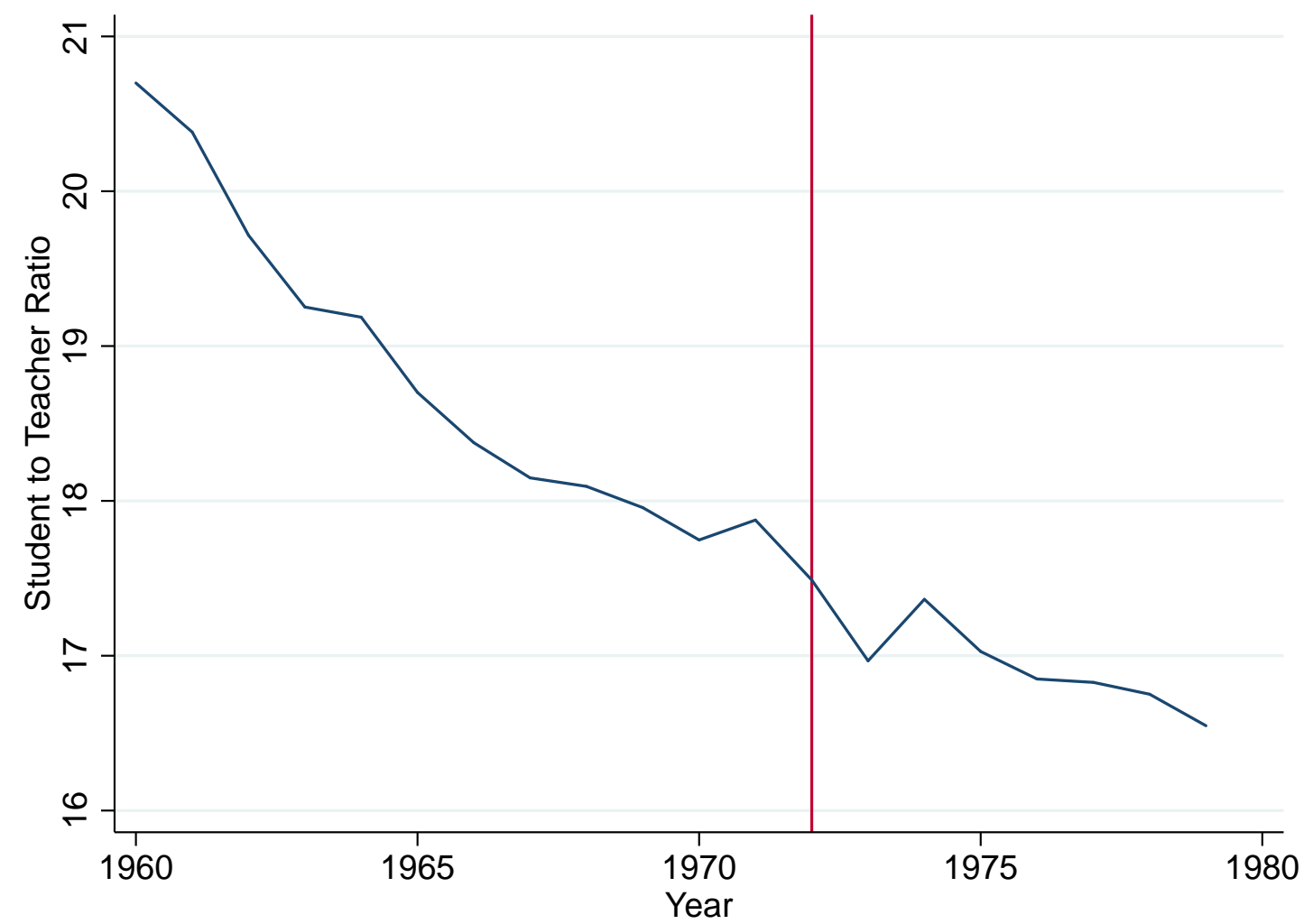

Notes: Y-axis is the student/teacher ratio in England and Wales for secondary schools. The student and teacher data come from Table "Miscellaneous Statistics 9" and "Miscellaneous Statistics 10" from Mitchell, Brian R. 1988. British Historical Statistics. New York: Cambridge University Press. The data are counts from January of the year indicated. The red line represents the first year of the new ROSLA. 


\section{Appendix Figure 3. Global Trends in Fertility During Study Period}
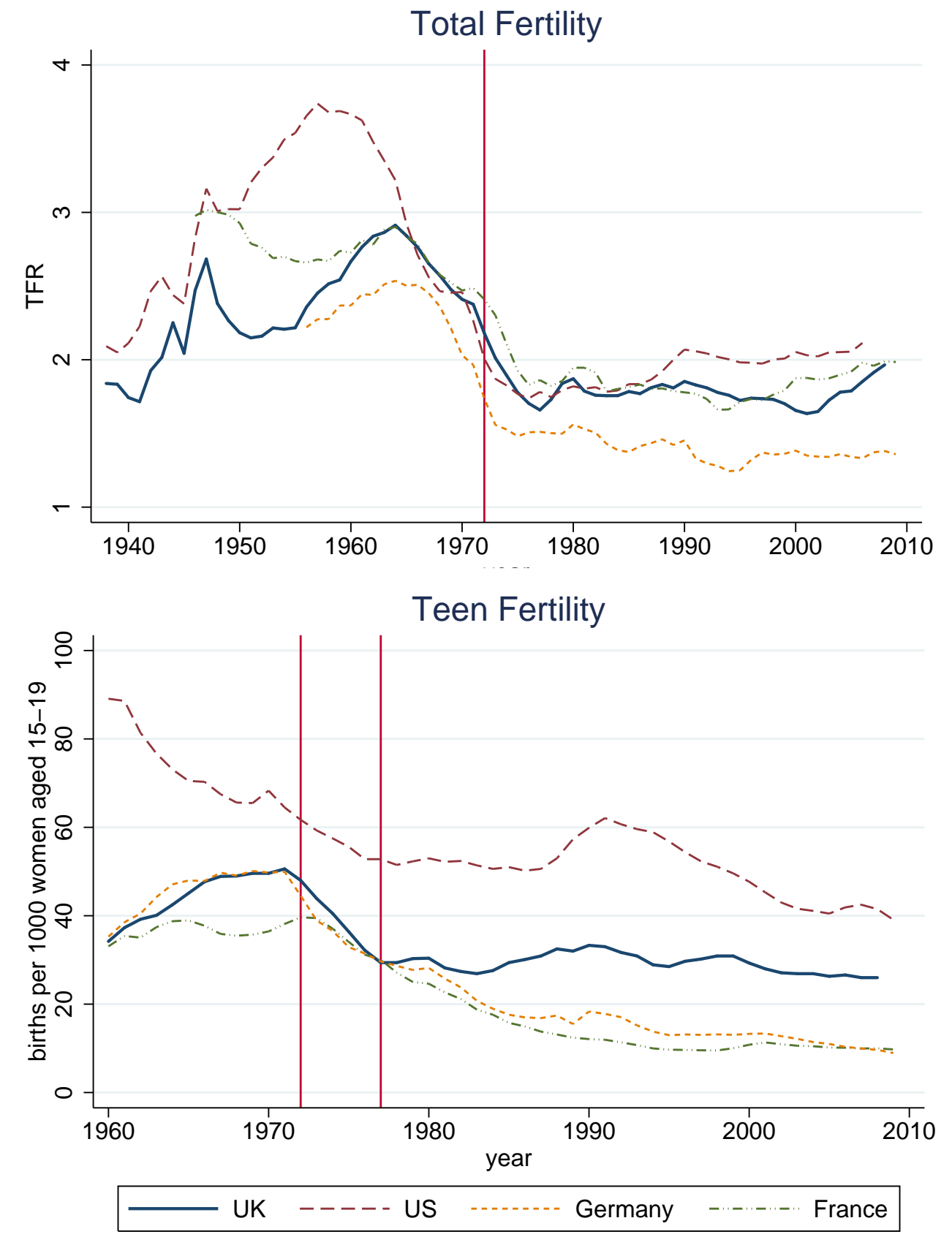

Notes: Total fertility rates in the UK, US, France, and Germany. The vertical line in the top figure indicates the date of the 1972 ROSLA, which came at the tail end of a demographic transition among industrialized nations. Women just affected by the reform experienced their childbearing years (roughly 1972 through 2002) in a period of low, stable fertility. The two vertical lines in the bottom figure denote the years when those just affected by the 1972 ROSLA would have been at prime teenage fertility years. UK data come from the UK Office of National Statistics. US, French, and German data come from the Human Fertility Database. 


\section{Appendix Figure 4. Effect of ROSLA on In- and Out-of-Marriage Fertility}
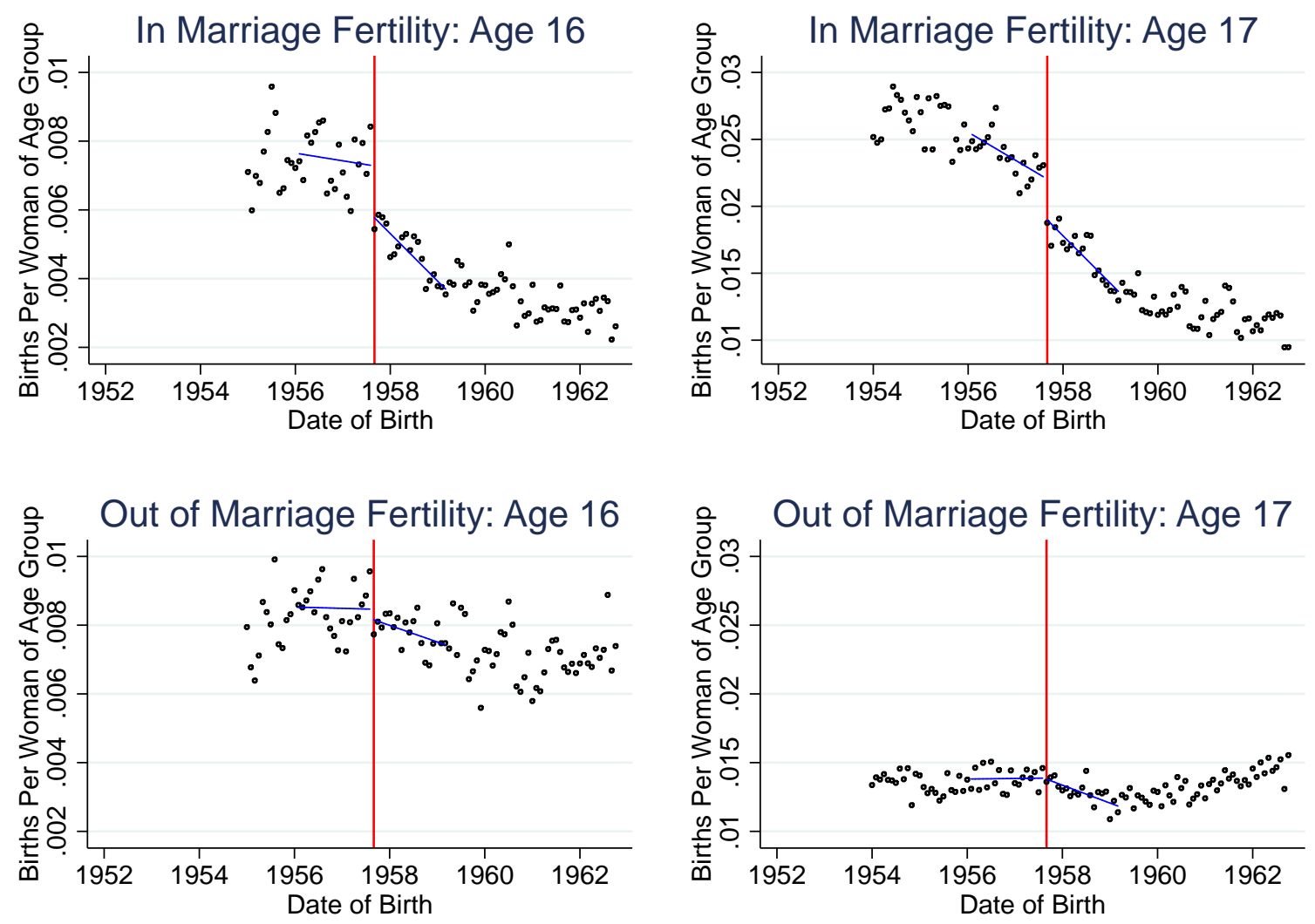

Notes: The impact of the 1972 ROSLA on in-marriage and out-of-marriage fertility. Each point represents the fertility rate (number of births/size of age group) for a cohort of women sharing the same month and year of birth. The plotted lines are local linear regression fits to those points over the chosen bandwidth. The vertical line indicates the ROSLA threshold with the first post-reform cohort born September 1957. 


\section{Appendix Figure 5. Effect of ROSLA on Age Gap of Spouses}
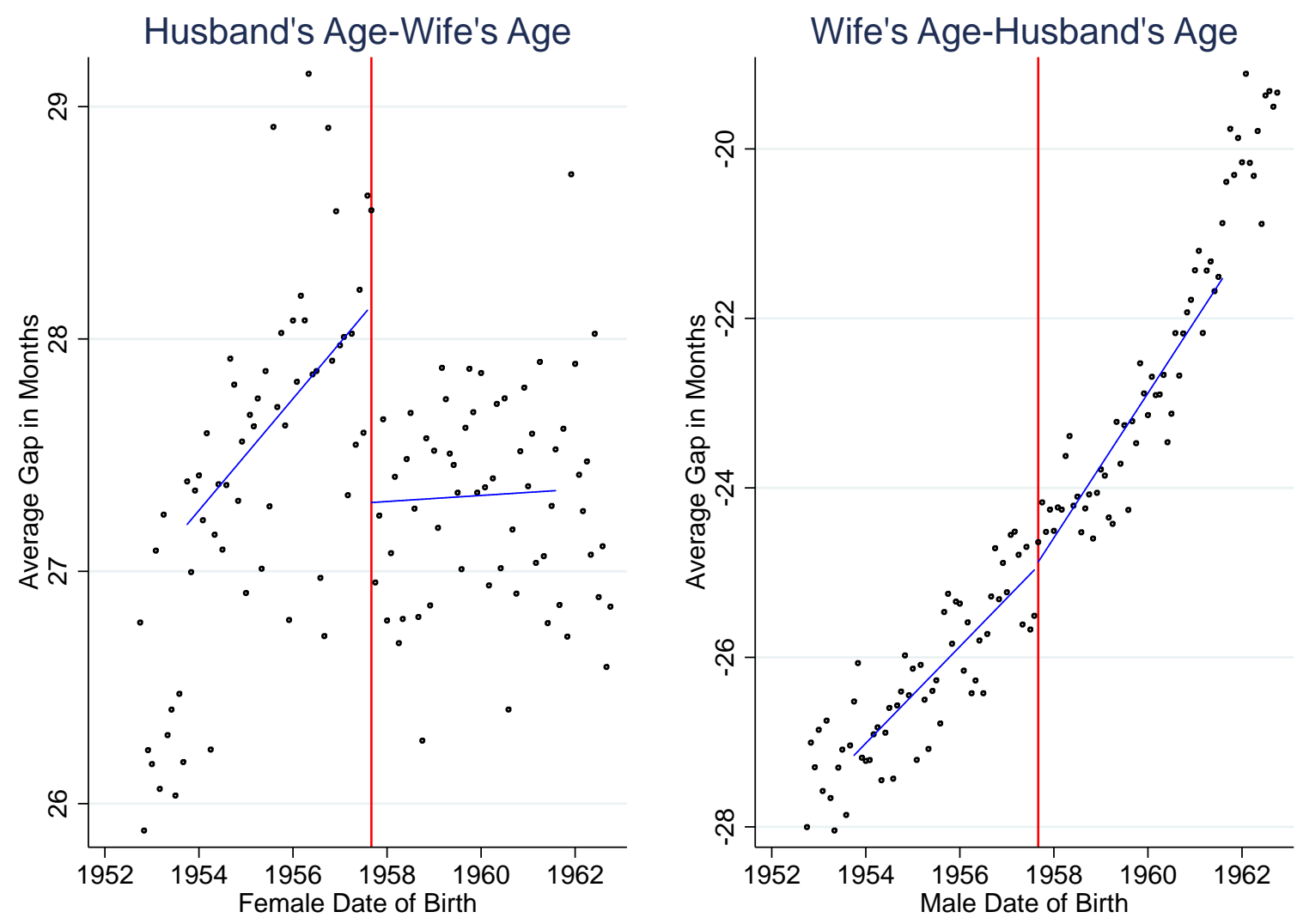

Notes: The impact of the 1972 ROSLA on age gap of spouses; women's mates are represented by the left panel and men's mates are represented by the right panel. In the left panel, each point represents the average age gap between husband and wife for women of the same month and year birth cohort. In the right panel, each point represents the average age gap between wife and husband for men of the same month and year of birth cohort. Each average age gap has been seasonally adjusted. Seasonality adjustments are formed by regressing the mean cohort age gap on a set of month-of-birth dummies and taking the residuals and adding the average age gap back. The plotted lines are local linear regression fits to those points over the chosen bandwidth. The vertical line indicates the ROSLA threshold with the first post-reform cohort born September 1957. 


\section{Appendix Figure 6. Effect of ROSLA on Age Gap of Spouses}
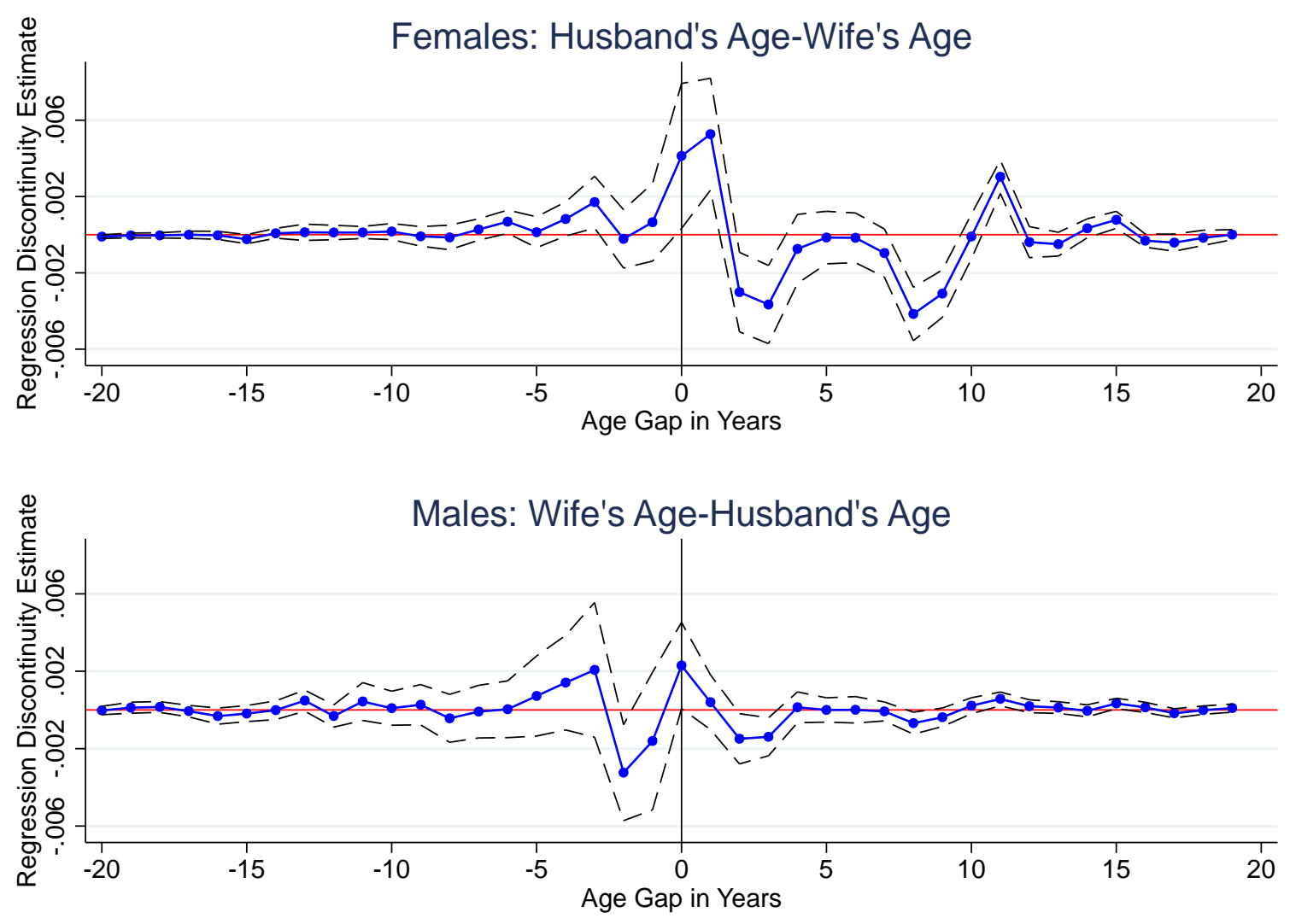

Notes: The impact of the 1972 ROSLA on the age gap between spouses; women's mates are represented by the top panel and men's mates are represented by the bottom panel. Each point represents a regression discontinuity estimate of the reduced-form effect of ROSLA on the probability of marrying a mate with a certain age gap. The top panel is age difference between wife and husband for women. The bottom panel is age difference between husband and wife for men. Regression discontinuity estimates control for seasonality through the inclusion of month-of-birth dummies. Pointwise $95 \%$ confidence intervals are plotted as dotted lines. 


\section{Appendix Figure 7. Self-Reports of Complier Status Across UK Regions}

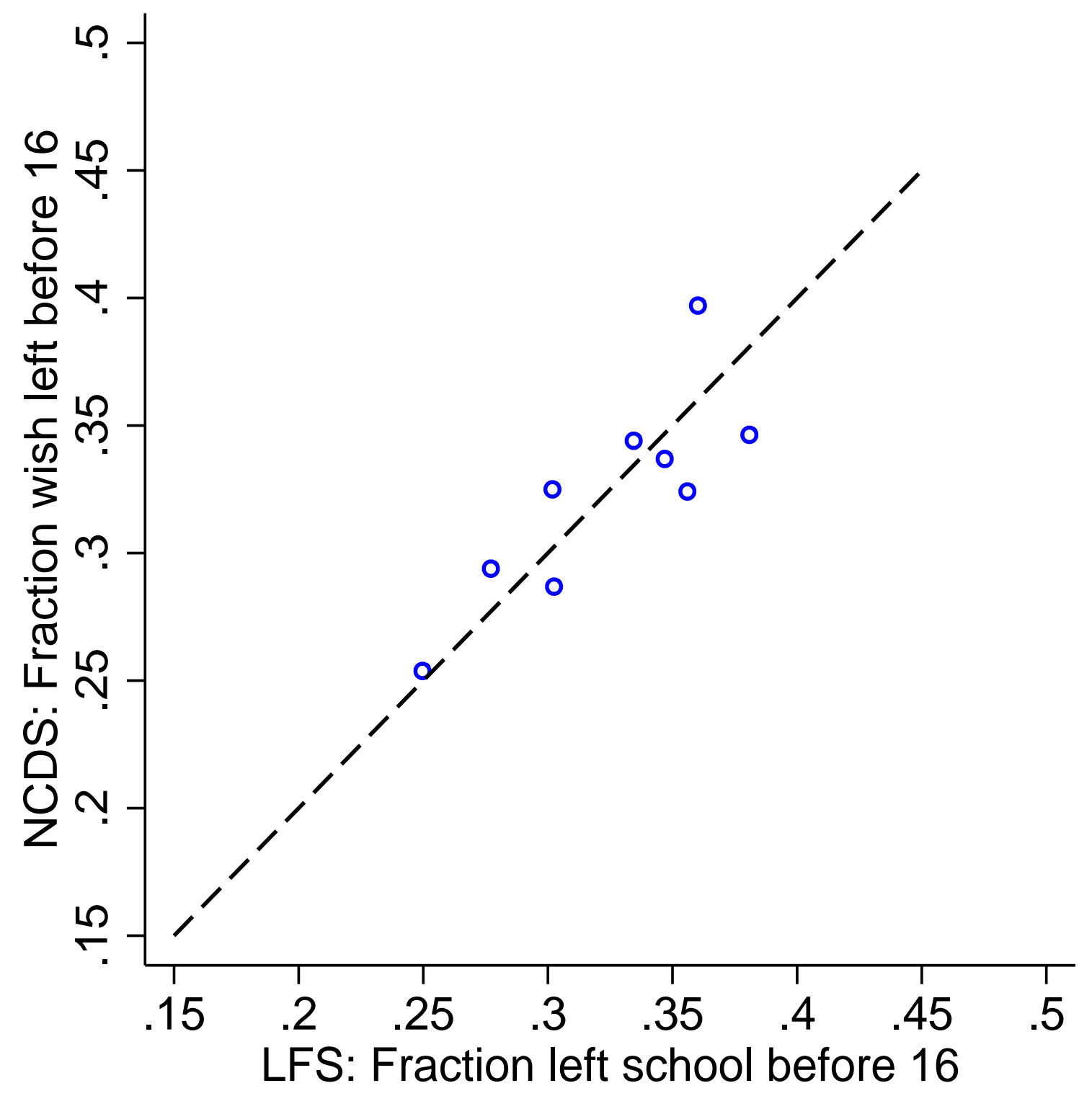

Notes: The vertical axis plots the fraction wishing to leave school before age 16, self-reported by NCDS respondents (a post-ROSLA cohort born in 1958). The horizontal axis plots the fraction actually exiting from school before age 16, self-reported by LFS respondents who were born in the pre-period, 1954-1957. The dashed line is the 45 degree line. Each point corresponds to a region of the UK. 
Appendix Table 1. Data Sources

\begin{tabular}{|c|c|c|c|}
\hline Data Source & Sample & Primary Variables & Notes \\
\hline $\begin{array}{l}\text { UK Labour Force } \\
\text { Survey (LFS) }\end{array}$ & $\begin{array}{l}\text { Sample of } \\
\text { households in } \\
\text { England and Wales }\end{array}$ & $\begin{array}{l}\text { age left full-time } \\
\text { education }\end{array}$ & individual-level \\
\hline $\begin{array}{l}\text { Live Births } \\
\text { Records Extract }\end{array}$ & $\begin{array}{l}100 \% \text { sample of } \\
\text { births in England and } \\
\text { Wales } 1970-2008\end{array}$ & live births & $\begin{array}{l}\text { counts by mother's date of birth } \\
\text { (measured in months) and child's } \\
\text { date of birth (measured in } \\
\text { months); not an individual-level } \\
\text { panel }\end{array}$ \\
\hline $\begin{array}{l}\text { Abortion Records } \\
\text { Extract }\end{array}$ & $\begin{array}{l}100 \% \text { sample of teen } \\
\text { abortions (15-19 } \\
\text { years old) in England } \\
\text { and Wales 1970-1980 }\end{array}$ & abortions & $\begin{array}{l}\text { counts by mother's date of birth } \\
\text { (measured in months) and date of } \\
\text { procedure (measured in months) }\end{array}$ \\
\hline $\begin{array}{l}\text { UK Census } \\
\text { Extracts }\end{array}$ & $\begin{array}{l}100 \% \text { sample for the } \\
2001 \text { Census of those } \\
\text { born in England and } \\
\text { Wales }\end{array}$ & $\begin{array}{l}\text { marital status, one's own } \\
\text { qualifications, partner's } \\
\text { age, partner's academic } \\
\text { qualifications }\end{array}$ & \\
\hline $\begin{array}{l}\text { National Child } \\
\text { Development } \\
\text { Study (1958 } \\
\text { Cohort) }\end{array}$ & $\begin{array}{l}100 \% \text { sample of } \\
\text { children born one } \\
\text { week in March } 1958\end{array}$ & $\begin{array}{l}\text { age at which would have } \\
\text { dropped out of school if } \\
\text { ROSLA had not } \\
\text { occurred, activities in } \\
\text { school, partnership } \\
\text { histories, activities out of } \\
\text { school }\end{array}$ & $\begin{array}{l}\text { one of the first post-ROSLA } \\
\text { cohorts; panel data set following } \\
\text { individuals at ages } 7,11,16,23,33 \text {, } \\
\text { and } 41 \text {; respondents self-identify as } \\
\text { ROSLA compliers or not at age } 16\end{array}$ \\
\hline
\end{tabular}


Appendix Table 2. Estimates using CCT method (2014)

Outcome/Bandwidth

left school by age 15

bandwidth

left school by age 16

bandwidth

left school by age 17

bandwidth

age left full-time ed

bandwidth

left school by age 15

bandwidth

left school by age 16

bandwidth

left school by age 17

bandwidth

age left full-time ed

bandwidth
Sample Original Estimate CCT Estimate

women

$-0.24 * *$

(0.01)

48

$(0.01)$

women

$-0.01$

$-0.02 *$

(0.01)

(0.01)

48

36

women

$-0.00$

$-0.01$

(0.00)

(0.01)

48

43

women

$0.24 * *$

$0.22^{* *}$

(0.04)

48

33

men

$-0.22 * *$

$-0.23^{* *}$

$(0.01)$

(0.01)

48

44

men

$-0.01$

$-0.01 *$

(0.01)

(0.01)

48

43

men

$-0.01 *$

$-0.02 * *$

(0.01)

(0.01)

48

41

men

$0.30 * *$

$0.38^{* *}$

(0.04)

48
47

Notes: Each column and row is the regression discontinuity estimate from a separate regression. Row headers list the dependent variable. All models include month of birth fixed effects, except for the outcomes labelled with asterisks. For the asterisked outcomes, the CCT bandwidth selector algorithm chose bandwidths less than 12 months. Robust standard errors are in parentheses. Bandwidth is measured in months. *: p-value < 0.05, **: p-value < 0.01, ***: pvalue $<0.001$ 


\section{Appendix Table 2 Con't. Estimates using CCT method (2014)}

Outcome/Bandwidth

no qualifications

bandwidth

$1+$ O-levels or 1 A-level

bandwidth

2+ A-Levels or Higher

bandwidth

other qualifications

bandwidth

no qualifications

bandwidth

$1+$ O-levels or 1 A-level

bandwidth

$2+$ A-Levels or Higher

bandwidth

other qualifications
Sample Original Estimate CCT Estimate

women

$-0.07 * *$

(0.00)

50

(0.00)

13

women

0.09 **

$0.09 * *$

$(0.00)$

(0.00)

50

29

women

0.00

$-0.00$

(0.00)

50

20

women

$-0.02 * *$

$-0.02^{* *}$

(0.00)

50

23

men

$-0.04 * *$

$-0.05^{* *}$

(0.00)

(0.00)

50

14

men

$0.08^{* *}$

$0.08^{* *}$

(0.00)

50

27

men

0.00

$0.00 * *$

(0.00)

50

26

men

$-0.04 * *$

$-0.04 * *$

(0.00)

bandwidth

Notes: Each column and row is the regression discontinuity estimate from a separate regression. Row headers list the dependent variable. All models include month of birth fixed effects, except for the outcomes labelled with asterisks. For the asterisked outcomes, the CСT bandwidth selector algorithm chose bandwidths less than 12 months. Robust standard errors are in parentheses. Bandwidth is measured in months. *: p-value $<0.05, \quad{ }^{*}$ : p-value $<0.01, * * *$ : pvalue $<0.001$ 


\section{Appendix Table 2 Con't. Estimates using CCT method (2014)}

Outcome/Bandwidth

age 16 birth rate

bandwidth

age 17 birth rate

bandwidth

age 18 birth rate

bandwidth

age 19 birth rate

bandwidth

age 15 abortion rate*

bandwidth

age 16 abortion rate*

bandwidth

age 17 abortion rate*

bandwidth

age 18 abortion rate*

bandwidth

age 19 abortion rate*
Sample Original Estimate CCT Estimate

women $\quad-0.0001$

(0.0008)

19

(0.0004)

12

women

$-0.0034 * *$

$-0.0016^{*}$

(0.0010)

19

(0.0007)

14

women

0.0022

0.0008

(0.0026)

19

(0.0010)

12

women

$-0.0004$

0.0008

(0.0014)

19

(0.0008)

12

women $\quad-0.00055$

$-0.00100$

(0.00036)

(0.00060)

19

13

women

$-0.00002$

$-0.00110$

(0.00057)

19

(0.00130)

10

women

0.00033

0.00060

(0.00042)

19

(0.00070)

11

women

0.00071

0.00130

(0.00058)

19

(0.00120)

12

women $\quad-0.00055$

0.00040

(0.00058)
(0.00060)

13

19

Notes: Each column and row is the regression discontinuity estimate from a separate regression. Row headers list the dependent variable. All models include month of birth fixed effects, except for the outcomes labelled with asterisks. For the asterisked outcomes, the CCT bandwidth selector algorithm chose bandwidths less than 12 months. Robust standard errors are in parentheses. Bandwidth is measured in months.*: p-value $<0.05, * *$ : p-value $<0.01, * * *$ : pvalue $<0.001$ 


\section{Appendix Table 2 Con't. Estimates using CCT method (2014)}

Outcome/Bandwidth

age 16 in-marriage birth rate*

bandwidth

age 17 in-marriage birth rate*

bandwidth

age 18 in-marriage birth rate*

bandwidth

age 19 in-marriage birth rate*

bandwidth

age 16 out-of-marriage birth rate*

bandwidth

age 17 out-of-marriage birth rate*

bandwidth

age 18 out-of-marriage birth rate*

bandwidth

age 19 out-of-marriage birth rate*

bandwidth
Sample Original Estimate CCT Estimate

$\begin{array}{lll}\text { women } & -0.0015^{* *} & -0.0027^{*}\end{array}$

(0.0004)

19

$(0.0011)$

6

women

$$
\begin{gathered}
-0.0031 * * \\
(0.0006)
\end{gathered}
$$

$-0.0055^{* *}$

19

(0.0008)

8

women

$-0.0010$

$-0.0001$

(0.0009)

19

women

$-0.0004$

0.0005

(0.0011)

19

(0.0011)

14

men

$-0.0003$

$-0.0018$

(0.0004)

19

6

men $\quad-0.0001$

(0.0004)

19

$-0.0004$

(0.0007)

13

men $\quad-0.0003$

$-0.0015$

(0.0005)

19

10

men $\quad 0.0003$

(0.0005)
0.0004

(0.0006)

Notes: Each column and row is the regression discontinuity estimate from a separate regression. Row headers list the dependent variable. All models include month of birth fixed effects, except for the outcomes labelled with asterisks. For the asterisked outcomes, the CCT bandwidth selector algorithm chose bandwidths less than 12 months. Robust standard errors are in parentheses. Bandwidth is measured in months. *: p-value $<0.05, \quad * *$ : p-value $<0.01, * * *$ : pvalue $<0.001$ 


\section{Appendix Table 2 Con't. Estimates using CCT method (2014)}

Outcome/Bandwidth

cumulative fertility rate $16-25$ years old*

bandwidth

cumulative fertility rate 16-30 years old*

bandwidth

cumulative fertility rate 16-35 years old*

bandwidth

cumulative fertility rate $16-40$ years old $*$

bandwidth

cumulative fertility rate $16-45$ years old*

bandwidth

Notes: Each column and row is the regression discontinuity estimate from a separate regression. Row headers list the dependent variable. All models include month of birth fixed effects, except for the outcomes labelled with asterisks. For the asterisked outcomes, the CCT bandwidth selector algorithm chose bandwidths less than 12 months. Robust standard errors are in parentheses. Bandwidth is measured in months. *: p-value $<0.05$, **: p-value $<0.01$, ***: pvalue $<0.001$

\begin{tabular}{ccc} 
Sample & Original Estimate & CCT Estimate \\
\hline women & -0.0063 & $-0.0301 * *$ \\
& $(0.0073)$ & $(0.0092)$ \\
women & 19 & 5 \\
& -0.0005 & -0.0222 \\
& $(0.0073)$ & $(0.0119)$ \\
women & 19 & 5 \\
& 0.0022 & -0.0101 \\
& $(0.0059)$ & $(0.0111)$ \\
women & 19 & 6 \\
& 0.0037 & -0.0053 \\
& $(0.0058)$ & $(0.0116)$ \\
& 19 & 7 \\
women & 0.0036 & -0.0058 \\
& $(0.0058)$ & $(0.0115)$ \\
& 19 & 7 \\
\hline
\end{tabular}




\section{Appendix Table 2 Con't. Estimates using CCT method (2014)}

\begin{tabular}{|c|c|c|c|}
\hline Outcome/Bandwidth & Sample & Original Estimate & CCT Estimate \\
\hline \multirow[t]{2}{*}{ husband has no qualifications } & women & $-0.0123 * *$ & $-0.0115^{* *}$ \\
\hline & & $(0.0019)$ & $(0.0016)$ \\
\hline bandwidth & & 36 & 46 \\
\hline \multirow[t]{2}{*}{ busband has $1+O$-levels or 1 A-level } & women & $0.0124^{* *}$ & $0.0111 * *$ \\
\hline & & $(0.0018)$ & $(0.0022)$ \\
\hline bandwidth & & 36 & 29 \\
\hline \multirow{2}{*}{ busband has $2+$ A-levels or higher } & women & 0.0028 & 0.0025 \\
\hline & & $(0.0021)$ & $(0.0020)$ \\
\hline bandwidth & & 36 & 41 \\
\hline \multirow[t]{2}{*}{ busband has other qualifications/qualifications unknown } & women & -0.0029 & -0.0028 \\
\hline & & $(0.0017)$ & $(0.0017)$ \\
\hline bandwidth & & 36 & 29 \\
\hline \multirow[t]{2}{*}{ wife has no qualifications } & men & $-0.0143 * *$ & $-0.0130 * *$ \\
\hline & & $(0.0019)$ & $(0.0016)$ \\
\hline bandwidth & & 36 & 44 \\
\hline \multirow[t]{2}{*}{ wife has $1+$ O-levels or 1 A-level } & men & $0.0140 * *$ & $0.0128^{* *}$ \\
\hline & & $(0.0017)$ & $(0.0020)$ \\
\hline bandwidth & & 36 & 29 \\
\hline \multirow[t]{2}{*}{ wife has $2+$ A-levels or higher } & men & 0.0017 & 0.0027 \\
\hline & & $(0.0019)$ & $(0.0014)$ \\
\hline bandwidth & & 36 & 32 \\
\hline \multirow[t]{2}{*}{ wife has other qualifications/qualifications unknown } & men & -0.0014 & -0.0009 \\
\hline & & $(0.0009)$ & $(0.0008)$ \\
\hline bandwidth & & 36 & 36 \\
\hline \multirow[t]{2}{*}{ busband's age-own age } & women & $-0.87 * *$ & $-0.75^{* *}$ \\
\hline & & $(0.24)$ & $(0.28)$ \\
\hline bandwidth & & 47 & 49 \\
\hline \multirow[t]{2}{*}{ wife's age-own age } & men & -0.07 & $0.42^{*}$ \\
\hline & & $(0.19)$ & $(0.18)$ \\
\hline bandwidth & & 47 & 27 \\
\hline
\end{tabular}

Notes: Each column and row is the regression discontinuity estimate from a separate regression. Row headers list the dependent variable. All models include month of birth fixed effects, except for the outcomes labelled with asterisks. For the asterisked outcomes, the CCT bandwidth selector algorithm chose bandwidths less than 12 months. Robust standard errors are in parentheses. Bandwidth is measured in months. *: p-value $<0.05$, **: p-value $<0.01$ 


\section{Appendix Table 3. Sensitivity of Regression Discontinuity Estimates to Bandwidth}

\begin{tabular}{|c|c|c|c|c|}
\hline Outcome & $\begin{array}{c}\text { Chosen } \\
\text { Bandwidth in } \\
\text { Months }\end{array}$ & $\begin{array}{c}\text { Chosen } \\
\text { Bandwidth - } 6\end{array}$ & $\begin{array}{c}\text { Chosen } \\
\text { Bandwidth }\end{array}$ & $\begin{array}{c}\text { Chosen } \\
\text { Bandwidth }+6\end{array}$ \\
\hline Left School by Age 15 for Women & 48 & $\begin{array}{c}-0.24 * * \\
(0.01)\end{array}$ & $\begin{array}{c}-0.24 * * \\
(0.01)\end{array}$ & $\begin{array}{c}-0.24 * * \\
(0.01)\end{array}$ \\
\hline Left School by Age 16 for Women & 48 & $\begin{array}{l}-0.02^{*} \\
(0.01)\end{array}$ & $\begin{array}{l}-0.01 \\
(0.01)\end{array}$ & $\begin{array}{l}-0.01 \\
(0.01)\end{array}$ \\
\hline Left School by Age 17 for Women & 48 & $\begin{array}{l}-0.01 \\
(0.01)\end{array}$ & $\begin{array}{l}-0.00 \\
(0.00)\end{array}$ & $\begin{array}{l}-0.00 \\
(0.00)\end{array}$ \\
\hline Age Left Schooling for Women & 48 & $\begin{array}{c}0.26^{* *} \\
(0.04)\end{array}$ & $\begin{array}{c}0.24 * * \\
(0.04)\end{array}$ & $\begin{array}{l}0.21 * * \\
(0.03)\end{array}$ \\
\hline Left School by Age 15 for Men & 48 & $\begin{array}{c}-0.22^{* *} \\
(0.01)\end{array}$ & $\begin{array}{c}-0.22^{* *} \\
(0.01)\end{array}$ & $\begin{array}{c}-0.21 * * \\
(0.01)\end{array}$ \\
\hline Left School by Age 16 for Men & 48 & $\begin{array}{l}-0.01 \\
(0.01)\end{array}$ & $\begin{array}{l}-0.01 \\
(0.01)\end{array}$ & $\begin{array}{l}-0.01 \\
(0.01)\end{array}$ \\
\hline Left School by Age 17 for Men & 48 & $\begin{array}{l}-0.01 * \\
(0.01)\end{array}$ & $\begin{array}{c}-0.01 * \\
(0.01)\end{array}$ & $\begin{array}{l}-0.01 \\
(0.01)\end{array}$ \\
\hline Age Left Schooling for Men & 48 & $\begin{array}{c}0.31^{* *} \\
(0.05)\end{array}$ & $\begin{array}{c}0.30^{* *} \\
(0.04)\end{array}$ & $\begin{array}{c}0.24 * * \\
(0.04)\end{array}$ \\
\hline
\end{tabular}

Notes: Each column and row is the regression discontinuity estimate from a separate regression. All regression estimates come from local linear regressions which allow the slope with respect to the running variable to vary pre and post reform. These regressions also include month-of-birth dummies. Robust standard errors in parentheses. ${ }^{*}: \mathrm{p}$-value $<0.05$, ** $: \mathrm{p}-$ value $<0.01, * * *$ : p-value $<0.001$ 


\section{Appendix Table 3 Con't. Sensitivity of Regression Discontinuity Estimates to Bandwidth}

Chosen Chosen Chosen Chosen

Outcome

Bandwidth in Bandwidth - 6

Bandwidth

Bandwidth +6

Fertility at Age 15

19

$-0.0002$

$-0.0002$

$-0.0001$

(0.0003)

(0.0003)

(0.0002)

Fertility at Age 16

19

$\begin{array}{lll}-0.0013 & -0.0009 & -0.0012 * \\ (0.0010) & (0.0006) & (0.0005)\end{array}$

Fertility at Age 17

19

$-0.0011$

$-0.0021 * *$

$-0.0030^{* *}$

(0.0008)

(0.0007)

(0.0006)

Fertility at Age 18

19

$-0.0002$

$-0.0008$

$-0.0021$

(0.0012)

(0.0011)

(0.0011)

Fertility at Age 19

19

$\begin{array}{ccc}0.0021 & 0.0004 & -0.0015 \\ (0.0011) & (0.0013) & (0.0012)\end{array}$

Notes: Each column and row is the regression discontinuity estimate from a separate regression. All regression estimates come from local linear regressions which allow the slope with respect to the running variable to vary pre and post reform. These regressions also include month-of-birth dummies. Robust standard errors in parentheses. ${ }^{*}$ :p-value $<0.05$, $^{* *}$ :pvalue $<0.01, * * *$ : p-value $<0.001$ 


\section{Appendix Table 3 Con't. Sensitivity of Regression Discontinuity Estimates to Bandwidth}

\begin{tabular}{|c|c|c|c|c|}
\hline Outcome & $\begin{array}{c}\text { Bandwidth in } \\
\text { Months }\end{array}$ & $\begin{array}{c}\text { Chosen } \\
\text { Bandwidth - } 6\end{array}$ & $\begin{array}{c}\text { Chosen } \\
\text { Bandwidth }\end{array}$ & $\begin{array}{c}\text { Chosen } \\
\text { Bandwidth }+6 \\
\end{array}$ \\
\hline In-Marriage Fertility at Age 15 & 19 & $\begin{array}{c}0.0000 \\
(0.0000)\end{array}$ & $\begin{array}{c}0.0000 \\
(0.0000)\end{array}$ & $\begin{array}{c}0.0000 \\
(0.0000)\end{array}$ \\
\hline In-Marriage Fertility at Age 16 & 19 & $\begin{array}{c}-0.0014^{*} \\
(0.0006)\end{array}$ & $\begin{array}{c}-0.0011 * * \\
(0.0003)\end{array}$ & $\begin{array}{c}-0.0013 * * \\
(0.0003)\end{array}$ \\
\hline In-Marriage Fertility at Age 17 & 19 & $\begin{array}{c}-0.0014^{*} \\
(0.0005)\end{array}$ & $\begin{array}{c}-0.0022 * * \\
(0.0005)\end{array}$ & $\begin{array}{c}-0.0028^{* *} \\
(0.0005)\end{array}$ \\
\hline In-Marriage Fertility at Age 18 & 19 & $\begin{array}{c}0.0014 \\
(0.0011)\end{array}$ & $\begin{array}{l}-0.0005 \\
(0.0010)\end{array}$ & $\begin{array}{l}-0.0018 \\
(0.0009)\end{array}$ \\
\hline In-Marriage Fertility at Age 19 & 19 & $\begin{array}{c}0.0021 \\
(0.0010)\end{array}$ & $\begin{array}{c}0.0001 \\
(0.0011)\end{array}$ & $\begin{array}{l}-0.0013 \\
(0.0010)\end{array}$ \\
\hline Out-of-Marriage Fertility at Age 15 & 19 & $\begin{array}{l}-0.0002 \\
(0.0003)\end{array}$ & $\begin{array}{l}-0.0002 \\
(0.0002)\end{array}$ & $\begin{array}{l}-0.0001 \\
(0.0002)\end{array}$ \\
\hline Out-of-Marriage Fertility at Age 16 & 19 & $\begin{array}{c}0.0001 \\
(0.0005)\end{array}$ & $\begin{array}{c}0.0002 \\
(0.0003)\end{array}$ & $\begin{array}{c}0.0002 \\
(0.0003)\end{array}$ \\
\hline Out-of-Marriage Fertility at Age 17 & 19 & $\begin{array}{c}0.0002 \\
(0.0008)\end{array}$ & $\begin{array}{c}0.0001 \\
(0.0006)\end{array}$ & $\begin{array}{l}-0.0002 \\
(0.0004)\end{array}$ \\
\hline Out-of-Marriage Fertility at Age 18 & 19 & $\begin{array}{c}-0.0016 * * \\
(0.0005)\end{array}$ & $\begin{array}{l}-0.0002 \\
(0.0005)\end{array}$ & $\begin{array}{l}-0.0004 \\
(0.0005)\end{array}$ \\
\hline Out-of-Marriage Fertility at Age 19 & 19 & $\begin{array}{l}-0.0000 \\
(0.0003)\end{array}$ & $\begin{array}{c}0.0003 \\
(0.0005)\end{array}$ & $\begin{array}{l}-0.0002 \\
(0.0004)\end{array}$ \\
\hline
\end{tabular}

Notes: Each column and row is the regression discontinuity estimate from a separate regression. All regression estimates come from local linear regressions which allow the slope with respect to the running variable to vary pre and post reform. These regressions also include month-of-birth dummies. Robust standard errors in parentheses. ${ }^{*}: \mathrm{p}-\mathrm{value}<0.05$, ** $: \mathrm{p}-$ value $<0.01, * * *$ : p-value $<0.001$ 


\section{Appendix Table 3 Con't. Sensitivity of Regression Discontinuity Estimates to Bandwidth}

\begin{tabular}{|c|c|c|c|c|}
\hline Outcome & $\begin{array}{c}\text { Chosen } \\
\text { Bandwidth in }\end{array}$ & $\begin{array}{c}\text { Chosen } \\
\text { Bandwidth - } 6\end{array}$ & $\begin{array}{c}\text { Chosen } \\
\text { Bandwidth }\end{array}$ & $\begin{array}{c}\text { Chosen } \\
\text { Bandwidth }+6\end{array}$ \\
\hline \multirow[t]{2}{*}{ Abortion at Age 15} & 19 & -0.00031 & -0.00036 & -0.00047 \\
\hline & & $(0.00041)$ & $(0.00038)$ & $(0.00031)$ \\
\hline \multirow[t]{2}{*}{ Abortion at Age 16} & 19 & -0.00087 & 0.00045 & -0.00024 \\
\hline & & $(0.00056)$ & $(0.00046)$ & $(0.00049)$ \\
\hline \multirow[t]{2}{*}{ Abortion at Age 17} & 19 & -0.00105 & 0.00008 & -0.00001 \\
\hline & & $(0.00065)$ & $(0.00049)$ & $(0.00041)$ \\
\hline \multirow[t]{2}{*}{ Abortion at Age 18} & 19 & 0.00018 & 0.00057 & 0.00020 \\
\hline & & $(0.00066)$ & $(0.00047)$ & $(0.00044)$ \\
\hline \multirow[t]{2}{*}{ Abortion at Age 19} & 19 & -0.00043 & -0.00063 & -0.00094 \\
\hline & & $(0.00079)$ & $(0.00060)$ & $(0.00057)$ \\
\hline \multirow[t]{2}{*}{ Cumulative Fertility Ages 16-25 } & 19 & -0.0017 & -0.0004 & -0.0108 \\
\hline & & $(0.0062)$ & $(0.0055)$ & $(0.0057)$ \\
\hline \multirow[t]{2}{*}{ Cumulative Fertility Ages 16-30 } & 19 & 0.0003 & 0.0031 & -0.0094 \\
\hline & & $(0.0070)$ & $(0.0059)$ & $(0.0065)$ \\
\hline \multirow[t]{2}{*}{ Cumulative Fertility Ages 16-35 } & 19 & 0.0036 & 0.0031 & -0.0087 \\
\hline & & $(0.0070)$ & $(0.0056)$ & $(0.0062)$ \\
\hline \multirow[t]{2}{*}{ Cumulative Fertility Ages 16-40 } & 19 & 0.0025 & 0.0041 & -0.0079 \\
\hline & & $(0.0064)$ & $(0.0058)$ & $(0.0062)$ \\
\hline \multirow[t]{2}{*}{ Cumulative Fertility Ages 16-45 } & 19 & 0.0006 & 0.0037 & -0.0084 \\
\hline & & $(0.0066)$ & $(0.0059)$ & $(0.0064)$ \\
\hline
\end{tabular}

Notes: Each column and row is the regression discontinuity estimate from a separate regression. All regression estimates come from local linear regressions which allow the slope with respect to the running variable to vary pre and post reform. These regressions also include month-of-birth dummies. Robust standard errors in parentheses. ${ }^{*}: \mathrm{p}-\mathrm{value}<0.05, * *: \mathrm{p}-$ value $<0.01, * * *$ : p-value $<0.001$ 


\section{Appendix Table 3 Con't. Sensitivity of Regression Discontinuity Estimates to Bandwidth}

\begin{tabular}{|c|c|c|c|c|}
\hline Outcome & $\begin{array}{c}\text { Chosen } \\
\text { Bandwidth in }\end{array}$ & $\begin{array}{c}\text { Chosen } \\
\text { Bandwidth - } 6 \\
\end{array}$ & $\begin{array}{c}\text { Chosen } \\
\text { Bandwidth } \\
\end{array}$ & $\begin{array}{c}\text { Chosen } \\
\text { Bandwidth }+6 \\
\end{array}$ \\
\hline Woman's Mate: No Qualifications & 36 & $\begin{array}{c}-0.0112^{* *} \\
(0.0021)\end{array}$ & $\begin{array}{c}-0.0123 * * \\
(0.0019)\end{array}$ & $\begin{array}{c}-0.0118^{* *} \\
(0.0017)\end{array}$ \\
\hline Woman's Mate: $1+$ O-levels or 1 A-level & 36 & $\begin{array}{c}0.0117 * * \\
(0.0020)\end{array}$ & $\begin{array}{c}0.0124 * * \\
(0.0018)\end{array}$ & $\begin{array}{c}0.0148^{* *} \\
(0.0017)\end{array}$ \\
\hline Woman's Mate: 2+ A-Levels or Higher & 36 & $\begin{array}{c}0.0029 \\
(0.0022)\end{array}$ & $\begin{array}{c}0.0028 \\
(0.0021)\end{array}$ & $\begin{array}{c}0.0007 \\
(0.0018)\end{array}$ \\
\hline Man's Mate: No Qualifications & 36 & $\begin{array}{c}-0.0130 * * \\
(0.0019)\end{array}$ & $\begin{array}{c}-0.0143^{* *} \\
(0.0019)\end{array}$ & $\begin{array}{c}-0.0119 * * \\
(0.0018)\end{array}$ \\
\hline Man's Mate: 1+ O-levels or 1 A-level & 36 & $\begin{array}{c}0.0124 * * \\
(0.0018)\end{array}$ & $\begin{array}{c}0.0140 * * \\
(0.0017)\end{array}$ & $\begin{array}{c}0.0139 * * \\
(0.0015)\end{array}$ \\
\hline Man's Mate: 2+ A-Levels or Higher & 36 & $\begin{array}{c}0.0019 \\
(0.0018)\end{array}$ & $\begin{array}{c}0.0017 \\
(0.0019)\end{array}$ & $\begin{array}{c}0.0000 \\
(0.0016)\end{array}$ \\
\hline
\end{tabular}

Notes: Each column and row is the regression discontinuity estimate from a separate regression. All regression estimates come from local linear regressions which allow the slope with respect to the running variable to vary pre and post reform. These regressions also include month-of-birth dummies. Robust standard errors in parentheses. ${ }^{*}$ :p-value $<0.05,{ }^{* *}$ :pvalue $<0.01,{ }^{* * *}: \mathrm{p}$-value $<0.001$ 
Appendix Table 4. Effect of ROSLA on In/Out of Marriage Teenage Fertility

\begin{tabular}{|c|c|c|c|c|c|c|c|c|c|c|}
\hline & \multicolumn{5}{|c|}{ Dependent Var: In-Marriage Fertility Rate at Age } & \multicolumn{5}{|c|}{ Dependent Var: Out-Marriage Fertility Rate at Age } \\
\hline & 15 & 16 & 17 & 18 & 19 & 15 & 16 & 17 & 18 & 19 \\
\hline \multicolumn{11}{|c|}{ Panel A: Linear cohort trend interacted with threshold } \\
\hline Discontinuity & $\begin{array}{c}0.0000 \\
(0.0000)\end{array}$ & $\begin{array}{c}-0.0015^{* *} \\
(0.0004)\end{array}$ & $\begin{array}{c}-0.0031 * * \\
(0.0006)\end{array}$ & $\begin{array}{l}-0.0010 \\
(0.0009)\end{array}$ & $\begin{array}{l}-0.0004 \\
(0.0011)\end{array}$ & $\begin{array}{l}-0.0002 \\
(0.0002)\end{array}$ & $\begin{array}{l}-0.0003 \\
(0.0004)\end{array}$ & $\begin{array}{l}-0.0001 \\
(0.0004)\end{array}$ & $\begin{array}{l}-0.0003 \\
(0.0005)\end{array}$ & $\begin{array}{c}0.0003 \\
(0.0005)\end{array}$ \\
\hline Observations & 38 & 38 & 38 & 38 & 38 & 38 & 38 & 38 & 38 & 38 \\
\hline Bandwidth & 19 & 19 & 19 & 19 & 19 & 19 & 19 & 19 & 19 & 19 \\
\hline Mean Dep Var & 0 & 0.00842 & 0.0231 & 0.0333 & 0.0453 & 0.00360 & 0.00956 & 0.0146 & 0.0163 & 0.0137 \\
\hline \multicolumn{11}{|c|}{ Panel B: Linear cohort trend interacted with threshold + month-of-birth dummies } \\
\hline Discontinuity & $\begin{array}{c}0.0000 \\
(0.0000)\end{array}$ & $\begin{array}{c}-0.0015^{* *} \\
(0.0004)\end{array}$ & $\begin{array}{c}-0.0031 * * \\
(0.0006)\end{array}$ & $\begin{array}{l}-0.0010 \\
(0.0009)\end{array}$ & $\begin{array}{l}-0.0004 \\
(0.0011)\end{array}$ & $\begin{array}{l}-0.0002 \\
(0.0002)\end{array}$ & $\begin{array}{c}0.0002 \\
(0.0003)\end{array}$ & $\begin{array}{c}0.0001 \\
(0.0006)\end{array}$ & $\begin{array}{l}-0.0002 \\
(0.0005)\end{array}$ & $\begin{array}{c}0.0003 \\
(0.0005)\end{array}$ \\
\hline Observations & 38 & 38 & 38 & 38 & 38 & 38 & 38 & 38 & 38 & 38 \\
\hline Bandwidth & 19 & 19 & 19 & 19 & 19 & 19 & 19 & 19 & 19 & 19 \\
\hline Mean Dep Var & 0 & 0.00842 & 0.0231 & 0.0333 & 0.0453 & 0.00360 & 0.00956 & 0.0146 & 0.0163 & 0.0137 \\
\hline \multicolumn{11}{|c|}{ Panel C: Linear cohort trend interacted with threshold with summer borns dropped } \\
\hline Discontinuity & $\begin{array}{c}0.0000 \\
(0.0000)\end{array}$ & $\begin{array}{l}-0.0011 \\
(0.0006)\end{array}$ & $\begin{array}{c}-0.0023 * * \\
(0.0006)\end{array}$ & $\begin{array}{l}-0.0007 \\
(0.0011)\end{array}$ & $\begin{array}{l}-0.0005 \\
(0.0014)\end{array}$ & $\begin{array}{l}-0.0002 \\
(0.0003)\end{array}$ & $\begin{array}{c}0.0003 \\
(0.0005)\end{array}$ & $\begin{array}{l}-0.0001 \\
(0.0004)\end{array}$ & $\begin{array}{c}0.0006 \\
(0.0005)\end{array}$ & $\begin{array}{c}0.0004 \\
(0.0007)\end{array}$ \\
\hline Observations & 29 & 29 & 29 & 29 & 29 & 29 & 29 & 29 & 29 & 29 \\
\hline Bandwidth & 19 & 19 & 19 & 19 & 19 & 19 & 19 & 19 & 19 & 19 \\
\hline Mean Dep Var & 0 & 0.00842 & 0.0231 & 0.0333 & 0.0453 & 0.00360 & 0.00956 & 0.0146 & 0.0163 & 0.0137 \\
\hline \multicolumn{11}{|c|}{$\begin{array}{l}\text { Notes: Each column and row is the regression discontinuity estimate from a separate regression. Column headers list the dependent variable. Panel A } \\
\text { includes linear controls for cohort trends, interacted with the threshold to allow different pre- and post-reform trends. Panel B adds dummies for month } \\
\text { of birth. Panel C drops summer borns to deal with the fact that they could drop out of school at the end of May of the year they reached the } \\
\text { compulsory schooling age. The mean of dependent variable is measured for the cohort born in August 1957, the last pre-reform cohort. Data come } \\
\text { from live birth records supplied by the UK Office of National Statistics, containing all births in England and Wales to mothers born in England, Wales, } \\
\text { and Scotland, 1970-2008. These are supplemented with data on cohort sizes generated by registrar reports of cohort sizes at birth and mortality rates } \\
\text { from the Human Mortality Database. Each observation is a cohort-cell mean. Regressions are weighted by cohort sizes. Robust standard errors are in } \\
\text { parentheses. Bandwidth is measured in months. }{ }^{*} \text { :p-value }<0.05,{ }^{* *} \text { :p-value }<0.01\end{array}$} \\
\hline
\end{tabular}




\section{Appendix Table 5. Shotgun Marriages Among Teens}

Year

$\begin{array}{lll}1970 & 1971 & 1972\end{array}$

\begin{tabular}{lllllll}
1973 & 1974 & 1975 & 1976 & 1977 & 1978 & 1979 \\
\hline
\end{tabular}

Age 16 births with conception

preceding marriage

$\begin{array}{llllllllll}2,561 & 2,724 & 2,767 & 2,637 & 2,231 & 1,633 & 1,449 & 1,435 & 1,327 & 1,144\end{array}$

Age 16 births in marriage

$\begin{array}{llllllllll}2,628 & 2,811 & 2,887 & 2,914 & 2,479 & 1,755 & 1,581 & 1,537 & 1,440 & 1,275\end{array}$

Implied fraction shotgun

$\begin{array}{llllllllll}0.97 & 0.97 & 0.96 & 0.90 & 0.90 & 0.93 & 0.92 & 0.93 & 0.92 & 0.90\end{array}$

Age 17 births with conception

preceding marriage

$\begin{array}{llllllllll}8,039 & 8,161 & 7,853 & 7,194 & 6,799 & 5,715 & 4,605 & 4,090 & 4,015 & 4,053\end{array}$

Age 17 births in marriage

$\begin{array}{llllllllll}8,945 & 9,303 & 9,017 & 8,754 & 8,370 & 7,002 & 5,585 & 4,968 & 4,861 & 4,895\end{array}$

Implied fraction shotgun

$\begin{array}{llllllllll}0.90 & 0.88 & 0.87 & 0.82 & 0.81 & 0.82 & 0.82 & 0.82 & 0.83 & 0.83\end{array}$

Notes: Table compares counts of all in-marriage births by age and year with counts of in-marriage births within 8 months of marriage. The third and sixth rows calculate the implied fraction of all in-marriage births for which the order of events was conception, followed by marriage, followed by birth. This calculation assumes gestation of at least 8 months. Source: Main estimation sample and UK Office of National Statistics dataset PBH52A "Births: 1963-2004, Live births within 8 months of marriage." 


\section{Appendix Table 6. Effect of ROSLA on Conception Rates}

\begin{tabular}{|c|c|c|c|c|}
\hline & \multicolumn{4}{|c|}{ Dependent Variable: Conception Rate at Age of Time of Birth } \\
\hline & 16 & 17 & 18 & 19 \\
\hline \multicolumn{5}{|c|}{ Panel A: Linear cohort trend interacted with threshold } \\
\hline Discontinuity & $\begin{array}{c}-0.0033 * * \\
(0.0007)\end{array}$ & $\begin{array}{c}-0.0050^{* *} \\
(0.0008)\end{array}$ & $\begin{array}{l}-0.0021 \\
(0.0012)\end{array}$ & $\begin{array}{l}-0.0020 \\
(0.0016)\end{array}$ \\
\hline Observations & 48 & 48 & 48 & 48 \\
\hline Bandwidth & 24 & 24 & 24 & 24 \\
\hline Mean Dependent Variable & 0.0275 & 0.0548 & 0.0684 & 0.0772 \\
\hline \multicolumn{5}{|c|}{ Panel B: Linear cohort trend interacted with threshold + month-of-birth dummies } \\
\hline Discontinuity & $\begin{array}{l}-0.0011 \\
(0.0007)\end{array}$ & $\begin{array}{c}-0.0028^{* *} \\
(0.0009)\end{array}$ & $\begin{array}{l}-0.0014 \\
(0.0012)\end{array}$ & $\begin{array}{l}-0.0010 \\
(0.0016)\end{array}$ \\
\hline Observations & 48 & 48 & 48 & 48 \\
\hline Bandwidth & 24 & 24 & 24 & 24 \\
\hline Mean Dependent Variable & 0.0275 & 0.0548 & 0.0684 & 0.0772 \\
\hline \multicolumn{5}{|c|}{ Panel C: Linear cohort trend interacted with threshold with summer borns dropped } \\
\hline Discontinuity & $\begin{array}{c}-0.0023^{*} \\
(0.0010)\end{array}$ & $\begin{array}{c}-0.0042^{* *} \\
(0.0009)\end{array}$ & $\begin{array}{l}-0.0014 \\
(0.0014)\end{array}$ & $\begin{array}{l}-0.0012 \\
(0.0018)\end{array}$ \\
\hline Observations & 36 & 36 & 36 & 36 \\
\hline Bandwidth & 24 & 24 & 24 & 24 \\
\hline Mean Dependent Variable & 0.0275 & 0.0548 & 0.0684 & 0.0772 \\
\hline
\end{tabular}

Notes: Each column and row is the regression discontinuity estimate from a separate regression. Conception rates are defined as the sum of birth rates and abortion rates (adjusted to take into account that timing of abortion and births are different, see text for more details). Column headers list the dependent variable. Panel A includes linear controls for cohort trends, interacted with the threshold to allow different pre- and post-reform trends. Panel B adds dummies for month of birth. Panel C drops summer borns to deal with the fact that they could drop out of school at the end of May of the year they reached the compulsory schooling age. The mean of the dependent variable is measured for the cohort born in August 1957, the last pre-reform cohort. Data come from live birth records and abortion records supplied by the UK Office of National Statistics, containing all births in England and Wales to mothers born in England, Wales, and Scotland, 1970-2008. These are supplemented with data on cohort sizes from the Human Mortality Database. Each observation is a cohort-cell mean. Regressions are weighted by cohort sizes. Robust standard errors are in parentheses. * :p-value $<0.05, \quad * *$ :p-value $<0.01, * * *:$-value $<0.001$ 
Appendix Table 7. Effect of ROSLA on Partner's Age

\begin{tabular}{|c|c|c|c|c|}
\hline & Wom & s Mate & Man & $\overline{\text { Mate }}$ \\
\hline & $\begin{array}{l}\text { Male Spouse Age - } \\
\text { Own Age (Months) }\end{array}$ & $\begin{array}{c}\text { Fraction of Mates in } \\
\text { Same Academic } \\
\text { Cohort }\end{array}$ & $\begin{array}{l}\text { Female Spouse Age - } \\
\text { Own Age (Months) }\end{array}$ & $\begin{array}{c}\text { Fraction of Mates in } \\
\text { Same Academic } \\
\text { Cohort }\end{array}$ \\
\hline Panel A: Linear & cohort trend interacted $w$ & threshold & & \\
\hline Discontinuity & $\begin{array}{c}-1.66^{* *} \\
(0.45)\end{array}$ & $\begin{array}{l}-0.0013 \\
(0.0036)\end{array}$ & $\begin{array}{l}-0.52 \\
(0.31)\end{array}$ & $\begin{array}{c}0.0124 * \\
(0.0052)\end{array}$ \\
\hline Observations & 94 & 94 & 94 & 94 \\
\hline Bandwidth & 47 & 47 & 47 & 47 \\
\hline Mean Dep Var & 29.84 & 0.1280 & -24.38 & 0.0965 \\
\hline Panel B: Linear a & ohort trend interacted wi & breshold + month-of-birt. & & \\
\hline Discontinuity & $\begin{array}{c}-0.87^{* *} \\
(0.24)\end{array}$ & $\begin{array}{c}0.0043^{*} \\
(0.0019)\end{array}$ & $\begin{array}{l}-0.08 \\
(0.20)\end{array}$ & $\begin{array}{l}0.0032^{*} \\
(0.0016)\end{array}$ \\
\hline Observations & 94 & 94 & 94 & 94 \\
\hline Bandwidth & 47 & 47 & 47 & 47 \\
\hline Mean Dep Var & 29.84 & 0.1280 & -24.38 & 0.0965 \\
\hline Panel C: Linear & ohort trend interacted wo & reshold with summer bo & & \\
\hline Discontinuity & $\begin{array}{c}-1.42^{* *} \\
(0.47)\end{array}$ & $\begin{array}{c}0.0018 \\
(0.0034)\end{array}$ & $\begin{array}{l}-0.46 \\
(0.37)\end{array}$ & $\begin{array}{c}0.0067 \\
(0.0041)\end{array}$ \\
\hline Observations & 71 & 71 & 71 & 71 \\
\hline Bandwidth & 47 & 47 & 47 & 47 \\
\hline Mean Dep Var & 29.84 & 0.1280 & -24.38 & 0.0965 \\
\hline
\end{tabular}

Notes: Each column and row is the regression discontinuity estimate from a separate regression. Column headers list the dependent variable. Panel A includes linear controls for cohort trends, interacted with the threshold to allow different pre- and post-reform trends. Panel B adds dummies for month of birth. Panel C drops summer borns to deal with the fact that they could drop out of school at the end of May of the year they reached the compulsory schooling age. The mean of the dependent variable is measured for the cohort born in August 1957, the last pre-reform cohort. Data come from the 2001 Census. Each observation is a cohort-cell mean. Regressions are weighted by cohort sizes. Robust standard errors are in parentheses. Bandwidth is measured in months. *: p-value $<0.05,{ }^{* *}$ : p-value $<$ 0.01 